\title{
WestVirginiaUniversity
}

THE RESEARCH REPOSITORY @ WVU

Graduate Theses, Dissertations, and Problem Reports

2005

\section{Fiber reinforced polymer composite decks for military applications}

\author{
Srikanth Mantri \\ West Virginia University
}

Follow this and additional works at: https://researchrepository.wvu.edu/etd

\section{Recommended Citation}

Mantri, Srikanth, "Fiber reinforced polymer composite decks for military applications" (2005). Graduate Theses, Dissertations, and Problem Reports. 1674.

https://researchrepository.wvu.edu/etd/1674

This Thesis is protected by copyright and/or related rights. It has been brought to you by the The Research Repository @WVU with permission from the rights-holder(s). You are free to use this Thesis in any way that is permitted by the copyright and related rights legislation that applies to your use. For other uses you must obtain permission from the rights-holder(s) directly, unless additional rights are indicated by a Creative Commons license in the record and/ or on the work itself. This Thesis has been accepted for inclusion in WVU Graduate Theses, Dissertations, and Problem Reports collection by an authorized administrator of The Research Repository @ WVU. For more information, please contact researchrepository@mail.wvu.edu. 


\title{
FIBER REINFORCED POLYMER COMPOSITE DECKS FOR MILITARY APPLICATIONS
}

\author{
SRIKANTH MANTRI \\ Thesis submitted to the \\ College of Engineering and Mineral Resources \\ at West Virginia University \\ in partial fulfillment of the requirements for the degree of \\ Master of Science \\ In \\ Mechanical Engineering \\ Kenneth H. Means, Ph.D., Chair \\ Hota GangaRao, Ph.D \\ Charles F Stanley Ph.D
}

DEPARTMENT OF MECHANICAL AND AEROSPACE ENGINEERING

Morgantown, West Virginia

2005 


\section{ABSTRACT \\ Fiber Reinforced Polymer Composite Decks for Military Application Srikanth Mantri}

The U.S Marine Corps is aiming to replace the M105 cargo trailers, M149 water tank trailers, and the M353 utility trailers with a new trailer platform known as the Medium Tactical Vehicle Replacement Trailers (MTVR-T). This project focused on developing a MTVR-T type trailer using Glass Fiber Reinforced Polymer composite decks. Systems \& Electronics Inc. (SEI) provided the initial design for the prototype trailer. Prodeck 4 was chosen as the decking material for the prototype trailer.

A detailed Finite Element model of the Fiber Reinforced Polymer (FRP) deck and steel support assembly was built. Four operational and transportation load conditions as identified by SEI were simulated in the FE model and the theoretical response of the proposed system was evaluated. Next, a prototype FRP trailer system using Prodeck 4 was fabricated at CFC-WVU. Four different load test setups were designed to simulate the operational and transportation loads on the MTVR-Trailer. Based on the FE data, an instrumentation plan was created for testing the FRP MTVR-Trailer under the four load conditions. The test data and FE results for these loading conditions reveal that the current trailer design meets all the load requirements tested. However, the current FRP trailer design using Prodeck 4 can be further optimized both in terms of reducing the size and shape of the deck cross-section and the support assembly. 
One key factor for acceptance of FRP deck trailers by the US Military will be the ease of repairing an FRP deck trailer in case of damage. A step-by-step procedure for identifying and repairing of composites is provided; several references on composite repair are also listed. Life cycle costs are another important factor for acceptance of FRP trailers by US Military. Currently, Bedford Reinforced Plastics can supply the Prodeck 4 for \$30-35 per square foot on a high volume basis. These costs can be reduced even further through optimized design of FRP decks to suit the trailer operational and transportational load requirements. Furthermore, the potential maintenance and operational cost savings that can be accrued using FRP decks in MTVR-Trailers are also discussed.

Finally, several important issues need to be resolved before developing a prototype for user trials including design of ISO lock attachments, large amplitude fatigue testing and aging evaluation of the FRP composite trailer under harsh environmental conditions. 


\section{ACKNOWLEDGMENTS}

First I would like to thank Dr. Hota Ganga Rao for giving me this opportunity to work with him as a graduate research assistant and whose contributions towards the successful completion of this project are innumerable. His great insight in the field of composites has inspired me a lot. I would also like to thank Dr. Kenneth Means and Dr. Charles Stanley for serving on my committee and for their valuable suggestions.

Special thanks are owed to Vimala Sekhar and Srinivas aluri for all their invaluable help and constant guidance which were the key factors in the successful completion of this project. These indispensable contributions will never be forgotten. I am very thankful to thank Jerry Nestor and Bill Comstock who have been instrumental in the timely completion of the project. Special thanks are also owed to Aneesh Bethi, Ayman Bataineh, Amarnath Varthakavi for their help during the fabrication and testing of the prototype FRP trailer system.

Financial support provided by Systems \& Electronics Inc. for whom this project has been done, is also gratefully acknowledged. I would also like to acknowledge Tony Kozich, Laura Alberswerth, Brian Nolan, Wally Baumer and other members from Systems \& Electronics Inc. for their contributions. Contributions of Bedford Reinforced Plastics, Inc. and Ashland Inc. are greatly appreciated. 


\title{
TABLE OF CONTENTS
}

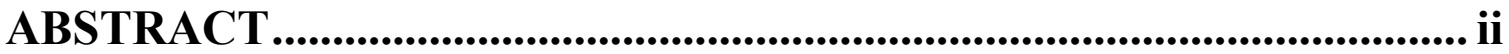

ACKNOWLEDGMENTS ......................................................................... iv

TABLE OF CONTENTS ......................................................................... v

LIST OF FIGURES ............................................................................. vii

CHAPTER 1 - INTRODUCTION ..................................................... 1

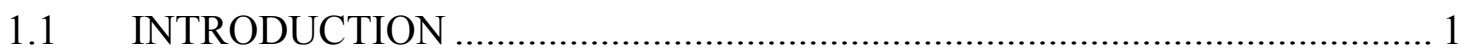

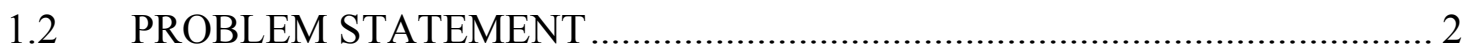

1.2.1 MEDIUM TACTICAL VEHICLE REPLACEMENT (MTVR)................ 2

1.2.2 MEDIUM TACTICAL VEHICLE REPLACEMENT TRAILER (MTVR-

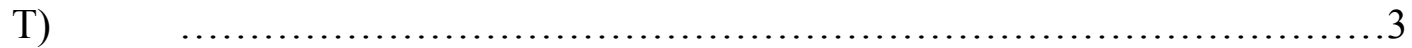

1.2.3 ADVANTAGES OF FRP COMPOSITES OVER STEEL AND

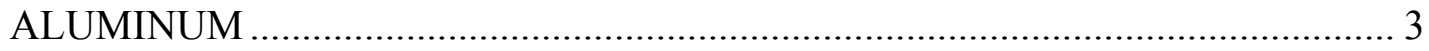

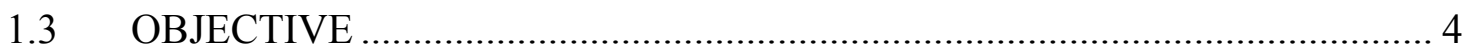

\section{CHAPTER 2 - DESCRIPTION OF PRODECK 4 ….................................... 7}

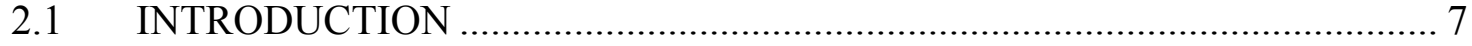

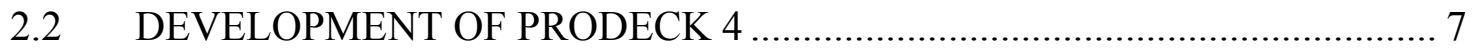

2.2.1 PHYSICAL NOMENCLATURE...................................................... 7

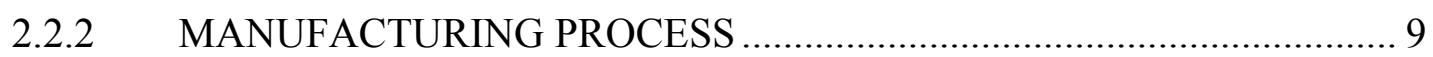

2.2.3 MECHANICAL PROPERTIES ……….......................................... 10

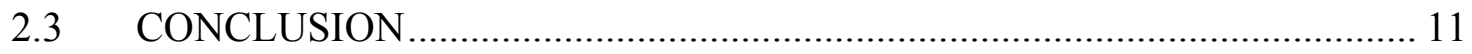

CHAPTER 3 - LOAD DEVELOPMENT _............................................. 12

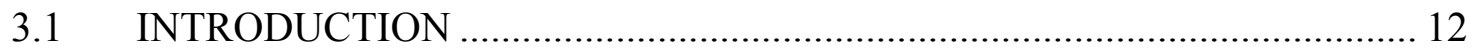

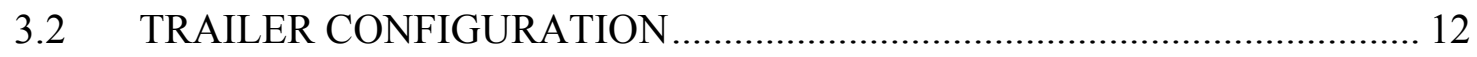

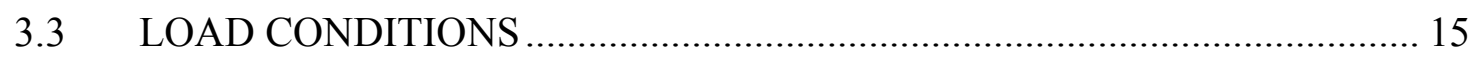

3.3.1 LOAD CASE 1(a) - UNIFORMLY DISTRIBUTED LOAD - 40,000 LBS.

3.3.2 LOAD CASE 1(b) - SIXCON CONTAINER LOAD (40,000 LBS DOWNWARD PATCH LOADING) ............................................................... 16 3.3.3 LOAD CASE 2 - HELICOPTER LIFT $(32,000$ LBS - UPWARD PATCH

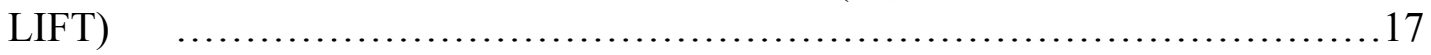


CHAPTER 4 - FINITE ELEMENT MODELING.................................. 20

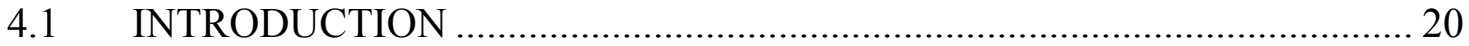

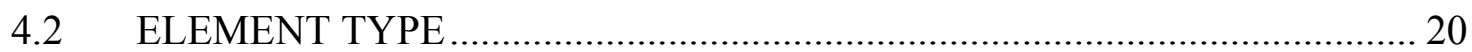

4.2.1 SHELL93 ELEMENT [6] .......................................................... 21

4.3 FINITE ELEMENT MODELING OF FRP DECK AND SUBSYSTEMS ..... 22

4.3.1 MODELING OF THE FRP COMPOSITE DECK.................................. 22

4.3.2 MODELING OF THE SUPPORT ASSEMBLY (STRINGERS) ……..... 25

4.3.3 MODEL CONSTRAINING …………………............................. 26

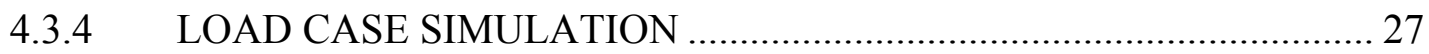

4.3.4.2 LOAD CASE 1(B) - SIXCON CONTAINER LOAD TEST (40,000 LBS

- DOWNWARD PATCH LOADING) ……………………………………….... 29

\section{CHAPTER 5 - FRP TRAILER ASSEMBLY AND TESTING ............. 35}

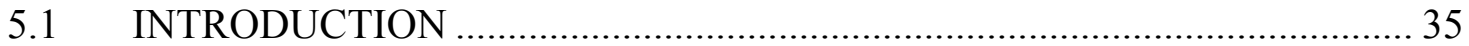

5.2 ASSEMBLING THE FRP TRAILER DECK PROTOTYPE ……………….... 35

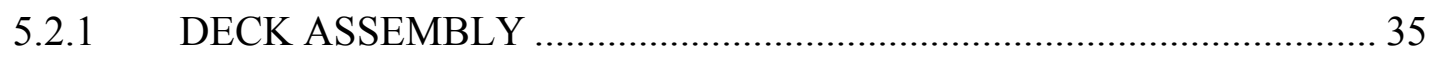

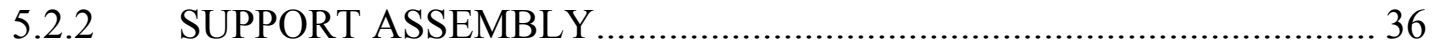

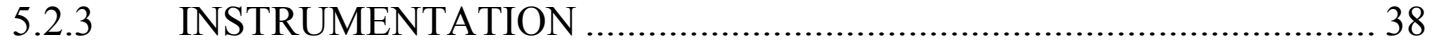

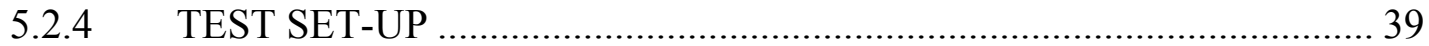

5.3 TESTING OF TRAILER ........................................................................... 43

5.3.1 LOAD CASE 1(a) - UNIFORMLY DISTRIBUTED LOAD - 40,000

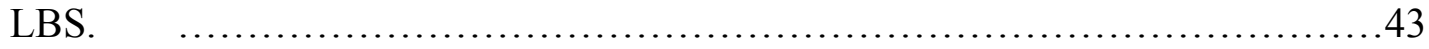

5.3.2 LOAD CASE 1(b) - SIXCON CONTAINER LOAD TEST - 40,000 LBS.

DOWNWARD PATCH LOADING..................................................................... 44

5.3.3 LOAD CASE 2 - HELICOPTER LIFT (32,000 LBS. - UPWARD

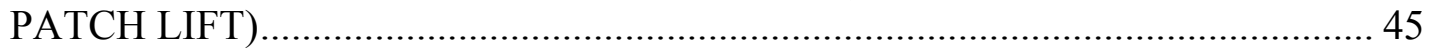

5.3.4 LOAD CASE 3 - RAIL IMPACT (50,000 LBS. - INPLANE SHEAR

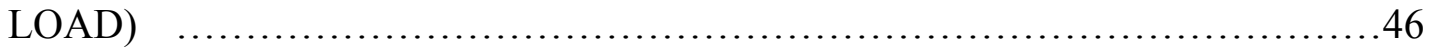

CHAPTER 6 - RESULTS AND DISCUSSIONS................................. 48

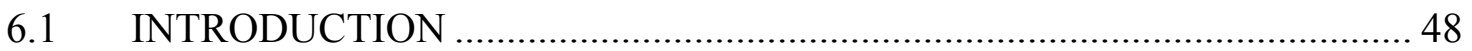

6.2 LOAD CASE 1 (a) - UNIFORMLY DISTRIBUTED LOAD - 40,000 LBS. 48

6.2.1 DEFLECTION ANALYSIS .............................................................. 48

6.3 LOAD CASE 1(b) - SIXCON CONTAINER LOAD TEST (40,000 LBS. -

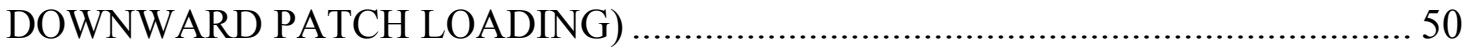

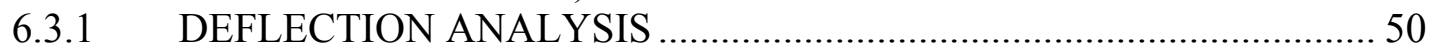


6.3.2 STRESSES UNDER CORNER CASTING LOCATIONS. 52

6.4 LOAD CASE 2 - HELICOPTER LIFT (32,000 LBS. - UPWARD PATCH

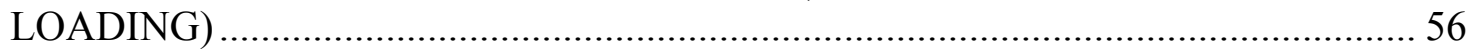

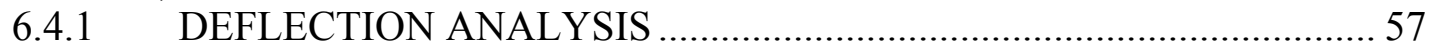

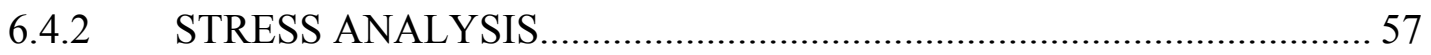

6.5 LOAD CASE 3 - RAIL IMPACT (50,000 LBS. - INPLANE SHEAR

LOADING). 59

CHAPTER 7 -FRP COMPOSITE REPAIR TECHNIQUES ............... 62

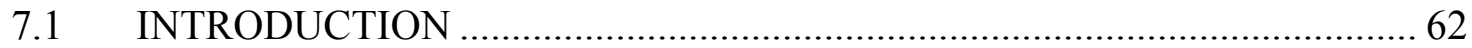

7.2 IDENTIFICATION AND REPAIR OF DAMAGE ......................................... 62

7.3 LITERATURE OF COMPOSITE REPAIR .................................................. 66

CHAPTER 8 - COST ANALYSIS ........................................................ 67

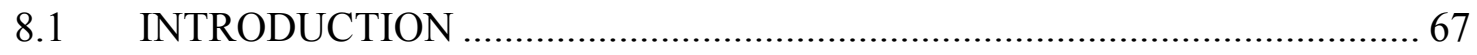

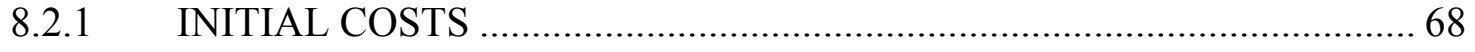

CHAPTER 9 - SUMMARY AND FUTURE WORK........................... 71

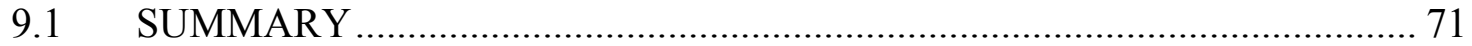

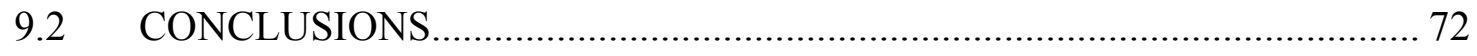

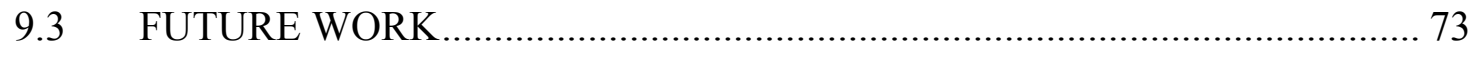

\section{APPENDIX A -THEORETICAL EVALUATION OF STRUCTURAL} PROPERTIES OF PRODECK 4 ........................................................... 76

EVALUATION OF STRUCTURAL PROPERTIES............................................. 79 


\section{LIST OF FIGURES}

Figure 1-1 (a) The M 149 water tank trailer [2] and (b) The M 105 Cargo trailer [3] ....... 1

Figure 2-1Cross-section of Prodeck 4 [4] .................................................................... 7

Figure 2-2 Schematic representation of the Pultrusion process [5] f................................. 9

Figure 3-1 The FRP trailer design ..................................................................... 13

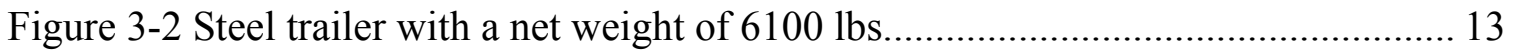

Figure 3-3 Aluminum trailer with a net weight of $4000 \mathrm{lbs}$............................................ 14

Figure 3-4 Load Case 1(a) - Uniformly Distributed Load of 40,000 lbs.......................... 16

Figure 3-5 SIXCON patch loading condition - Top view ............................................... 17

Figure 3-6 Corner castings on the deck surface........................................................ 17

Figure 3-7 Schematic representation of the Helicopter-Lift case .................................... 18

Figure 3-8 Schematic representation of Rail Impact load case......................................... 19

Figure 4-1 Element orientation of the Shell 93 element [6] ........................................... 21

Figure 4-2 Assembly of six modules of Prodeck 4 modules ............................................. 22

Figure 4-3 Mesh of the deck cross-section ..................................................................... 23

Figure 4-4 FE model of complete deck (Isometric View) ................................................ 24

Figure 4-5 Composite deck with steel stringers............................................................ 25

Figure 4-6 Side view of the FE model of deck and stringer assembly ............................. 26

Figure 4-7 Uniformly distributed load of 40,000 lbs on the deck surface - side view..... 28

Figure 4-8 Uniformly distributed load of 40,000 lbs on the deck surface....................... 28

Figure 4-9 Steel reinforced SIXCON patches ................................................................ 30

Figure 4-10 SIXCON patch loading - Side view …………........................................... 30

Figure 4-11 Helicopter Lift patches - side view.......................................................... 31

Figure 4-12 Inplane shearing forces on the deck surface …………………………….... 33

Figure 4-13 Axial forces on the deck due to bolts ...................................................... 34

Figure 5-1 Application of PLIOGRIP ${ }^{\circledR}$ on the deck before laying the stringer................ 37

Figure 5-2 Stringer, Cross-beam assembly underneath the deck..................................... 38

Figure 5-3 I-beams supporting the sub assembly replicate the wheel base ...................... 39

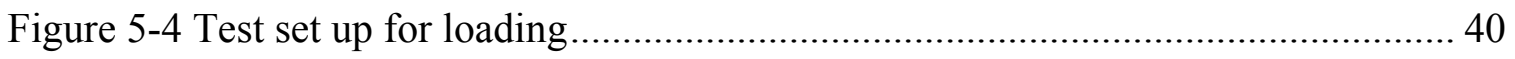

Figure 5-5 Load case 1(a) - 40 kips Uniformly Distributed Load .................................... 43 
Figure 5-6 Load case 1(b) - SIXCON Load Test (40 kip-patch loading.) ....................... 44

Figure 5-7 Load Case 2 - the Helicopter Lift Test........................................................ 45

Figure 5-8 Load case 3 - Rail Impact Test. ................................................................ 47

Figure 6-1 Deflection profile of the deck due to UDL of 40,000lbs. ............................. 49

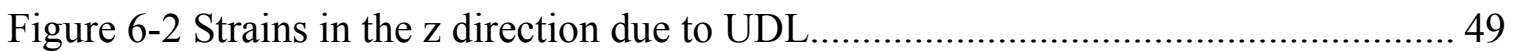

Figure 6-3 Deflection profile of the deck in z-direction due to SIXCON patch loading.. 51

Figure 6-4 Comparison of Experimental and FE deflections at location A..................... 51

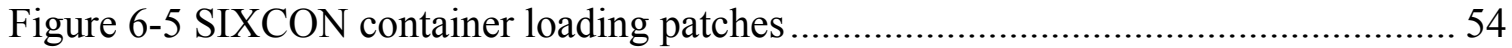

Figure 6-6 Patch reinforcement and strain gage location ......................................... 55

Figure 6-7 Stress in Y-direction under the SIXCON patch ......................................... 55

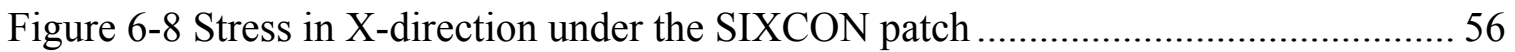

Figure 6-9 Deflection profile in the Z-direction due to Helicopter lift loading............... 57

Figure 6-10 Strains in the X-direction showing compression on top flange ................... 58

Figure 6-11 Plot of centerline stresses in the deck for Helicopter Lift case. ................... 59

Figure 6-12 Loading pattern used in FE for the rail impact test ................................. 60

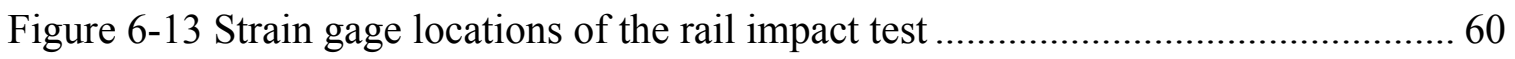

Figure 6-14 The $\mathrm{Z}$ component of displacement due to rail impact................................ 61

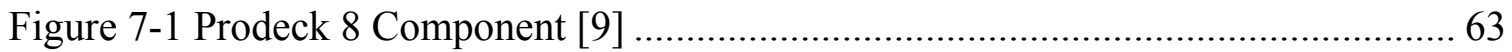

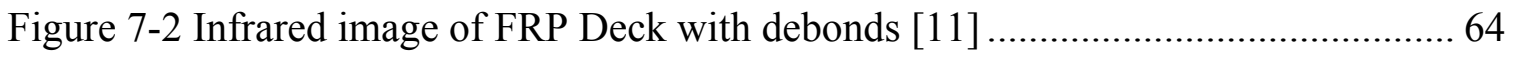

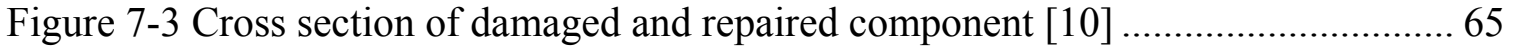




\section{LIST OF TABLES}

Table 3.1 Design deck weight comparison .............................................................. 14

Table 5.1 Strain gage locations............................................ 52

Table 6.1 Measured experimental strains....................................64

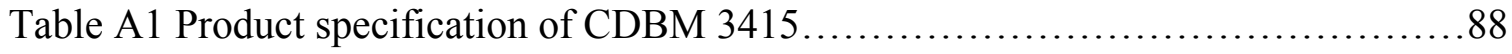

Table A2 Product specification of DDBM 4015.................................. 88

Table A3 Material properties of the lamina................................... 89 


\section{CHAPTER 1 - INTRODUCTION}

\subsection{INTRODUCTION}

The U.S Marine Corps is aiming to replace the M105 cargo trailers, M149 water tank trailers, and the M353 utility trailers with a new trailer platform [1]. One of the reasons for exploring the potential of replacements can be attributed to problems associated with their existing trailers, especially a lack of capacity and off-road capability. These replacements are identified as the Medium Tactical Vehicle Replacement Trailers (MTVR-T).

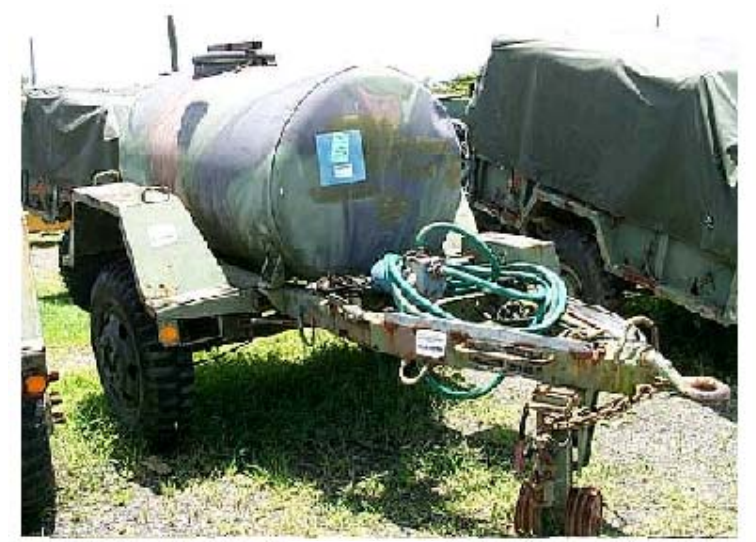

(a)

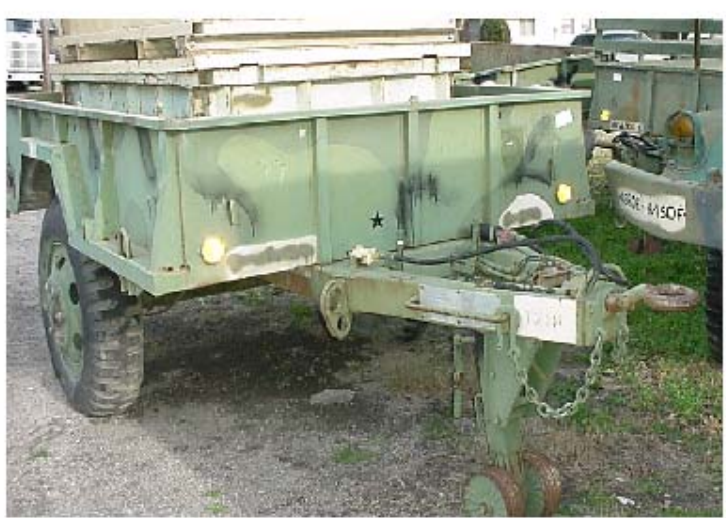

(b)

Figure 1-1 (a) The M 149 water tank trailer [2] and (b) The M 105 Cargo trailer [3]

The current trailer systems use conventional materials such as high strength aluminum or steel. These conventional materials have several problems including high material density and therefore higher self-weight, excessive fatigue damages at connections, problems related to corrosion, and wear and tear. Most of these problems 
can be alleviated using high strength fiber reinforced polymer (FRP) composites, which are lightweight, with a unit weight of about $25 \%$ that of steel. The use of FRP composite materials can significantly improve the durability of the MTVR trailers.

\subsection{PROBLEM STATEMENT}

The Medium Tactical Vehicle Replacement (MTVR) along with MTVR-Trailer (MTVR-T) is a tactical vehicle that is commonly used for cargo transportation by the U.S. military [1]. The U.S. military has called for an effective alternative to replace the aging fleet of M105, M149, and M353 trailers [1]. FRP composite decks, due to their light weight and excellent durability, pose their stake not only as the best alternatives to overcome limitations of steel and high-strength aluminum trailers but also as superior materials in terms of the intended function of the trailer.

\subsubsection{MEDIUM TACTICAL VEHICLE REPLACEMENT (MTVR)}

The Medium Tactical Vehicle Replacement (MTVR), also known as the "seventon truck" is currently being used, replacing the old 5-ton tuck. The MTVR has been targeted to have a payload of 7 tons off-road, 12 tons on-road with high performance characteristics compared to the 5 ton trucks [1]. The MTVR is capable of negotiating terrain twice as rough as the current fleet and with a mission profile of $70 \%$ off road (7.1 tons) and 30\% on-road (15 tons), and improved cross-country speed of up to $30 \mathrm{mph}$ [1]. The MTVR is a safer and more reliable system which has been demonstrated through 
extensive use of proven commercial heavy truck componentry that meets today's overthe-road truck safety standards [1].

\subsubsection{MEDIUM TACTICAL VEHICLE REPLACEMENT TRAILER (MTVR-T)}

The United States Marine Corps (USMC) Medium Tactical Vehicle Replacement Trailers (MTVR-T) are expected to replace the existing M105, M149 and M353 Trailers. The new MTVR-Trailers will augment the payload and complement the capability of the MTVR series of tactical vehicles [1]. Up to three different configurations of MTVR-T are to be designed, and these trailers are expected to deliver and dispense water at the unit level and transport ammunition, breakbulk cargo, engineering equipment, generators, air compressors, welders, and communications equipment. It is proposed that MTVR-T shall be capable of transporting payloads over 7,000 lbs (threshold), 10,000 lbs (objective),

over the entire mission profile of the MTVR [1]. Apart from needing to negotiate the offroad terrains and manage excessive large amplitude fatigue at the connections, these trailers and platforms are expected to operate in extreme temperatures. With such stringent requirements and harsh environmental conditions, an effective and robust trailer decking system is being sought.

\subsubsection{ADVANTAGES OF FRP COMPOSITES OVER STEEL AND ALUMINUM}

- Light weight: Fiber reinforced polymer composite materials are much lighter than either aluminum or steel. 
- High strength-to-weight ratio: Since glass FRP composites weigh about a quarter as much as steel and are about 2 to 3 times stronger than steel, the result is a higher strength-to-weight ratio than conventional materials.

- Corrosion resistance: Corrosion is the disintegration of metals because of electrochemical process. Steel in its native form is one of the elements most affected by corrosion. However, GFRP composites are far less susceptible to corrosion.

Some of the other advantages of composite materials over traditional aluminum and steel materials are:

- Higher resistance to impact

- Higher dielectric strength (insulator)

- Lower maintenance and longer durability

- Better radar transparency (non magnetic)

\subsection{OBJECTIVE}

The primary objective of this project is to evaluate the use of glass FRP composite decks as an effective alternative to conventional materials such as steel or aluminum for the proposed MTVR-T. The specific objectives are to

- develop a comparative analysis between FRP and conventional materials with respect to weight, performance, and cost per unit performance.

- design an FRP composite decking system for the MTVR-T.

- fabricate and test a full-scale FRP composite deck prototype based on the 


\section{MTVR-T.}

- evaluate the experimental data with FE analysis.

The entire project was divided into various sub-tasks in order to accomplish the above objectives.

- TASK 1 is the evaluation of the current decking systems for military vehicles. Specifically, the MTVR trailer decking systems will be reviewed for cost, weight, and performance.

- TASK 2 is to identify the various loads and load combinations on the current decking systems of MTVR-Trailers, with input from SEI. Chapter 3 deals with the load development and identification of critical load cases with respect to the preliminary trailer design.

- TASK 3 is the preliminary deck design. In this task, the proposed FRP decking system for the MTVR-Trailer is to be designed and evaluated for various loading conditions already identified. A four inch pultruded FRP Deck known as Prodeck 4 produced by Bedford Reinforced Plastics Inc. was proposed for the MTVRTrailer and evaluated.

- TASK 4 is evaluation of alternatives for the supporting elements (i.e. beams) that stiffen the FRP deck of the proposed trailer.

- TASK 5 is the design of connections between the steel beams and FRP deck.

- TASK 6 deals with structural evaluation (FEA) of the MTVR trailer deck.

- TASK 7 involves the evaluation of several deck repairing concepts. This task deals with the understanding of some of the common damages occurring in 
composites and various repair techniques employed. Chapter 8 deals with the concepts of composite damage evaluation and repair.

- TASK 8 is the full scale prototype testing and evaluation of the FRP composite deck for the MTVR-Trailer. 


\section{CHAPTER 2 - DESCRIPTION OF PRODECK 4}

\section{$2.1 \quad$ INTRODUCTION}

This chapter deals with the review of a low-profile FRP deck known as Prodeck

4. This decking system is currently being used as bridge decking at multiple locations in the United States and extensive lab and field data based on this usage exist. The physical nomenclature of the deck along with weight, density, and mechanical properties (strength and stiffness) are presented here.

\subsection{DEVELOPMENT OF PRODECK 4}

\subsubsection{PHYSICAL NOMENCLATURE}

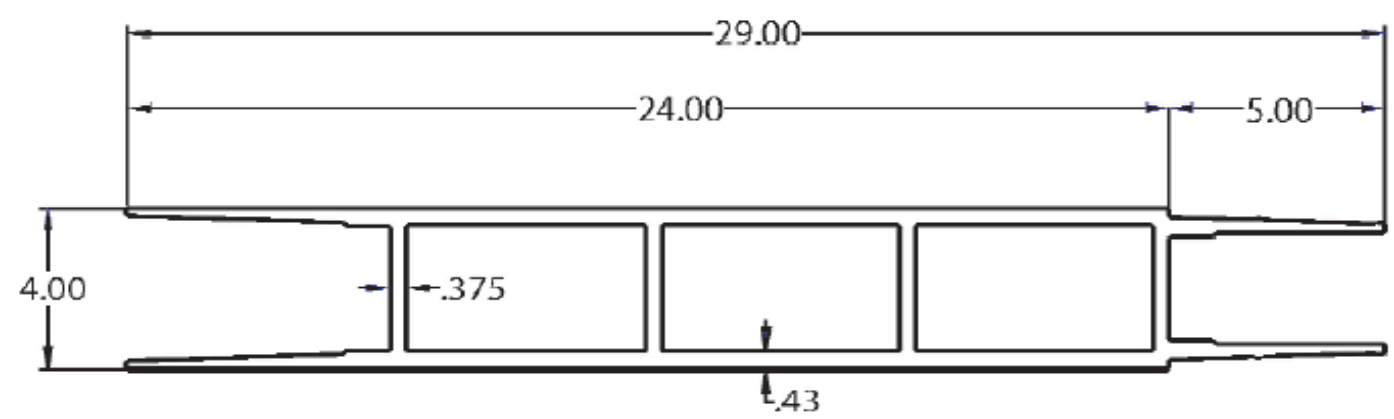

(a)

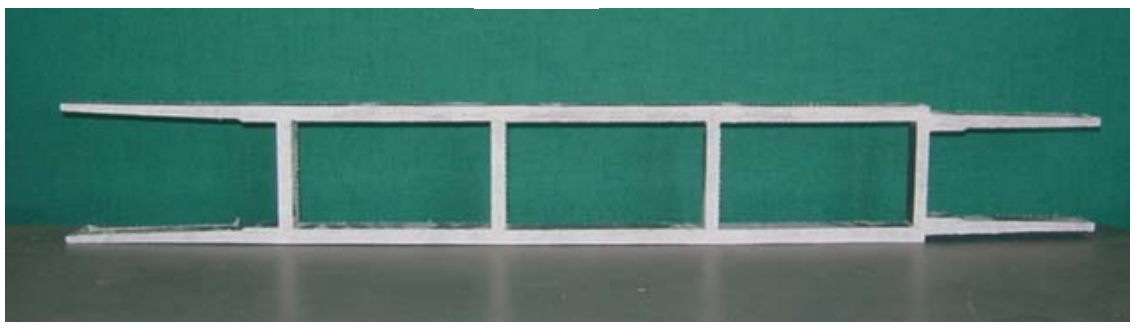

(b)

Figure 2-1Cross-section of Prodeck 4 [4] 
Figure 2.1 shows the cross section of the multi-cellular shaped (29" x 4") FRP deck component, commercially sold as Prodeck 4 and manufactured by Bedford Reinforced Plastics, Inc. The multi-cellular shaped low-profile FRP bridge deck is made of E-glass fiber and vinyl ester resin. The low-profile deck is designed to withstand AASHTO HS25 loads for 4 feet stringer spacing. The 4" deep, low-profile deck is cost effective and is manufactured to have high strength (40 ksi to failure) and low weight ( $11.5 \mathrm{lb} / \mathrm{ft}^{2}$ ) compared to the first-generation FRP bridge decks which weighed about 25$35 \mathrm{lb} / \mathrm{ft}^{2}$. The horizontal members on the top and bottom are referred to as the top flange and the bottom flange, and the vertical members are referred to as webs. The flanges are at a thickness of $0.43 "$, and the webs are 0.38 " thick.

The flanges and webs of the low-profile FRP bridge deck component are made of triaxial fabrics, continuous rovings, and mats. The fibers continue from the flange to the web and then again to the flange. The resin used in the deck was vinyl ester resin which is a high elongation resin. The typical low-profile FRP deck has a fiber volume fraction of approximately $50 \%$. This individual Prodeck 4 component (Figure $2.1 \mathrm{~b}$ ) is referred to as one "module".

An end-to-end combination of various such modules of equal lengths creates a deck surface. The manufacturing process for Prodeck 4 is described in Section 2.2.2. 


\subsubsection{MANUFACTURING PROCESS}

Current manufacturing techniques for FRP decks include Pultrusion, Filament winding, Vacuum Assisted Resin Transfer Molding (VARTM), Resin Infusion and Hand/Automated Lay-up. The type of manufacturing process is an important factor in the quality, finish, and cost of the end product. Prodeck 4 used in this research is

manufactured using the Pultrusion process. Pultrusion is a continuous manufacturing process used for the production of constant cross-sectioned shapes of any length. While the Pultrusion machine design varies with the geometry of a part to be pultruded, the basic Pultrusion process is described in a schematic form in Figure 2.3.

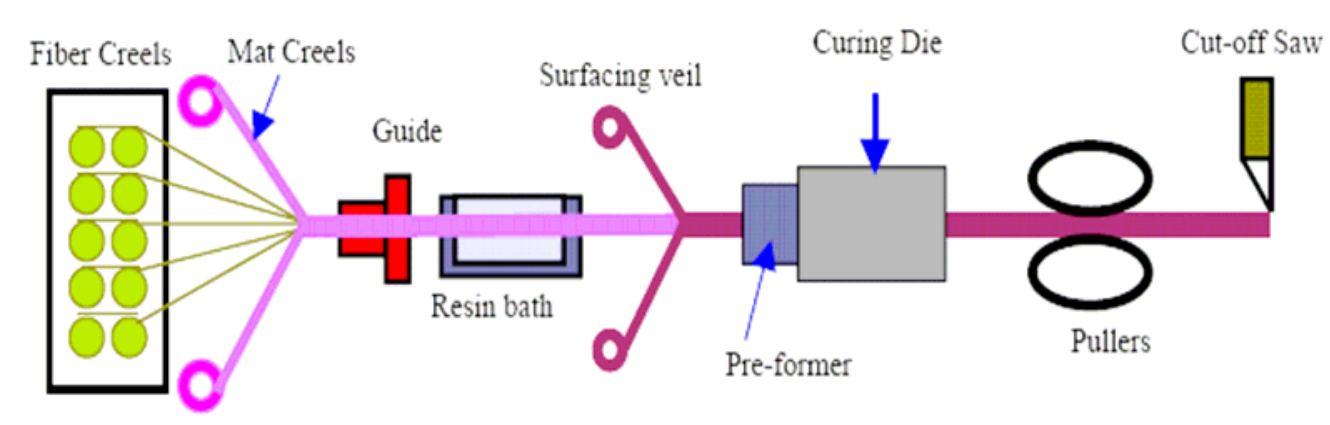

Figure 2-2 Schematic representation of the Pultrusion process [5]

The preforming guides position the roving and mat dispensed from the creel and mat racks in specified locations, of the cross section of the product. Then the reinforcements are made to pass through the wet-out bath and the injection chamber, where they are wetted by the thermoset resin, supplied under pressure. The extreme pressure forces out any air or excess resin from the reinforcement as it enters the die. The 
part is subjected to multiple curing temperatures inside the die. The layers of reinforcements are mechanically fixed to each other, which results in a solidified laminate. The finished product exiting the die is then pulled by reciprocating pullers at a constant speed. The product is cut to the specified length with the aid of a moving cutoff saw.

An important consideration in the pultrusion process is the design and manufacture of a pultrusion die to strict tolerances of thickness, angularity, and radii. Due to the high cost of pultrusion dies $(\sim \$ 80$ to $\$ 100 \mathrm{k})$ and fiber guides, variations in the cross sections of the shapes are feasible only if sufficiently high production warrants the tooling investment.

\subsubsection{MECHANICAL PROPERTIES}

Two principal characteristics of primary importance in FRP deck applications are stiffness and strength. The stiffness of an FRP deck is its ability to resist changes in shape when a load is applied. In FRP deck design for bridges, a deflection limit is usually used to consider the deck's stiffness. Deck strength is its ability to resist cyclic loading under applied loads (fatigue, dynamic, and environmental loads, etc.).

Since composite materials are produced by a combination of various constitutive materials such as fibers and matrices, the overall properties of the material depend upon various parameters such as the amount of fiber and amount of matrix, as defined through the fiber volume fraction, the fiber architecture, method of production, etc. Some of the 
material properties of fibers and matrix in Prodeck 4 (E-glass fibers and fabrics and vinyl-ester resins) are listed below (data provided by the manufacturer).

- Modulus of elasticity of fiber $\left(\mathrm{E}_{\mathrm{f}}\right)=10.5 \times 10^{6} \mathrm{psi}$

- Modulus of elasticity of matrix $\left(\mathrm{E}_{\mathrm{m}}\right)=7.34 \times 10^{5} \mathrm{psi}$

- Shear modulus of fiber $\left(G_{\mathrm{f}}\right)=4.18 \times 10^{6} \mathrm{psi}$

- Shear modulus of matrix $\left(\mathrm{G}_{\mathrm{m}}\right)=0.237 \times 10^{6} \mathrm{psi}$

- Poisson's ratio of fiber $\left(v_{\mathrm{f}}\right)=0.256$

- Poisson's ratio of matrix $\left(v_{\mathrm{m}}\right)=0.549$

Using these material properties, the Classical Laminate Theory (CLT) approach is used for computing the bending stiffness of the multicellular shaped FRP deck. The step by step procedure for CLT is provided in Appendix A.

\subsection{CONCLUSION}

Classical Laminate Theory (CLT) has been used to determine the theoretical stiffness of the FRP bridge deck. The theoretical evaluation carried out to predict the bending stiffness (EI) of the multicellular shaped FRP deck yielded a value of $2.35 \times 10^{8}$ $\left(1 \mathrm{~b}-\mathrm{in}^{2}\right)$ as the stiffness in the longitudinal direction and $0.34 \times 10^{8}\left(1 \mathrm{~b}-\mathrm{in}^{2}\right)$ in the transverse direction. 


\section{CHAPTER 3 - LOAD DEVELOPMENT}

\subsection{INTRODUCTION}

This chapter looks into the basic prototype model of the MTVR-Trailer and various operational and loading conditions that the MTVR-T's are expected to experience during field deployment. The MTVR trailers are expected to be capable of transporting payloads of 7,000 lbs (threshold), 10,000 lbs (objective). This includes transporting various types of cargo including ammunition, break-bulk cargo, power generation systems, bulk liquids, engineering equipment, generators, air compressors, welders, and communications equipment. Four load cases were identified by SEI as being the most pertinent to the preliminary trailer design based on U.S. Military specifications and are explained in this chapter.

\subsection{TRAILER CONFIGURATION}

The proposed prototype trailer as shown in Figure 3.1, is a two stringer supported trailer bed with cross members and a suspension system. The prototype design has a wheel base of 50" and the center of gravity of the empty trailer is $35.3 "$ above the ground for both the steel and aluminum trailer designs. These trailers have a hitch mechanism integrated at the front end, so that they can be attached to a driving vehicle. The essence of this research is to replace this existing steel or aluminum trailer bed with a composite deck in order to enhance the overall performance of the trailer. The deck has a plan view area of about $138 "$ x $98 "$. 


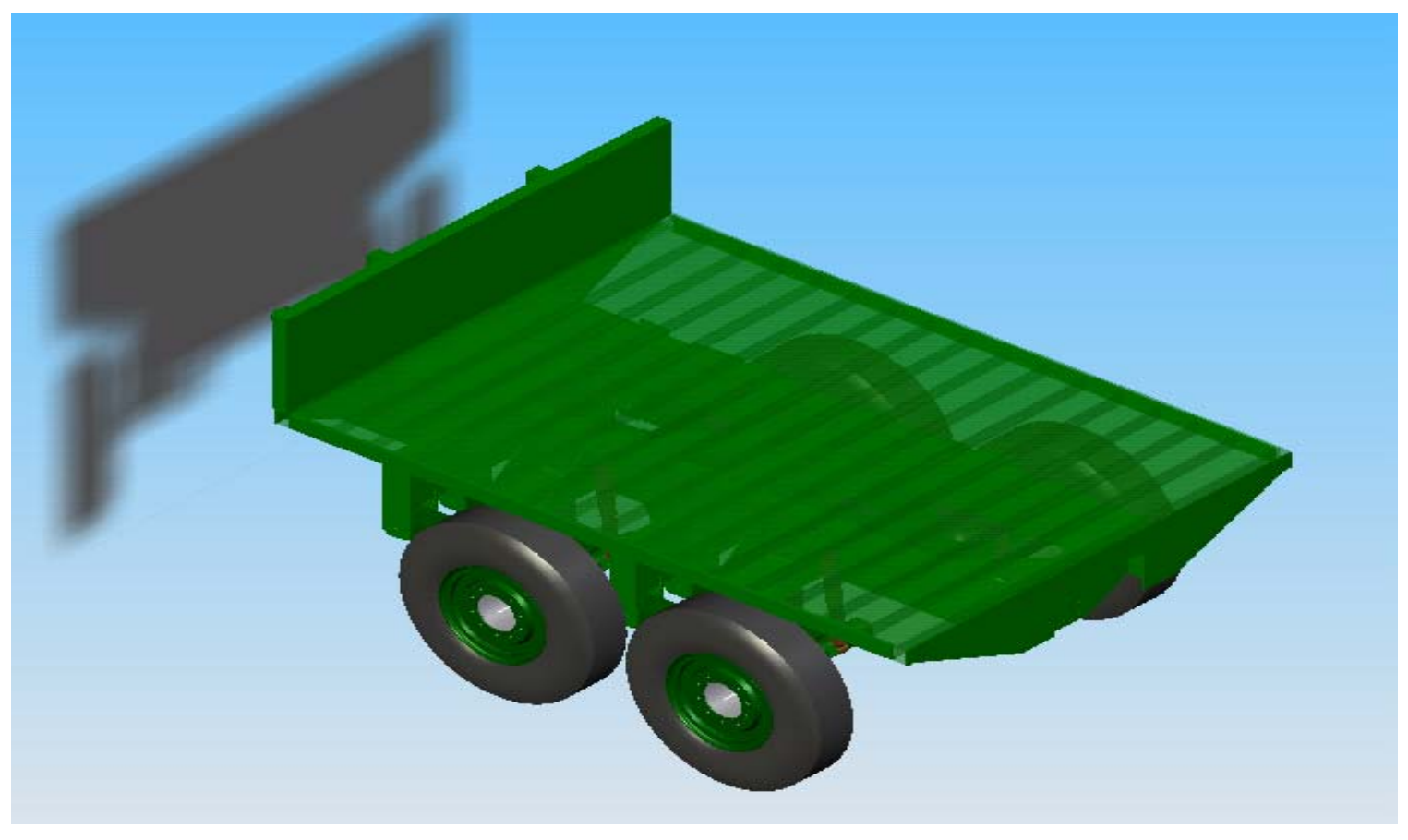

Figure 3-1 The FRP trailer design

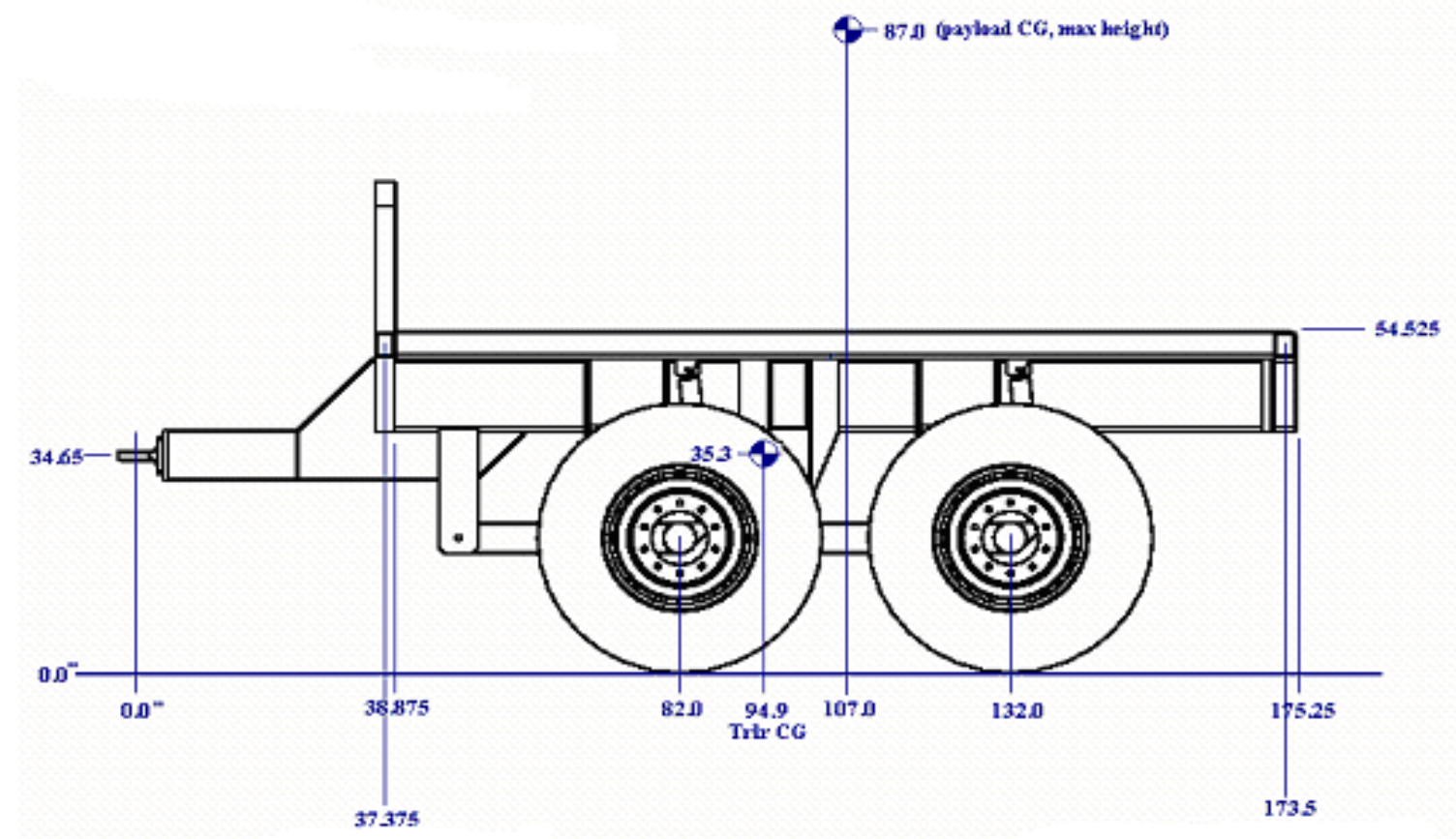

Figure 3-2 Steel trailer with a net weight of $6100 \mathrm{lbs}$ 


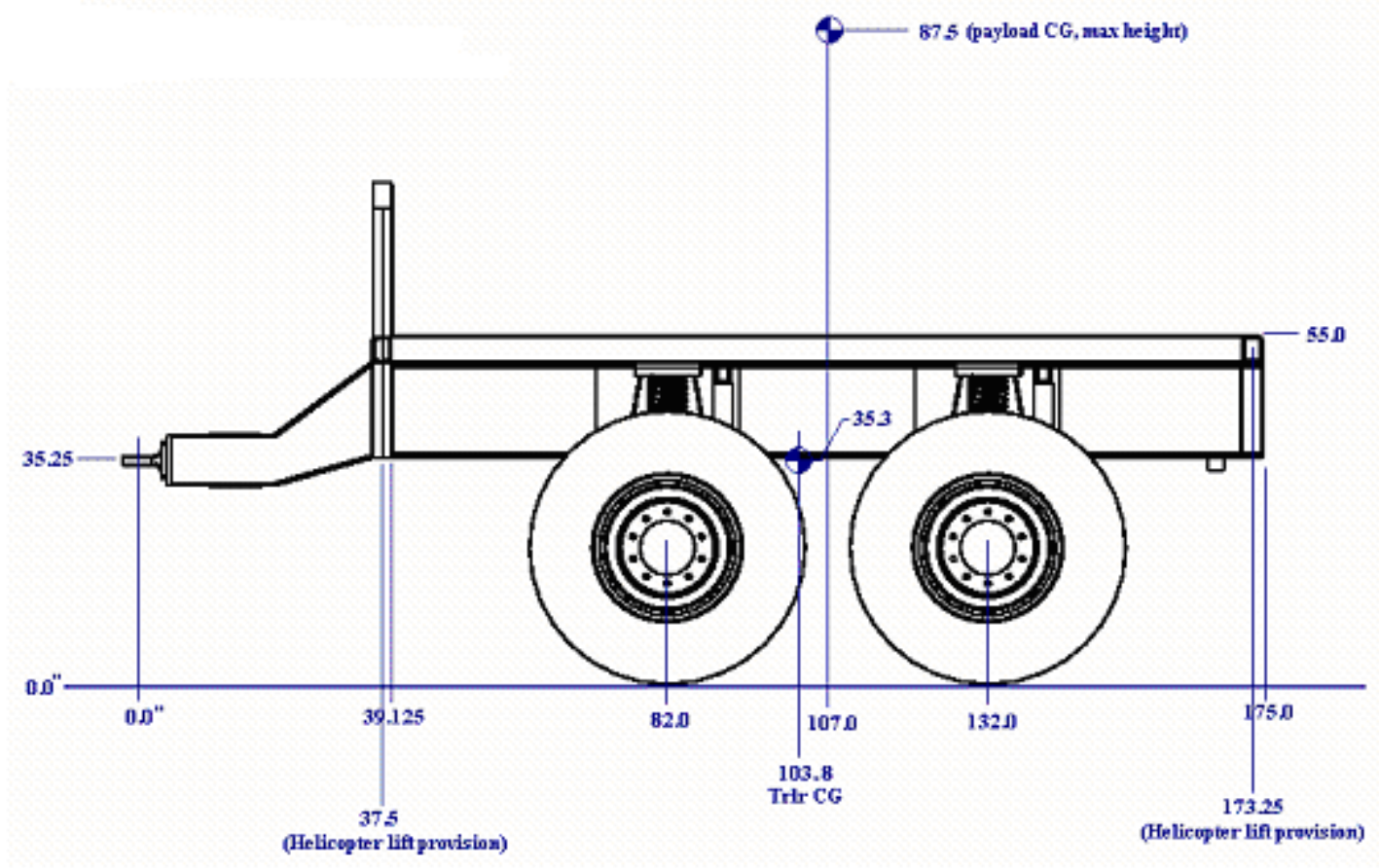

Figure 3-3 Aluminum trailer with a net weight of $4000 \mathrm{lbs}$

Weight comparison between the three trailer decking systems made using steel, aluminum and GFRP composite materials is shown in the Table 3.1.

Table 3.1 Design deck weight comparison

\begin{tabular}{|c|c|c|c|}
\hline & Steel & Aluminum & GFRP* \\
\hline Design deck weight & $1319 \mathrm{lbs}$ & $585 \mathrm{lbs}$ & $1012 \mathrm{lbs}$ \\
\hline
\end{tabular}

* This weight is based on off-the-shelf FRP product and it can be optimized both from the view points of cost and weight. 


\subsection{LOAD CONDITIONS}

Based on specifications given by the U.S. Military, SEI has identified four load cases which are considered critical to the preliminary trailer design.

1. Load Case 1(a) - Uniformly Distributed Load - 40,000 lbs.

2. Load Case 1(b) - SIXCON Container Load (40,000 lbs - downward patch loading.)

3. Load Case 2 - Helicopter Lift (32,000 lbs - upward patch lift)

4. Load Case 3 - Rail Impact (50,000 lbs - in-plane shear)

The above-mentioned load cases are all static in nature and are devised to replicate various loading scenarios that the trailer deck would be subjected to in the field. Some of these were dynamic loads which were converted to equivalent static loads

\subsubsection{LOAD CASE 1(a) - UNIFORMLY DISTRIBUTED LOAD - 40,000 LBS.}

This load condition simulates a bulk cargo payload on the trailer deck. The loading pattern is that of a uniformly distributed load over the entire deck surface area. The actual applied maximum load is $10,000 \mathrm{lbs}$ but due to the dynamic action from the truck movement, an equivalent of $3.9 \mathrm{~g}$ is to be used as a pseudo-static load of about $40,000 \mathrm{lbs}$ (taken from the maximum vertical g-rms value of MIL-STD-810F, Table 514.5C-VII). 


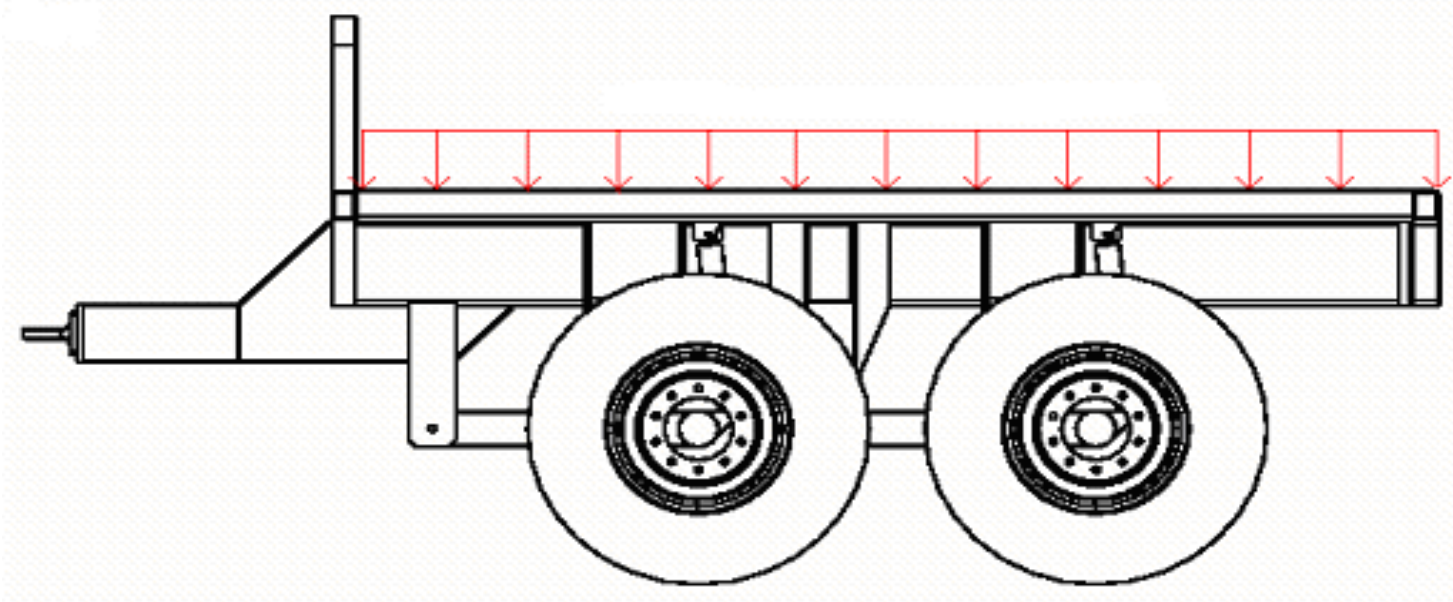

Figure 3-4 Load Case 1(a) - Uniformly Distributed Load of 40,000 lbs.

\subsubsection{LOAD CASE 1(b) - SIXCON CONTAINER LOAD (40,000 LBS - DOWNWARD PATCH LOADING)}

This load case is intended to simulate the loading of a SIXCON container on the MTVR-Trailer. These containers are placed over four patches referred to as the corner castings. Corner castings are thin metal plates that are mounted on the bottom surface of the container at the corners such that the container rests on these patches. An acceleration loading of $3.9 \mathrm{~g}$ is again used and based on the maximum vertical g-rms value of MIL-STD-810F, Table 514.5C-VII. 


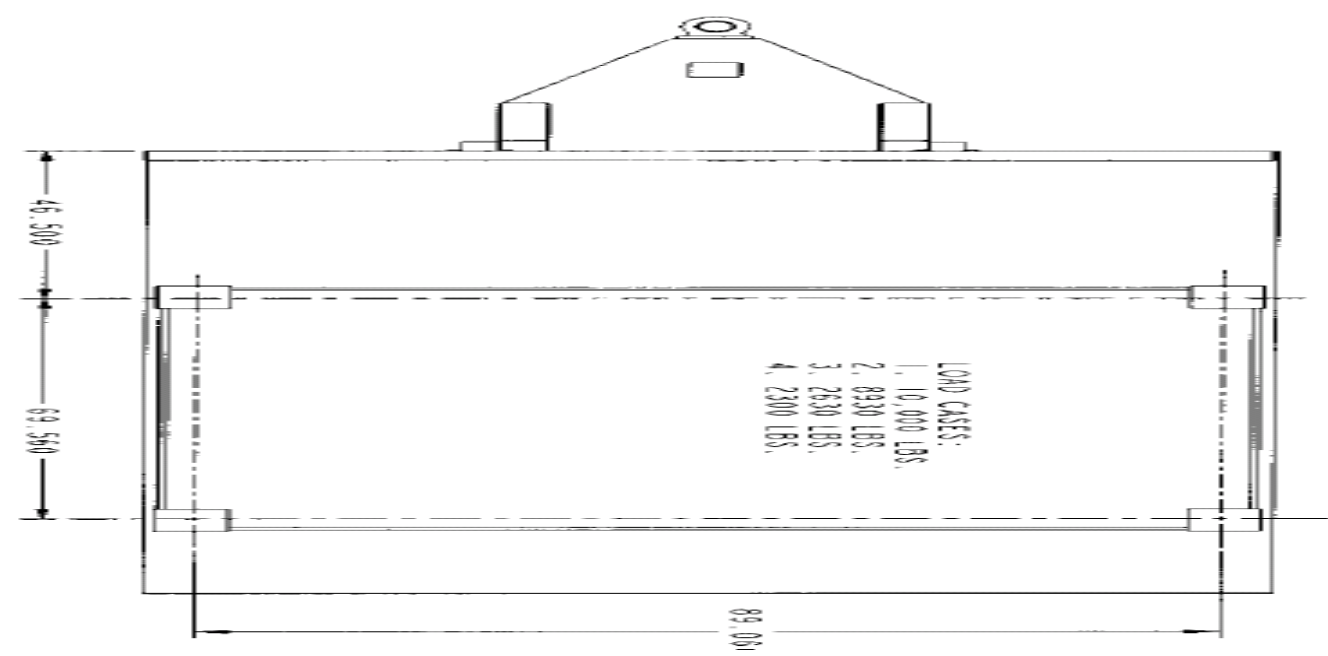

Figure 3-5 SIXCON patch loading condition - Top view
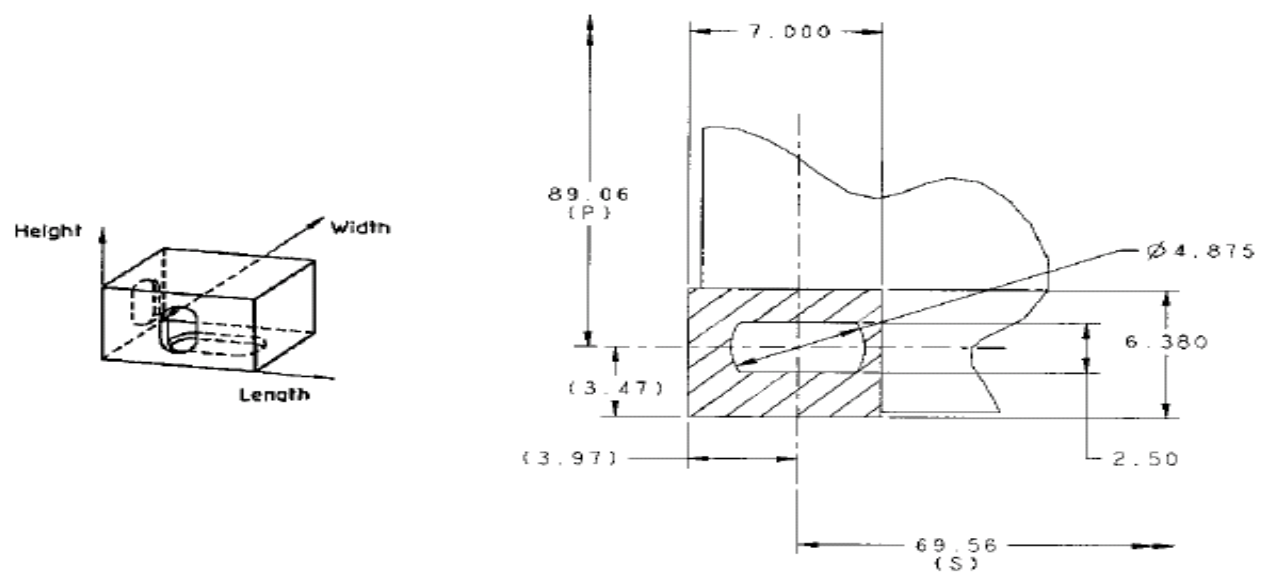

Figure 3-6 Corner castings on the deck surface

\subsubsection{LOAD CASE 2 - HELICOPTER LIFT (32,000 LBS - UPWARD PATCH LIFT)}

This load case simulates the loads applied on the trailer while it is being transported by a helicopter with or without payload. The slings used to transport the 
trailer are attached at the four corners of the trailer and the trailer is airlifted using a helicopter for transportation from one place to another to enable rapid field deployment.

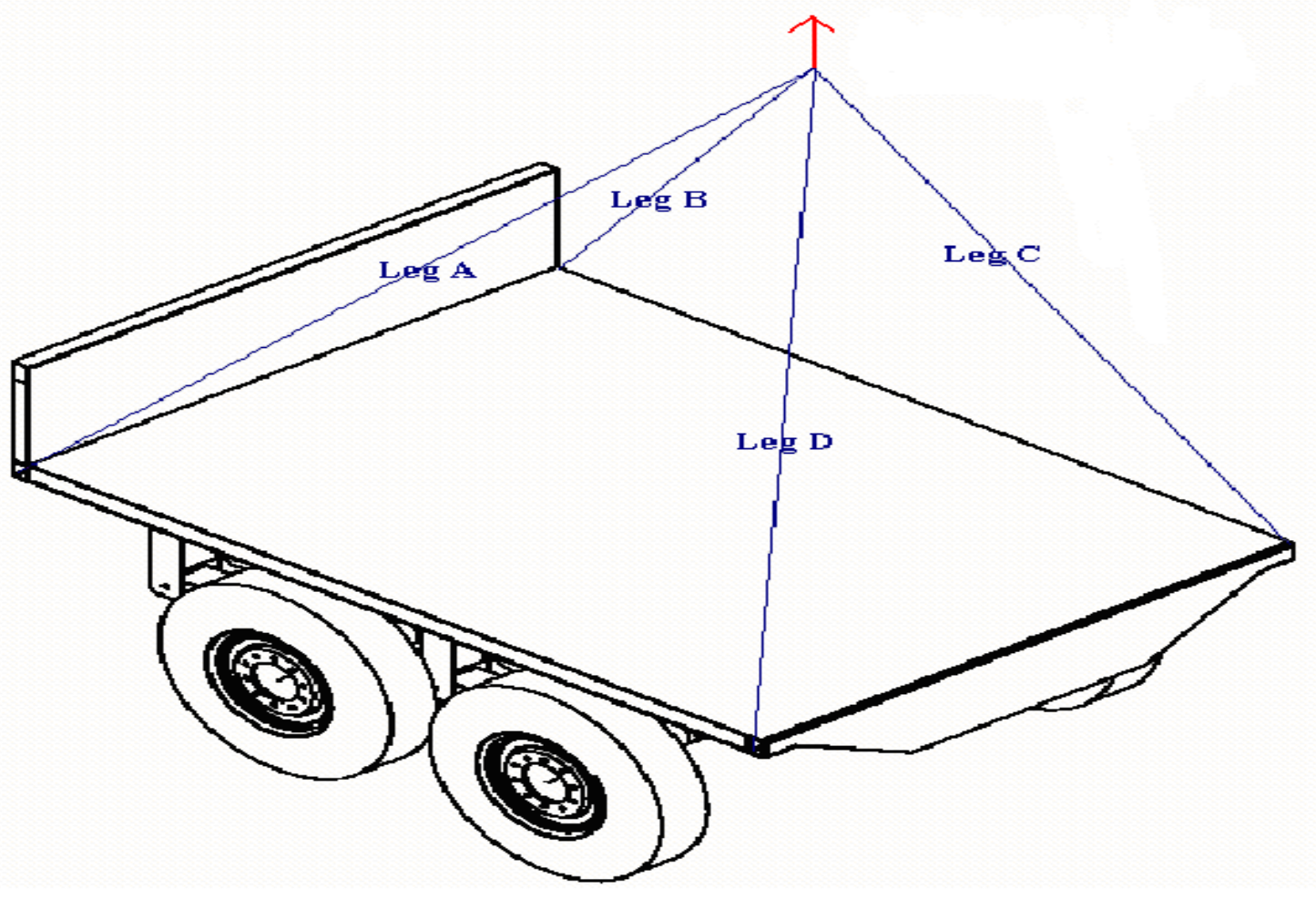

Figure 3-7 Schematic representation of the Helicopter-Lift case

Due to the sudden accelerations of the helicopter lift, the trailer is expected to sustain a gravitational loading on the order of 3.2 times its weight (with the payload), based on MIL-STD-209J. Hence the trailer must be designed for an applied trailer load of $32,000 \mathrm{lbs}$ upward lift supported at the four ends of the deck.

\subsubsection{LOAD CASE 3 - RAIL IMPACT (50,000 LBS - INPLANE SHEAR LOAD)}

This load condition was designed to simulate the rail impact (sudden acceleration or deceleration) of a trailer carrying a full payload of 10,000 lbs. In this load case, due to 
the presence of the high c.g. payload ( 24 in. above deck), the center of gravity of the system is elevated much higher than that of an unloaded trailer, thereby subjecting the deck to bending moment forces along with the inplane shearing forces.

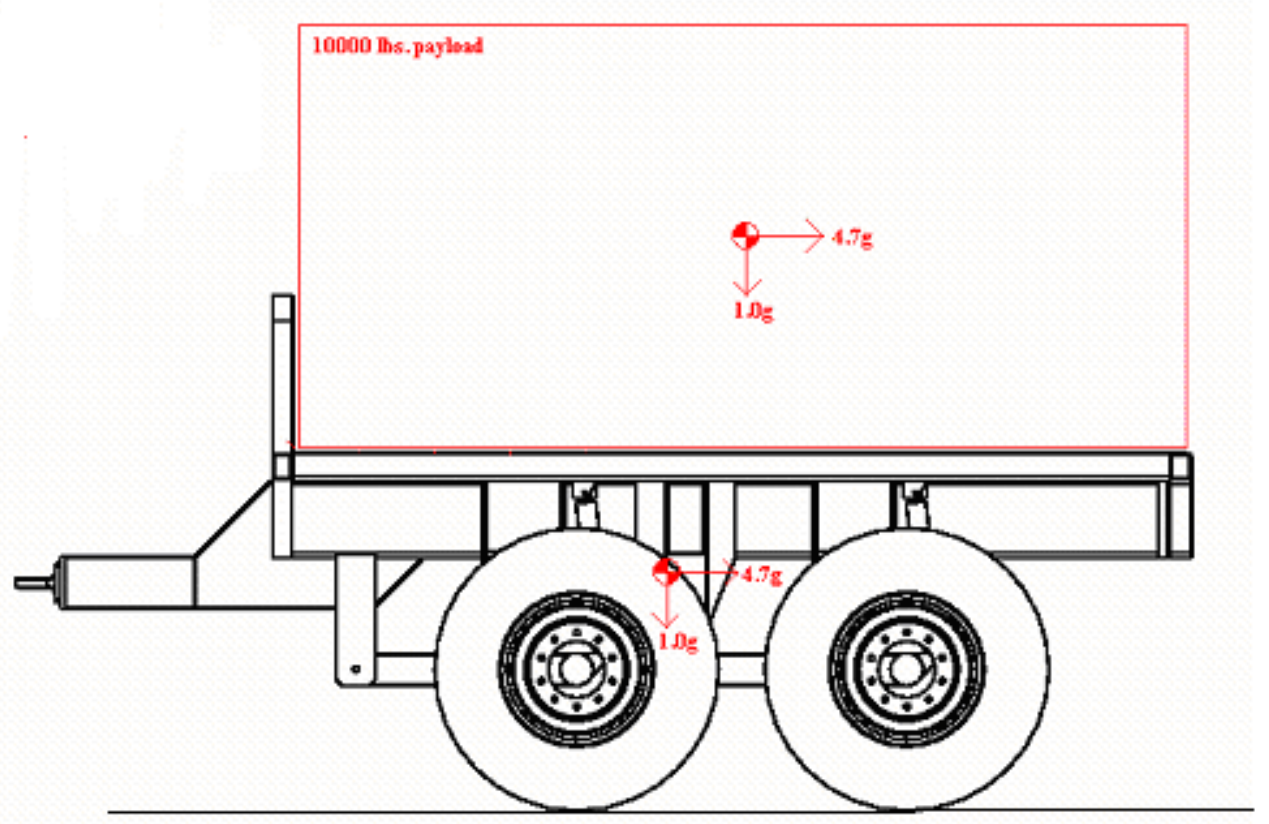

Figure 3-8 Schematic representation of Rail Impact load case

It should be noted that the $4.7 \mathrm{~g}$ longitudinal load can be either in the forward or in the aft directions. 


\section{CHAPTER 4 - FINITE ELEMENT MODELING}

\subsection{INTRODUCTION}

This chapter deals with finite element modeling of Prodeck 4 using the commercial finite element code ANSYS $^{\circledR}$. This chapter presents a complete description of the modeling techniques, model constraining (boundary conditions), and load application patterns for the identified test cases.

\subsection{ELEMENT TYPE}

The FRP deck assembly has been analyzed using the SHELL 93 element of ANSYS 8.1. The solid (SOLID 46) and shell (SHELL 99) elements were also considered for Prodeck 4 analysis. Since, solid elements are preferred for structures with more complex shapes, their use here was ruled out. While the SHELL99 is good for simple shell structures, its usage could be considered unnecessarily complicated for this application. The SHELL99 is an 8-node, 3-D shell element with six degrees of freedom at each node. It is designed to model thin to moderately thick plates and simple shell structures [6]. The input for Shel199 element dealing with the analysis of composite materials and components is based on layer wise properties for each lamina. Such an analysis approach can be time consuming. However, because of the availability of global deck properties for Prodeck 4 [7], SHELL 93 instead of SHELL 99 element has been adopted for the theoretical evaluations. 


\subsubsection{SHELL93 ELEMENT [6]}

SHELL93 is an 8-noded structural element with six degrees of freedom per node. The element is defined by eight nodes, four thicknesses, and the orthotropic material properties. The geometry, node locations, and the coordinate system for this element are shown in Figure 4.1.

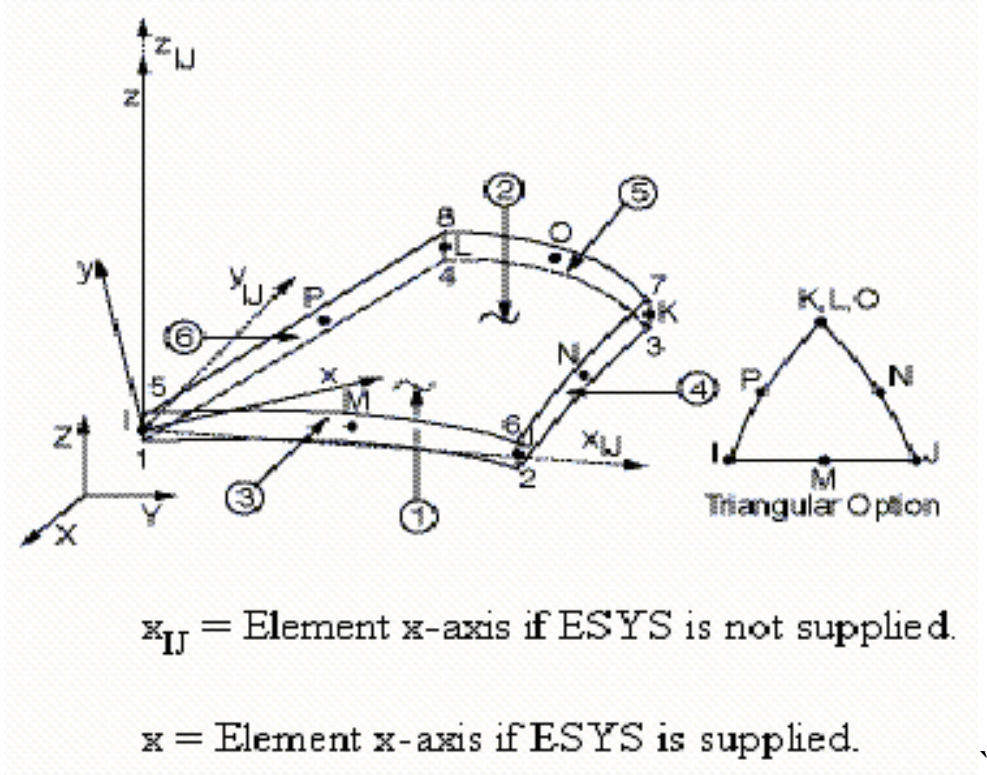

Figure 4-1 Element orientation of the Shell 93 element [6]

Pressures may be input as surface loads on the element faces as shown by the circled numbers on the geometry. Positive pressures act into the element. The solution output (stiffness formulation) associated with the element is comprised of nodal displacements. 


\subsection{FINITE ELEMENT MODELING OF FRP DECK AND SUBSYSTEMS}

\subsubsection{MODELING OF THE FRP COMPOSITE DECK}

The modeling of the Prodeck 4 was accomplished using text commands since the geometry of the deck was relatively simple. The elements were directly generated from the nodes that are created from the deck geometry rather than meshing after creating the areas. Use of Geometric User Interface (GUI) to model composite materials is much more difficult, since utmost care should be taken to ensure that the material property directions match with the co-ordinate axes of the elements. The text input method is much better in that regard. However, GUI was used at the load application stage to facilitate selection of particular sets of nodes and elements by picking directly from the graphics window.

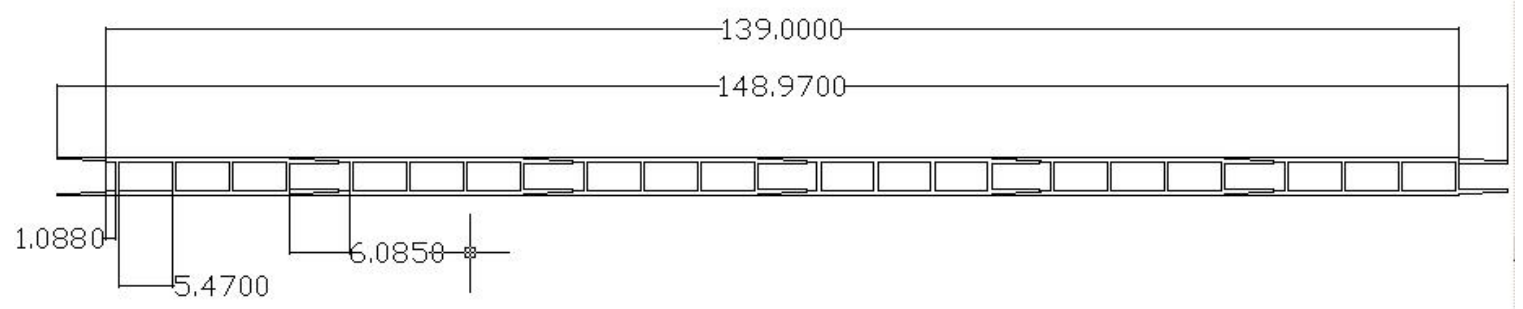

Figure 4-2 Assembly of six modules of Prodeck 4 modules

Since the required dimension of the deck has been identified as 138 " x 98", six Prodeck 4 modules (24" x 98") were assembled while eliminating the overhanging flanges of the end modules, thereby creating a $137.5 "$ x 98 " deck surface. 
The first step in building a FE model for the FRP deck was the generation of nodes in the working space along the length (138 inches) and depth (4 inches) to facilitate element creation for a Prodeck 4 module. This thereby aligned the local (element) coordinate system with the global (model) co-ordinate system. The elements on the crosssection of the deck at the top and bottom flanges and the webs were then generated (Figure 4.3).

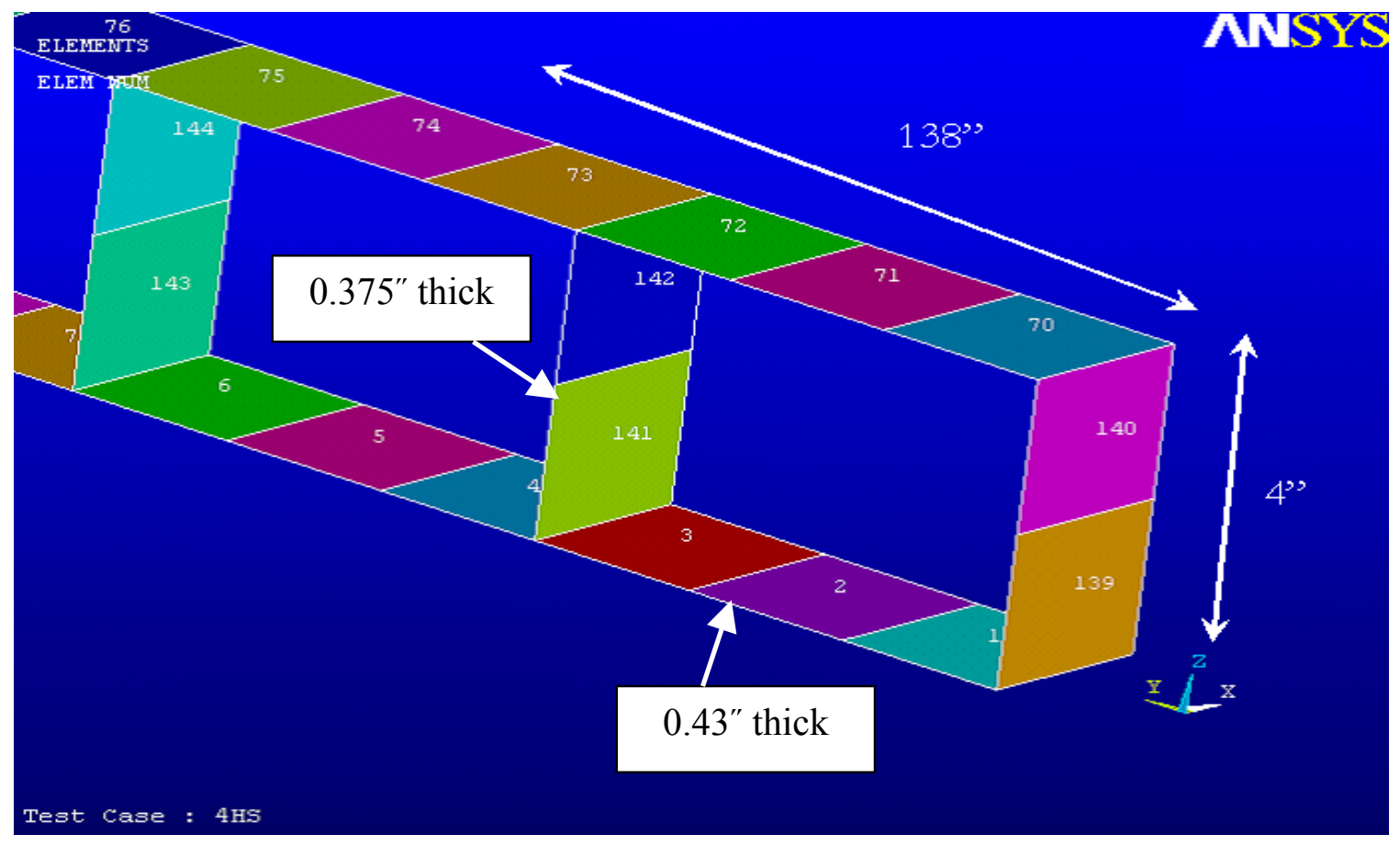

Figure 4-3 Mesh of the deck cross-section

There are 69 elements spanning the length $\left(138^{\prime \prime}\right)$ of the deck and 2 elements for the height of the web. Hence each cell has two elements each of 2 " height for each web and 3 elements for each flange. These elements are all SHELL 93 elements but have 
different thicknesses. The top and the bottom flange elements are 0.43 " thick and the web elements are $0.375^{\prime \prime}$ thick.

This cross-section of the deck was then extruded in the X-direction (see Figure 4.3) to obtain the required width (98") of the deck. The extrusion pattern was done in such a manner that there are nodes available on the deck at particular locations for merging with the nodes of the stringer elements. The completely extruded deck is shown in Figure 4.4.

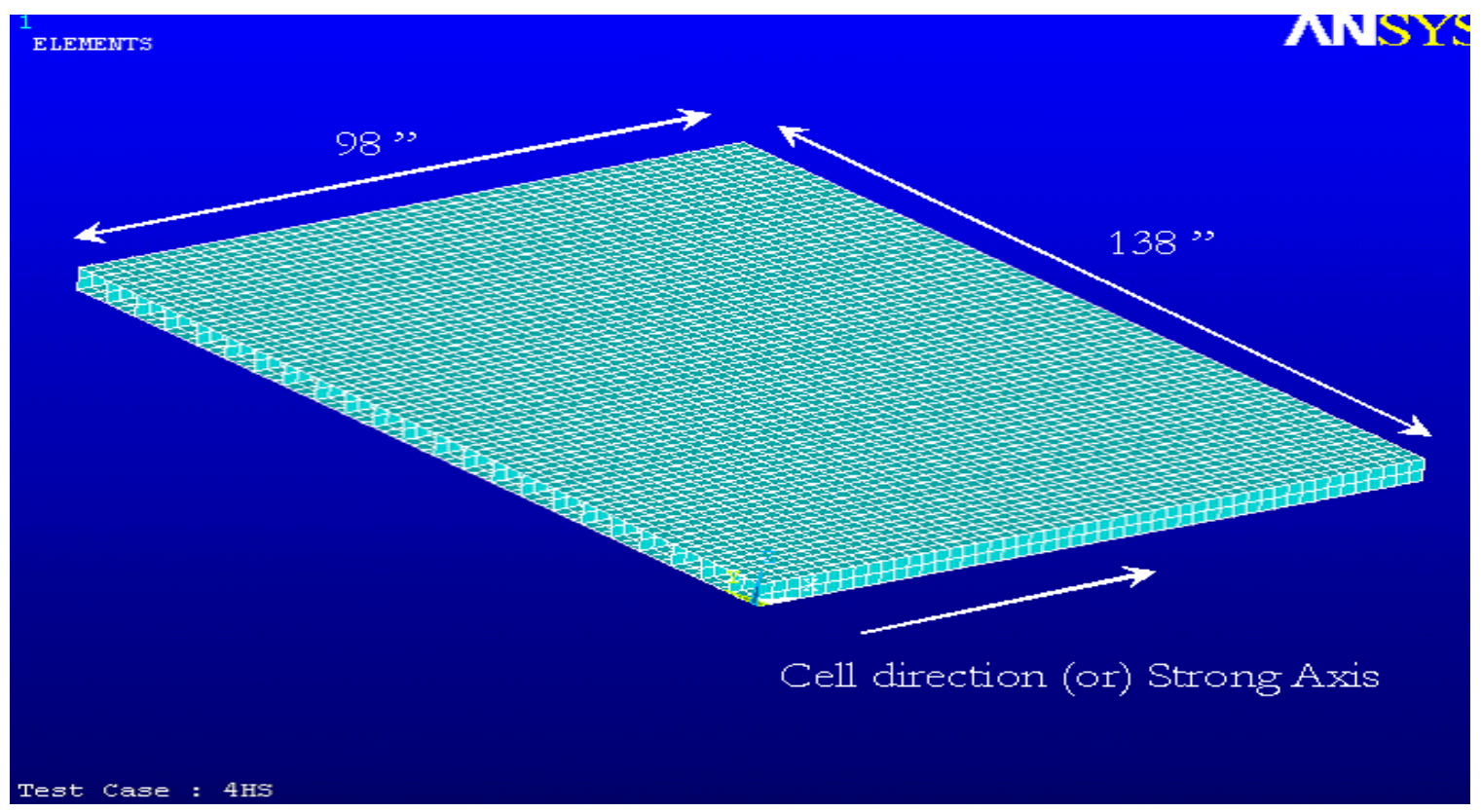

Figure 4-4 FE model of complete deck (Isometric View) 


\subsubsection{MODELING OF THE SUPPORT ASSEMBLY (STRINGERS)}

The two longitudinal beams (or support stringers) were modeled after completing the deck modeling. It is assumed that bonding between the deck and stringers is one hundred percent. This condition was achieved in the FE model by merging the deck nodes with the stringer nodes. The stringers are positioned 35 " apart and are symmetrical about the deck width, i.e., center line running along the length of the deck. For modeling of these stringers, the nodes were created in the $\mathrm{X}$-direction and again arrayed in the $\mathrm{Y}$ direction in the form of an 'I' cross-section. The elements used for modeling of the stringer elements were again SHELL93 elements. These elements have the isotropic material properties of steel with elastic modulus of $29 \times 10^{6}$ psi and Poisson's ratio of 0.3 . The thickness of the flange of the I-beam is $0.44 "$ and the web thickness is 0.25 " (based on a W12x30 structural steel beam).

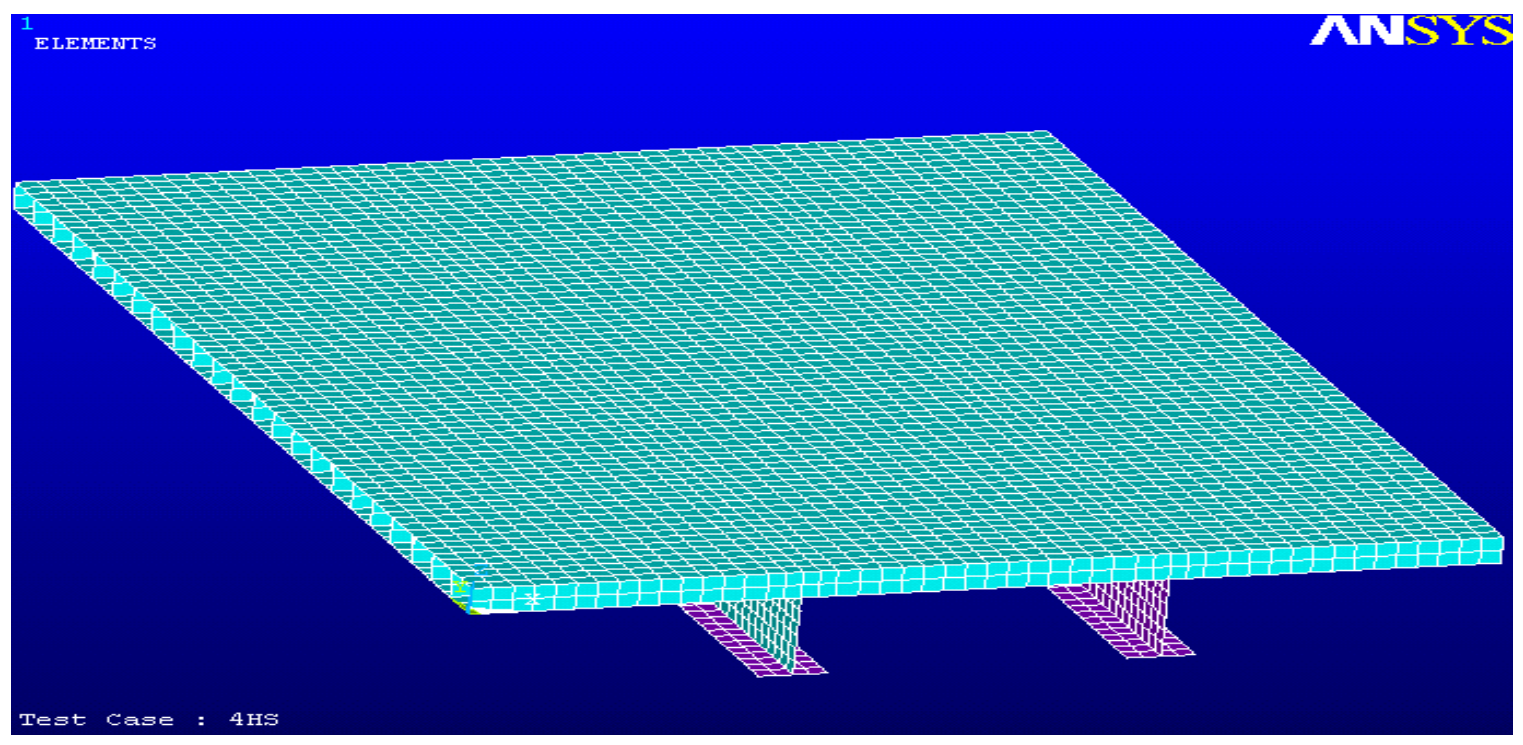

Figure 4-5 Composite deck with steel stringers 


\subsubsection{MODEL CONSTRAINING}

Once the finite element model of the trailer deck and the stringer assembly was complete, the model was constrained at particular locations in order to simulate the chassis attachment positions. In order to achieve this, the nodes on the bottom flange of the stringers were constrained for all directions of freedom at two patch locations which are 50" apart longitudinally. This simulated the wheel base of the trailer. The schematic representation of the imposed constraints is displayed in Figure 4.6.

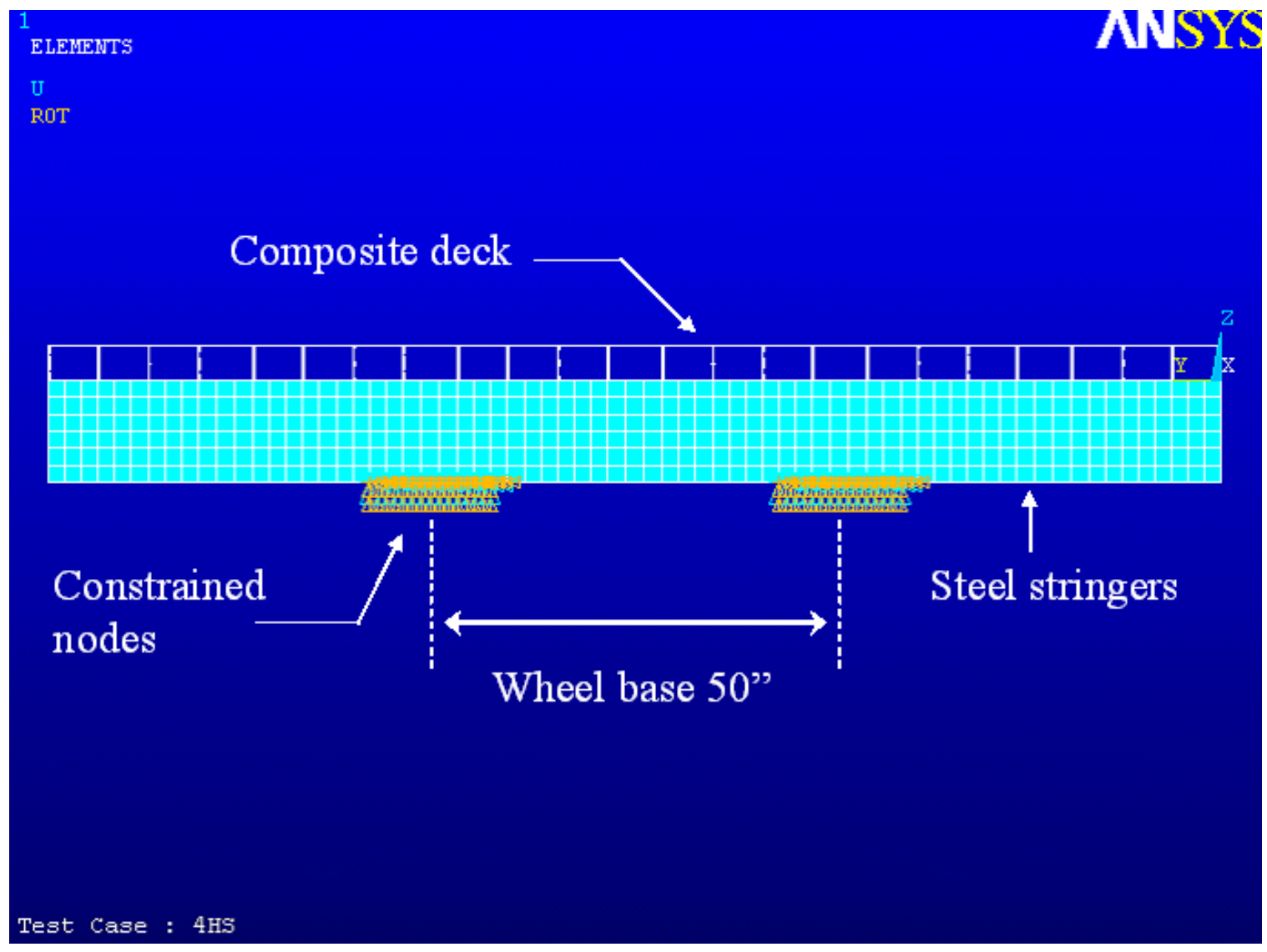

Figure 4-6 Side view of the FE model of deck and stringer assembly 


\subsubsection{LOAD CASE SIMULATION}

The loading conditions identified in Chapter 3 were then simulated in the finite element model. FE analysis was carried out in order to find critical stress locations on the trailer deck assembly, which would also be used as the basis to instrument the FRP deck during the experimental phase.

\subsubsection{LOAD CASE 1(a) - UNIFORMLY DISTRIBUTED LOAD - 40,000 lbs.}

As explained earlier these trailers are expected to carry bulk cargo either in the form of containers or distributed loads which have a uniform loading pattern over the deck surface. The critical loading scenario identified was a uniform load of 40,000 lbs uniformly distributed over the entire cross-section of the deck. This load was applied to the elements on the top surface of the deck in the form of a uniform pressure acting in the downward direction.

Total applied load $(P)=40,000$ lbs.

Area of cross-section $(A)=138^{\prime \prime} \times 98^{\prime \prime}=13524 \mathrm{in}^{2}$.

Pressure applies $=\frac{P}{A}=\frac{40000 \mathrm{lbs}}{13524 \mathrm{in}^{2}}=2.958 \mathrm{lb} / \mathrm{in}^{2} . \approx \mathbf{3}$ psi.

Hence a uniform pressure of 3 psi was applied over the elements of the top surface of the deck. 


\section{Uniform pressure of 3 psi. acting downwards}

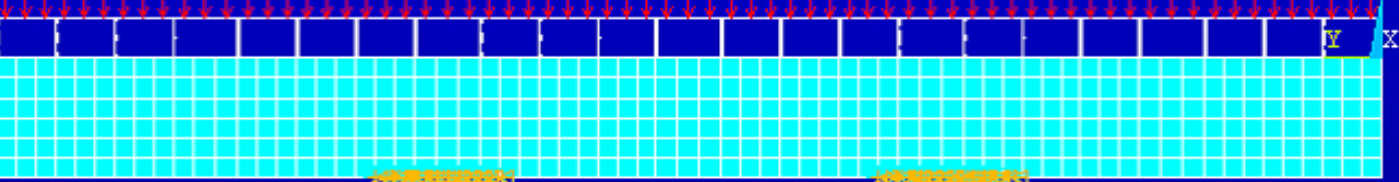

Figure 4-7 Uniformly distributed load of 40,000 lbs on the deck surface - side view

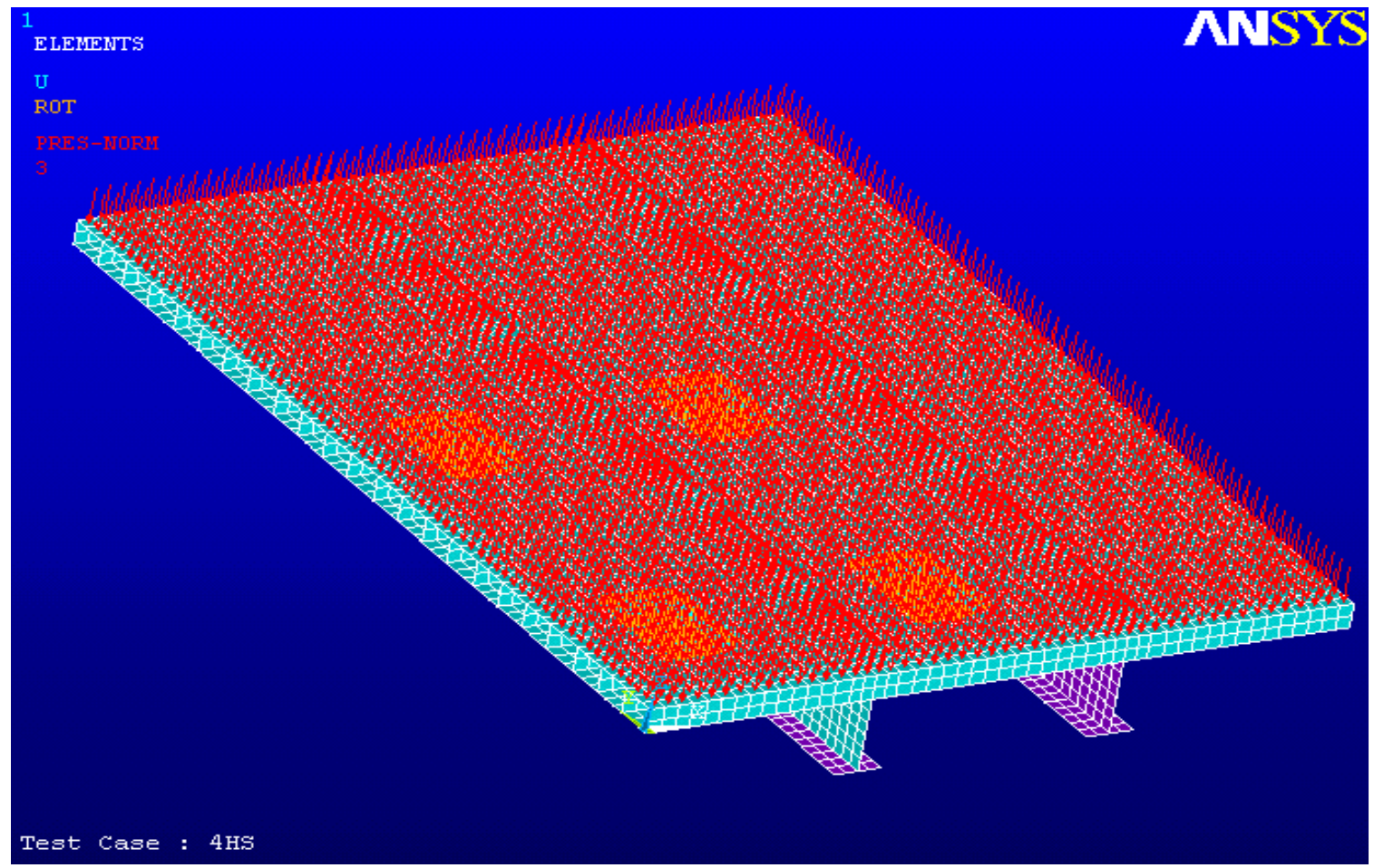

Figure 4-8 Uniformly distributed load of 40,000 lbs on the deck surface 


\subsubsection{LOAD CASE 1(B) - SIXCON CONTAINER LOAD TEST (40,000 LBS - DOWNWARD PATCH LOADING)}

This load case simulates the trailer carrying a SIXCON container placed on four corner-castings on the deck surface. These four corner-castings are metal entities on the deck which share the entire load of $40,000 \mathrm{lbs}$ without the container actually touching the deck surface. Hence the load of 40 kips is distributed equally among the 4 patches. The patches and the deck act in unison. The modeling of these patches was done by reinforcing the elements under these patches by converting them into elements with an effective thickness of a steel plate. This conversion was accomplished by using the modular ratio concept from classic strength of material principles.

Modulus of Steel $\left(E_{s}\right)=29 \times 10^{6} \mathrm{psi}$

Modulus of Composite $\left(E_{y}\right)=1.4 \times 10^{6} \mathrm{psi}$

Modular ratio $(\mathrm{R})=\frac{E_{s}}{E_{y}}=20.71$

Thickness of steel plate $=0.5^{\prime \prime}$

Thickness of composite flange $=0.43$ "

Hence, the effective thickness in terms of steel plate $=\left(0.5^{\prime \prime}\right)+\left(\frac{0.43^{\prime \prime}}{20.71}\right) \approx 0.52^{\prime \prime}$

Therefore, the elements under these SIXCON patches were modeled with the material properties of steel and an element thickness of 0.52 ". Alternately, this could have been done by converting the elements into an effective composite thickness using the modular ratio of composite to steel rather than steel to composite. 


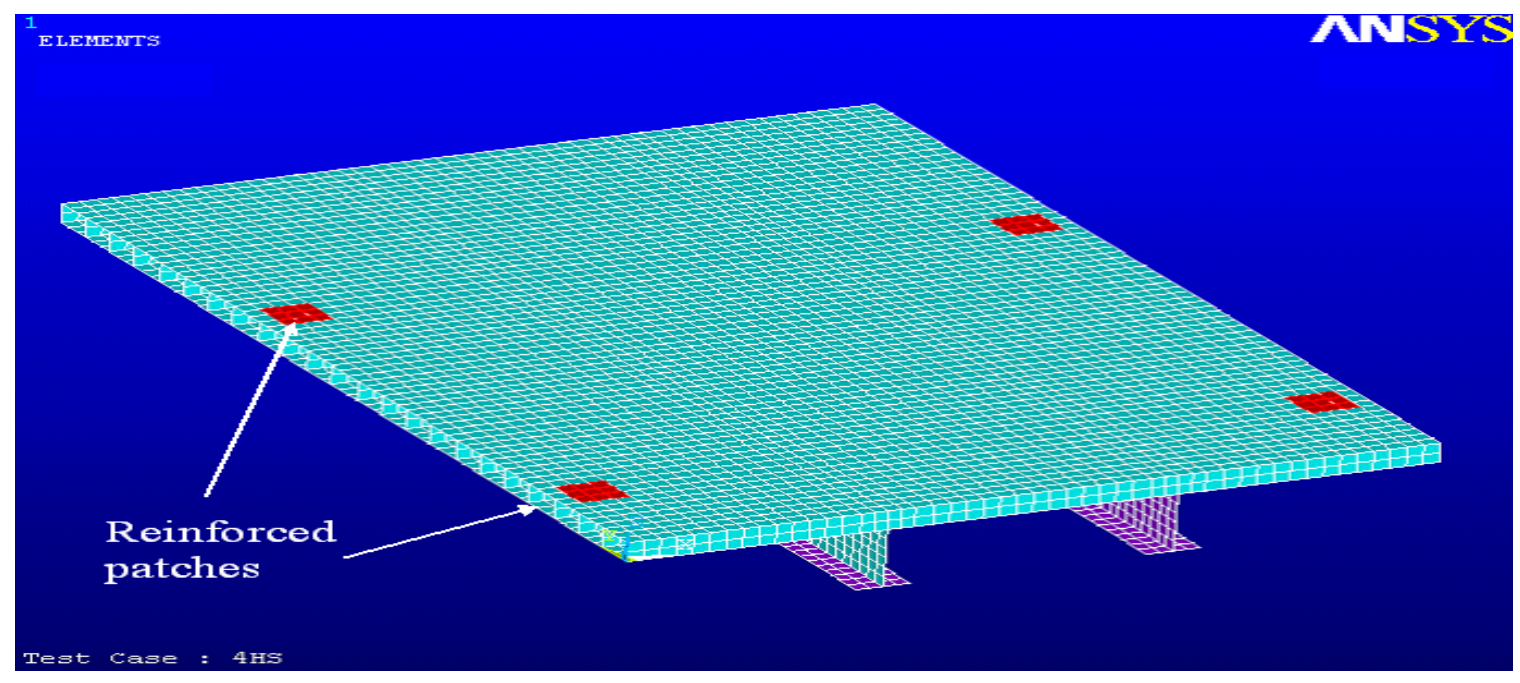

Figure 4-9 Steel reinforced SIXCON patches

Total load applied over 4 patches $=40,000 \mathrm{lbs}$.

Load applied per patch $(P)=10,000 \mathrm{lbs}$.

Single patch area $(A)=6.24 " \times 6 "=37.44 \mathrm{in}^{2}$.

Uniform pressure applied on to the elements $=\frac{P}{A} \approx \mathbf{2 6 8} \mathbf{~ l b} / \mathbf{i n}^{2}$.

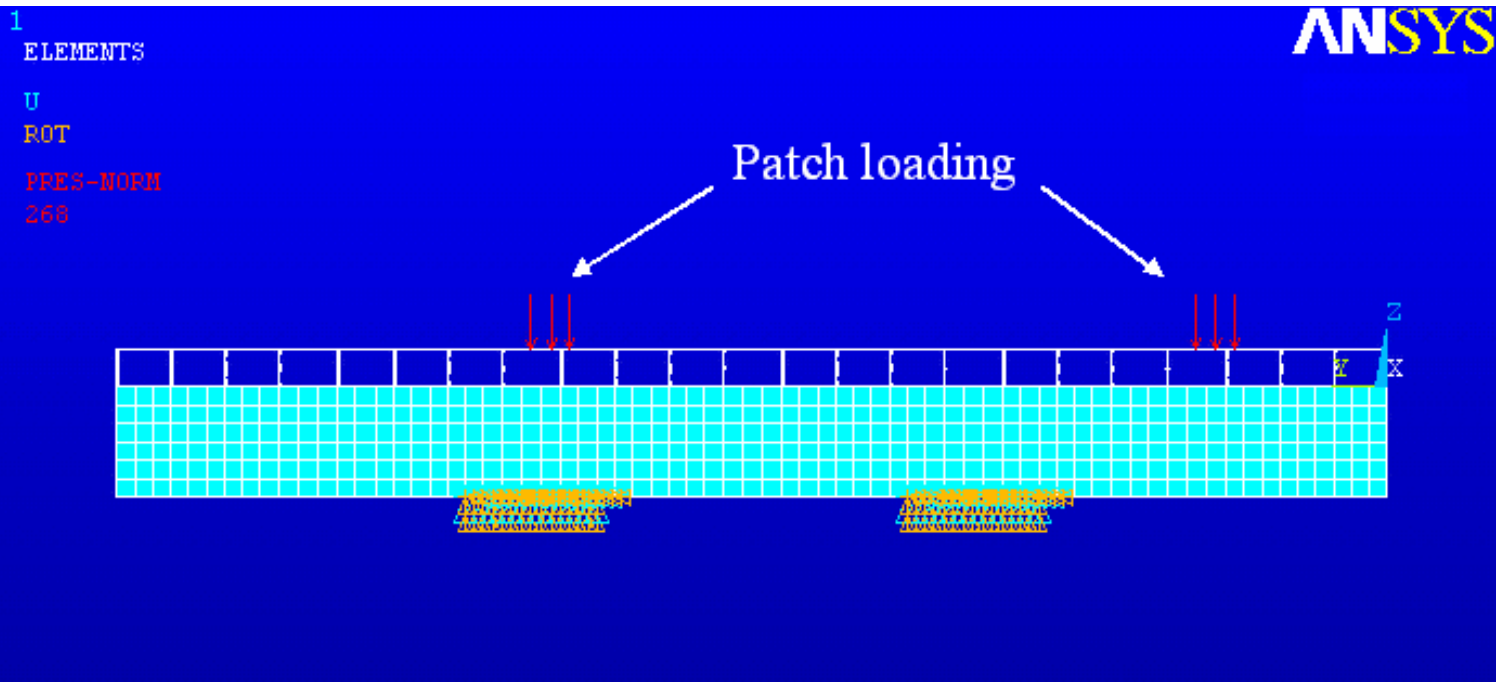

Figure 4-10 SIXCON patch loading - Side view 


\subsubsection{LOAD CASE 2- HELICOPTER LIFT (32,000 LBS. - UPWARD PATCH}

\section{LIFT)}

This load case simulates a loading pattern in which the deck is subjected to an upward pull of $32,000 \mathrm{lbs}$. This loading condition is to test the deck's resistance to the $\mathrm{g}$ forces experienced in the event of an air lift. An equivalent load to this scenario is the upward pull of the deck, constraining the bottom stringers rigidly. The total load applied in the FEA model and during test was based on $3.2 \mathrm{~g}$ times a 10,000 lbs. payload, but in reality, the loading should be $3.2 \mathrm{~g}$ times the self-weight of the trailer plus the payload weight. Since (a) only the deck was being fabricated for the physical testing, (b) the suspension and support systems have not yet been optimized, and (c) the full trailer weight cannot yet be estimated, the loading was reduced to the $32,000 \mathrm{lbs}$. listed here.

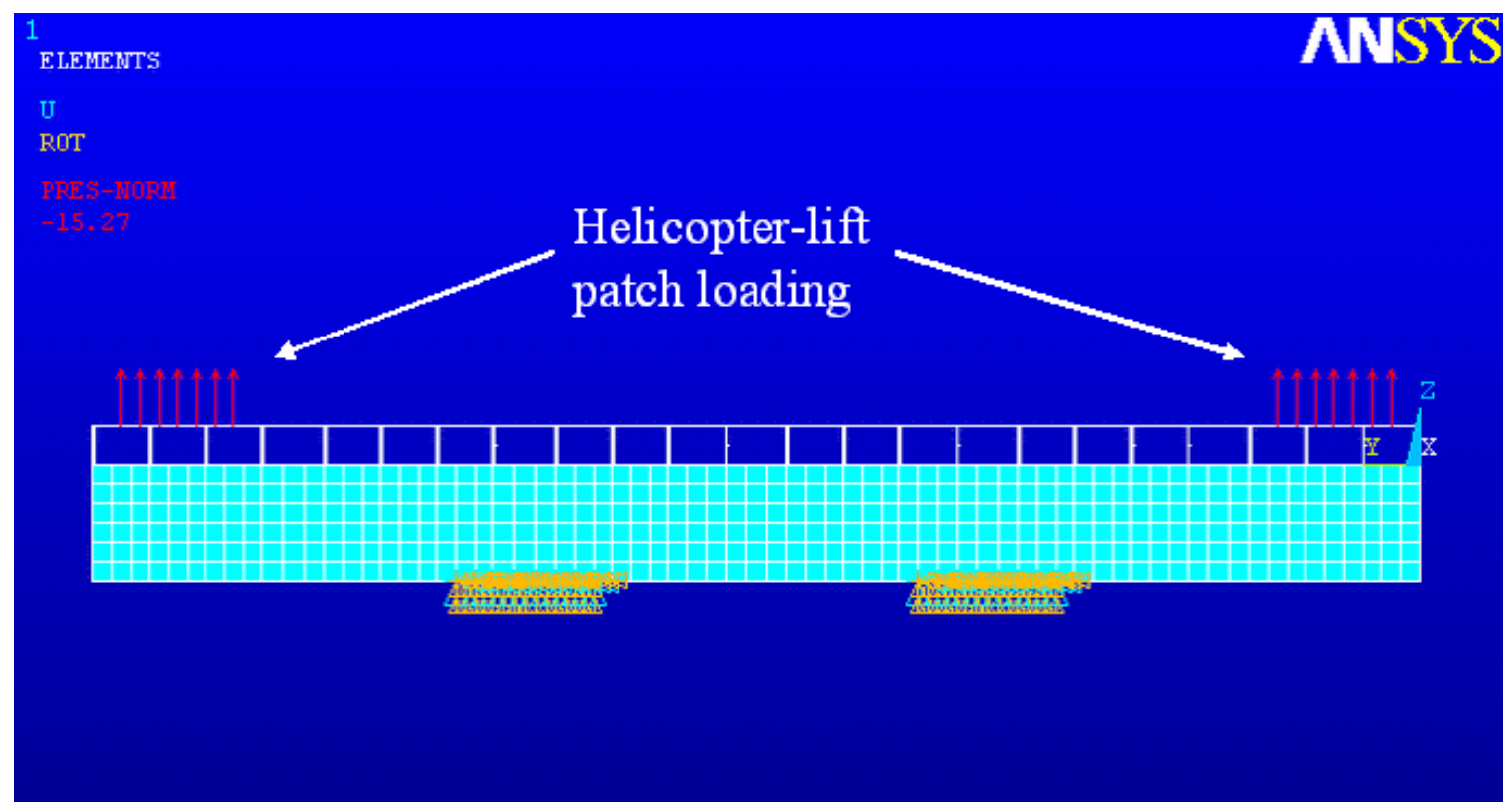

Figure 4-11 Helicopter Lift patches - side view 
The patch was modeled by reinforcing the deck elements in the same fashion as shown for the SIXCON loading case using the modular ratio (R) of steel and composite.

Total load applied over 4 patches $=32,000 \mathrm{lbs}$.

Load applied per patch $(P)=8,000$ lbs.

Single patch area $(A)=81.83 \mathrm{in}^{2}$.

Uniform pressure applied on the elements $=\frac{P}{A} \approx \mathbf{9 8} \mathbf{~ l b /} / \mathbf{i n}^{2}$.

\subsubsection{LOAD CASE 3 - RAIL IMPACT (50,000 LBS. - INPLANE SHEAR LOAD)}

This load condition is devised to test the ability of the deck surface to resist (inplane) shearing loads, as in the case of accelerations or decelerations of the fully-loaded trailer due to a rail impact. According to the approximated loading pattern identified by SEI for this test set-up, each steel distribution beam was to be bolted to the deck at 6 locations with a force of about 50,000 lbs (4.7g x 10kip payload) applied in the horizontal direction at a height of 24 " above the deck surface. Since the plane of loading is offset from the plane of the deck, the deck is subjected to inplane shearing forces and bending moment.

\section{SHEARING FORCE (inplane)}

Total applied horizontal load $(P)=50,000 \mathrm{lbs}$.

Number of bolts sharing the horizontal load $(n)=12$ 
Inplane shearing force on each bolt $(\mathrm{F})=\left(\frac{P}{n}\right)=4166.6 \mathrm{lbs}$.

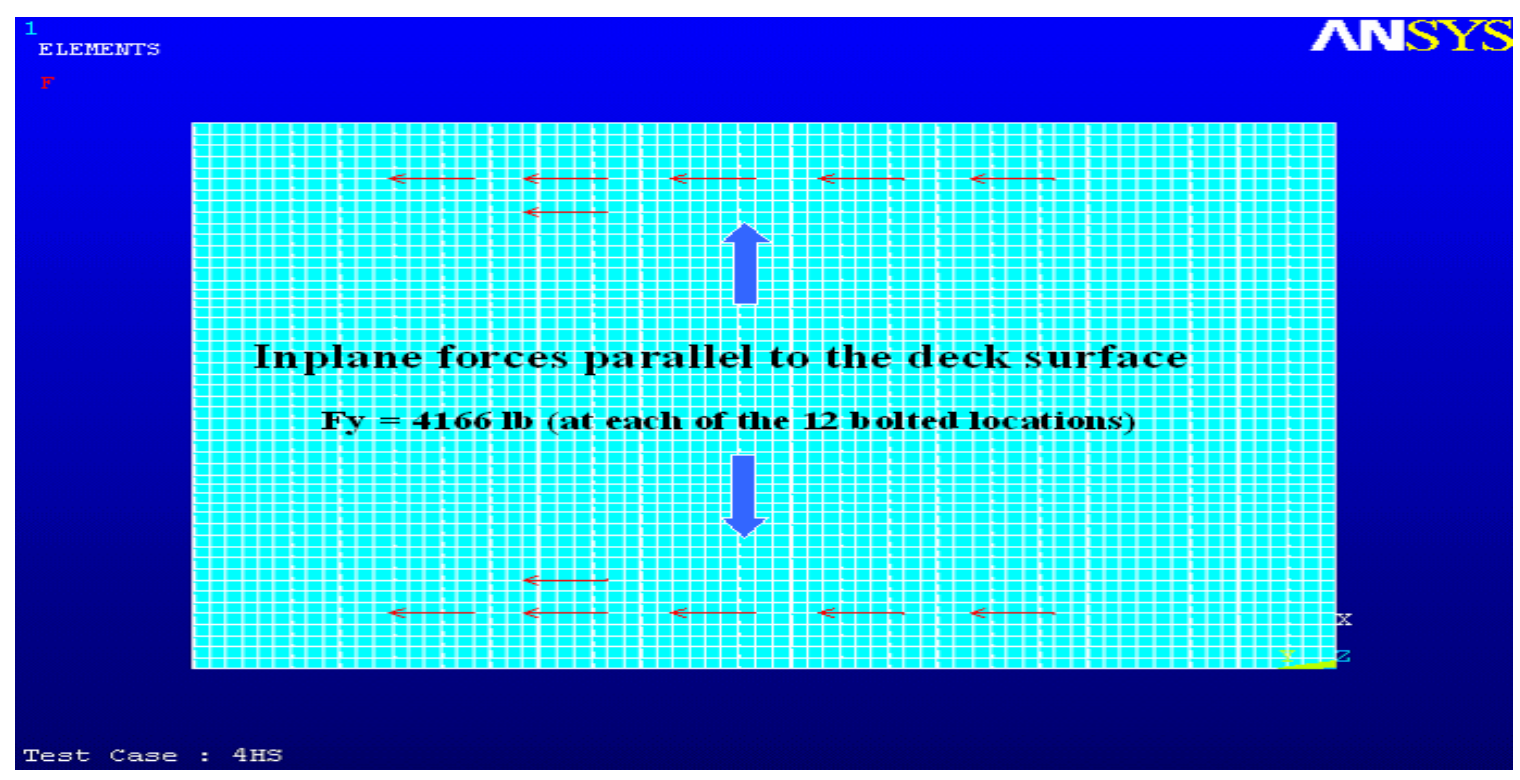

Figure 4-12 Inplane shearing forces on the deck surface

\section{MOMENT FORCE (out of plane)}

Total applied horizontal load $(P)=50,0001 \mathrm{bs}$.

Distance offset from the surface of the deck $(d)=24$ in.

Moment generated per beam $\left(\mathrm{M}_{\mathrm{n}}\right)=(P) *(d)=(1,200,000 / 2)=600,000 \mathrm{lb}$-in .

Since 6 bolts on each beam were used in the longitudinal direction and the force applied was about the center, the moment created is distributed among the bolts as shown. The moment distribution for an applied load of 50,000 lbs is shown in Figure 4.13 . 


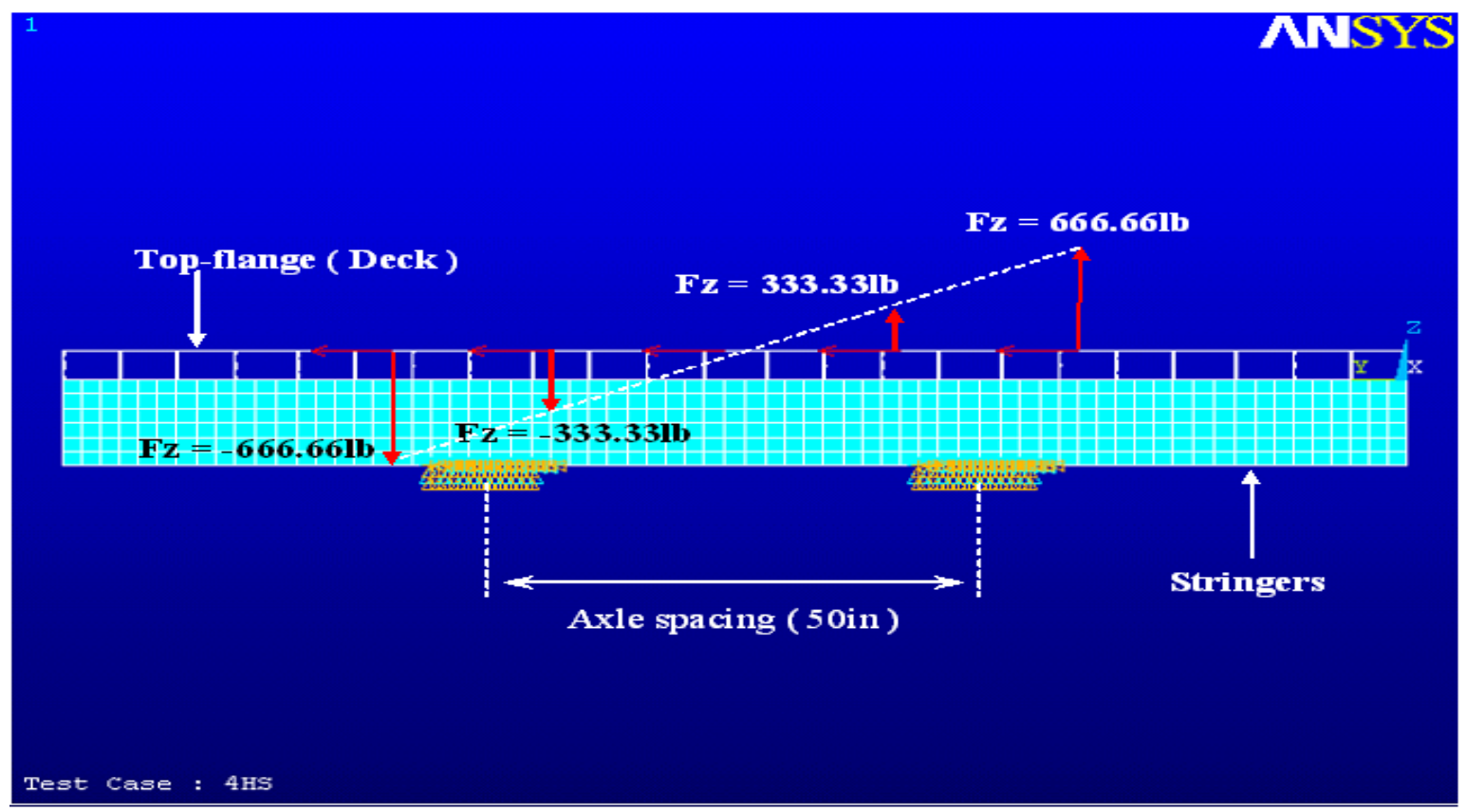

Figure 4-13 Axial forces on the deck due to bolts 


\section{CHAPTER 5 - FRP TRAILER ASSEMBLY AND TESTING}

\subsection{INTRODUCTION}

The assembly of the prototype trailer and various test setups conceived to replicate the loading patterns are presented in this chapter. Details of instrumentation and the test procedures adopted are also discussed.

\subsection{ASSEMBLING THE FRP TRAILER DECK PROTOTYPE}

\subsubsection{DECK ASSEMBLY}

The composite deck used for this decking prototype was a 4 inch thick FRP module known as Prodeck 4. The overall dimensions of the deck have been maintained at 137.51 inches in length and 98 inches in width. This trailer deck was created by joining six pultruded modules (each 98 inches long) end-to-end with the overhanging flanges of the fore and aft modules cut off to give a final area of 98 inch x 137.51 inch. The modules were glued to one another using PLIOGRIP ${ }^{\circledR}$ (a surface adhesive for bonding) at the manufacturing plant. Apart from the PLIOGRIP ${ }^{\circledR}$, an additional layer of glass fabric reinforcement was provided on the outer surface at the junction of two deck modules. 


\subsubsection{SUPPORT ASSEMBLY}

The trailer support assembly consists of two main W12x30 type wide flange Ibeams with cross-beams connecting the two wide flange beams. The beams (also known as stringers) are spaced 35 inches center-to-center. The stringers were glued to the deck surface using PLIOGRIP ${ }^{\circledR}$. Extensive surface preparation was done before the application of PLIOGRIP ${ }^{\circledR}$. The following is the step-wise procedure for bonding of stringers to FRP deck.

STEP 1: The surface of the deck which comes in contact with the stringers was first grinded to get a smooth finish using an 80 grit sand paper. The stringers were previously sand blasted by the supplier; hence no grinding was required in the laboratory.

STEP 2: The ground deck surface and sand blasted beam surfaces were then cleaned with Acetone to remove any chemical impurities and dust remaining after sanding.

STEP 3: This leaves an oxidized layer over the area which must be vacuumed 15 to 20 minutes after Acetone application so that the oxidized layer can be fully removed for better adhesion of the PLIOGRIP ${ }^{\circledR}$.

STEP 4: The PLIOGRIP ${ }^{\circledR}$ is squeezed over the deck surface and then the previously sand-blasted and cleaned I-beams were placed over it. The deck and stringer set up was left to cure overnight. 


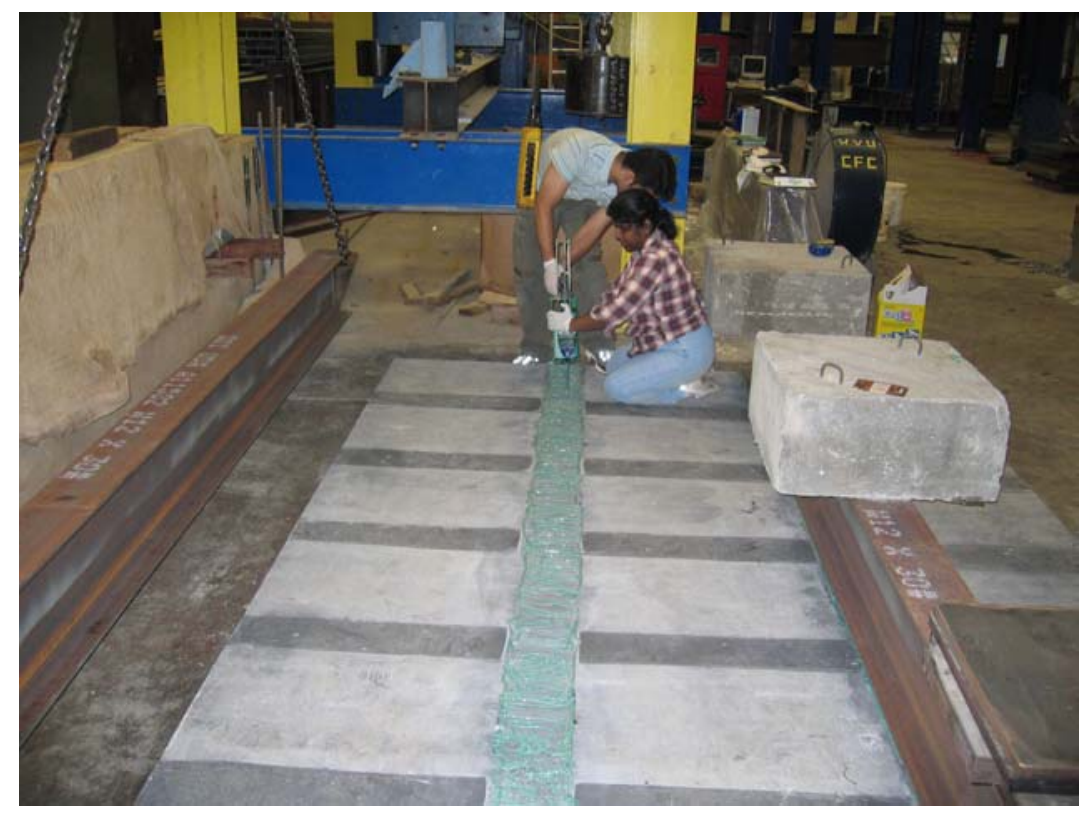

Figure 5-1 Application of PLIOGRIP ${ }^{\circledR}$ on the deck before laying the stringer

After curing, the six support cross-members (diaphragms) were welded into place. The purpose of these cross members is to provide strength to the trailer in case of torsional loads. Standard C-sections ( 1010 x 30) were used as cross-beams. The six cross beams were placed as shown in Figure 5.2. 


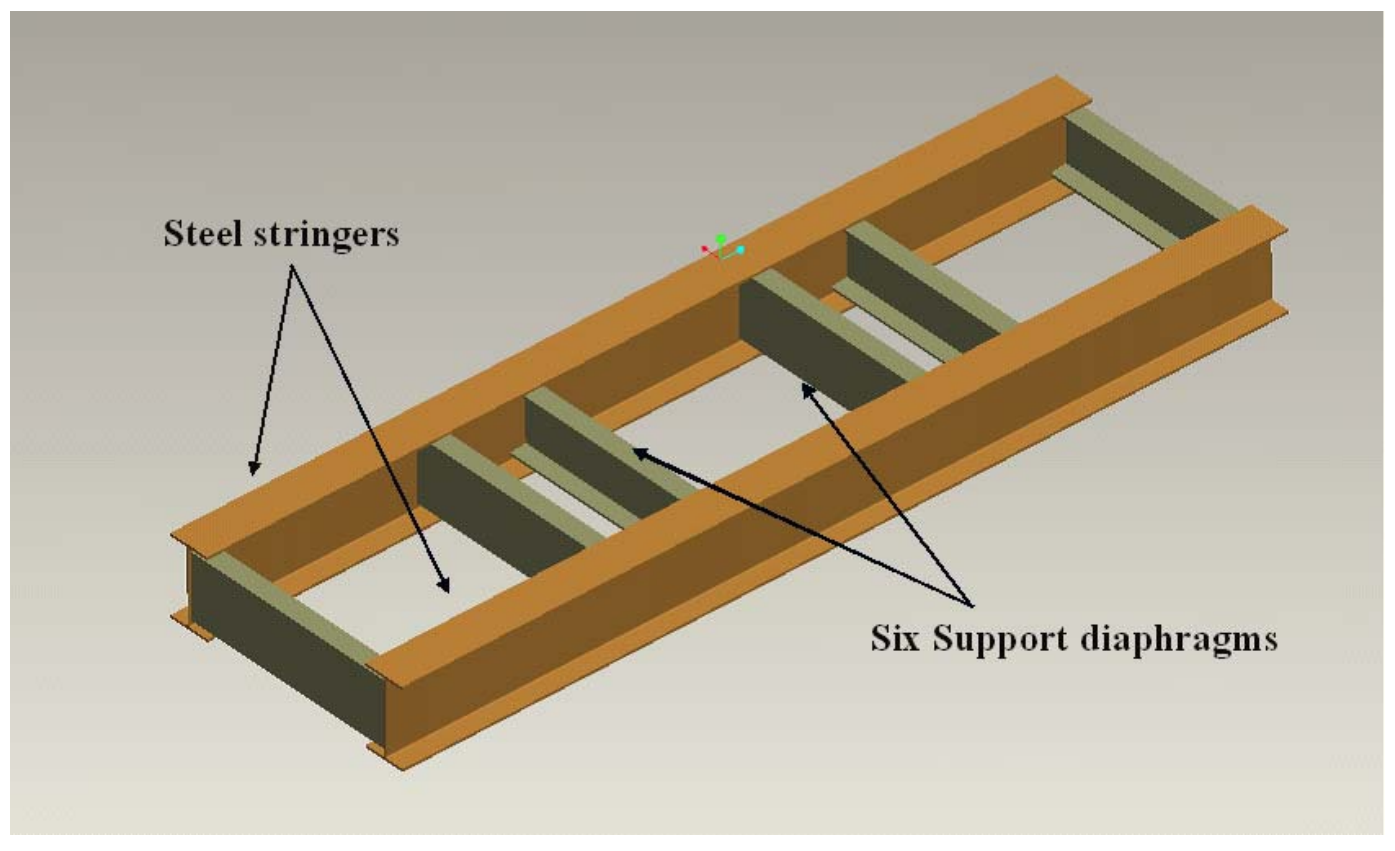

Figure 5-2 Stringer, Cross-beam assembly underneath the deck

\subsubsection{INSTRUMENTATION}

The trailer system was instrumented with electrical resistance strain gages and LVDTs to measure deflections of the deck. The locations for mounting these gages were decided based on the finite element analysis results of the decking system and previous knowledge of the FRP composite behavior under various loading patterns.

- A data acquisition system was used to interpret the output from the strain gages.

- A Dual pump hydraulic actuator was used to apply the loads.

- An MTS 407 controller was used to operate the actuator.

- A hydraulic ram was used for the shear test for horizontal load application. 


\subsubsection{TEST SET-UP}

The deck and support assembly set up was then mounted on two I-beams placed 50 inches apart to replicate the wheel base in the longitudinal direction (Figure 5.3). The stringers were welded to these beams. The whole system was in turn bolted to the ground to have it completely secured against upward and downward movement, thus arresting the motion in the vertical direction (Figure 5.4).

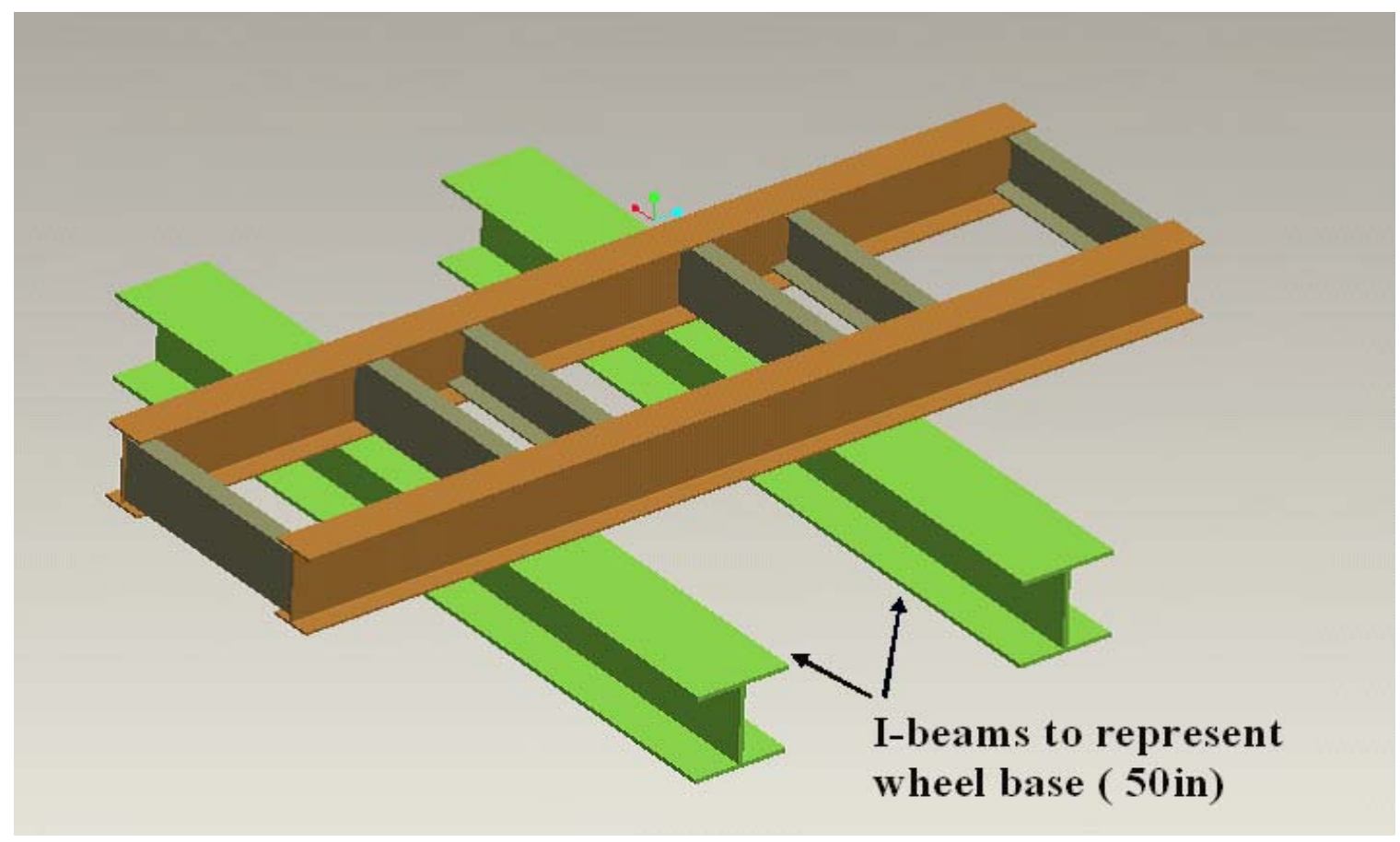

Figure 5-3 I-beams supporting the sub assembly replicate the wheel base 


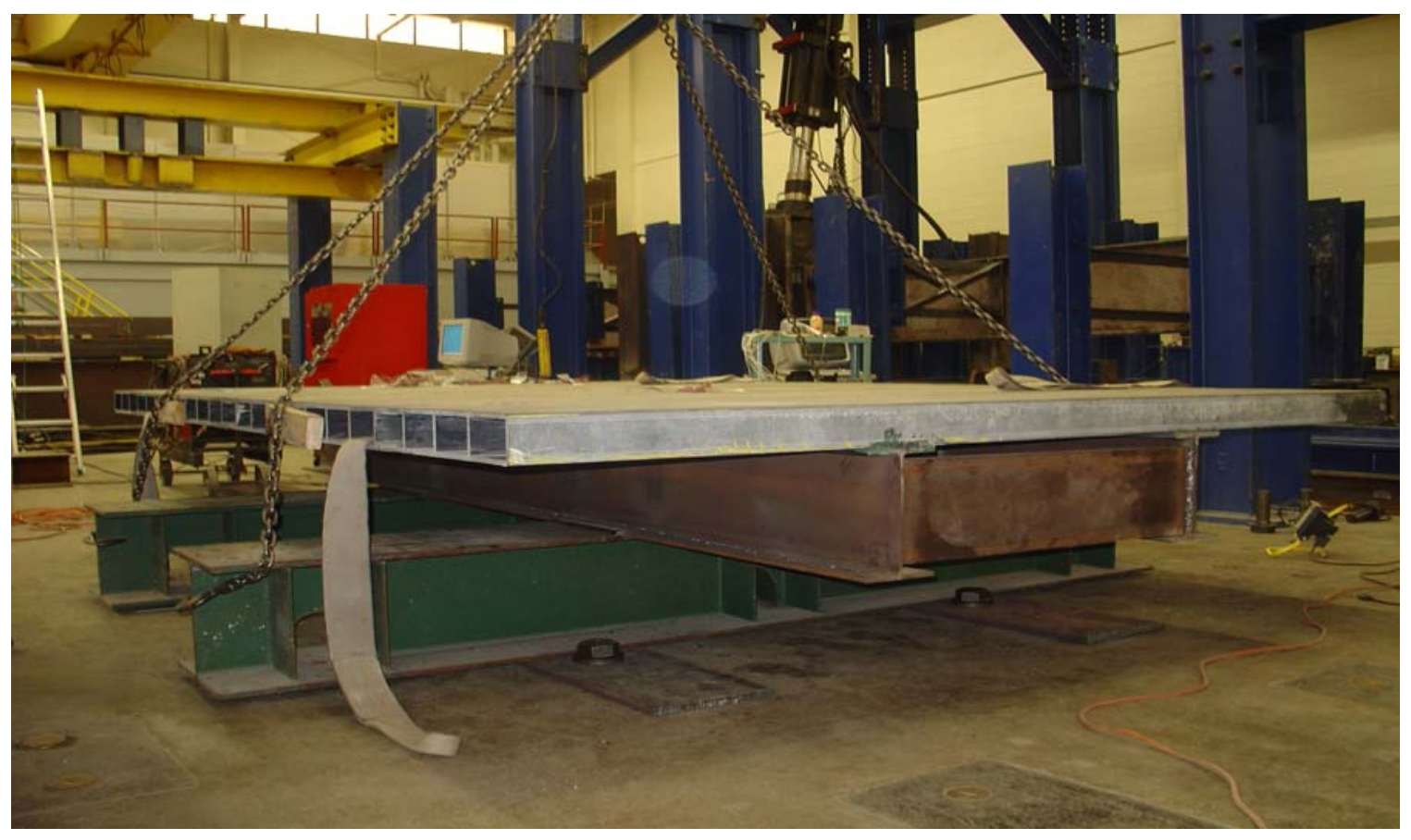

Figure 5-4 Test set up for loading 
Table 5.1 Strain gage locations

\begin{tabular}{|c|c|c|c|c|c|c|}
\hline \multirow{2}{*}{ Gages } & \multicolumn{3}{|c|}{ Location (in) } & \multirow{2}{*}{ Placement } & \multirow{2}{*}{ Alignment } & \multirow{2}{*}{ Description } \\
\hline & $\mathbf{X}$ & $\mathbf{Y}$ & $\mathbf{Z}$ & & & \\
\hline Gage-1 & 49 & 9.25 & 4 & Top of top-flange & $\mathrm{X}$-direction & In line with Helicopter-Lift patch centers \\
\hline Gage-2 & 31.5 & 21.94 & 4 & Top of top-flange & $\mathrm{X}$-direction & In line with SIXCON patch centers \\
\hline Gage-3 & -31.5 & 21.94 & 4 & Top of top-flange & $\mathrm{X}$-direction & In line with SIXCON patch centers \\
\hline Gage-4 & 49 & -46.50 & 4 & Top of top-flange & $\mathrm{X}$-direction & In line with SIXCON patch centers \\
\hline Gage-5 & 49 & -21.94 & 0 & Bottom of bottom-flange & $\mathrm{X}$-direction & In line with SIXCON patch centers \\
\hline Gage-6 & 49 & 9.25 & 0 & Bottom of bottom-flange & $\mathrm{X}$-direction & In line with Helicopter-Lift patch centers \\
\hline Gage-7 & 35.75 & 9.25 & 0 & Adjacent to Flange & $\mathrm{X}$-direction & Used to measure composite action (HL) \\
\hline Gage- 8 & 33.125 & 9.25 & 0 & Flange of Beam-1 & $\mathrm{X}$-direction & Used to measure composite action (HL) \\
\hline Gage-9 & 49 & -46.5 & 0 & Bottom of bottom-flange & $\mathrm{X}$-direction & In line with SIXCON patch centers \\
\hline Gage-10 & 4.5 & -46.5 & 4 & Bottom of top-flange & Y-direction & Placed in the cell under SIXCON patch \\
\hline Gage-11 & 4.5 & 21.94 & 4 & Bottom of top-flange & $\mathrm{X}$-direction & Placed in the cell under SIXCON patch \\
\hline Gage-12 & 4.5 & 21.94 & 4 & $\begin{array}{l}\text { Bottom of top- } \\
\text { Flange }\end{array}$ & Y-direction & Placed in the cell under SIXCON patch \\
\hline Gage-13 & -4.5 & -46.5 & 4 & Bottom of top-flange & $\mathrm{X}$-direction & Placed in the cell under SIXCON patch \\
\hline Gage-14 & -31.5 & 69 & -12 & Beam - 2 & $\mathrm{X}$-direction & Placed at the mid-span of Beam \\
\hline
\end{tabular}

- $\quad$ Negative direction implies distance measured from front end of the trailer (for Y) and from the left side of the trailer (for X). 
Table 5.1 Strain gage locations (Continued)

\begin{tabular}{|c|c|c|c|c|c|c|}
\hline \multirow{2}{*}{ Gages } & \multicolumn{3}{|c|}{ Location (in) } & \multirow{2}{*}{ Placement } & \multirow{2}{*}{ Alignment } & \multirow{2}{*}{ Description } \\
\hline & $\mathbf{X}$ & $\mathbf{Y}$ & $\mathbf{Z}$ & & & \\
\hline Gage-15 & 49 & D-2 & -11 & On the second diaphragm & $\mathrm{X}$-direction & For strain on diaphragm for SIXCON-1(b) \\
\hline Gage-16 & 49 & D-1 & -11 & On the second diaphragm & $\mathrm{X}$-direction & For strain on diaphragm for helicopter lift \\
\hline Gage-17 & 6.25 & -9.25 & 4 & Top of bottom flange & $\mathrm{X}$-direction & Placed in cell under Helicopter-lift patch \\
\hline Gage-18 & 6.25 & -9.25 & 4 & Top of bottom flange & Y-direction & Placed in cell under Helicopter-lift patch \\
\hline Gage-19 & -6.25 & 9.25 & 4 & Top of bottom flange & Y-direction & Placed in cell under Helicopter-lift patch \\
\hline Gage-20 & 9 & & 2 & On the bolt & Z-direction & Mounted axially on the bolt for HL \\
\hline Gage-21 & 9 & & 4 & $\begin{array}{l}\text { Next to the reinforced steel patch } \\
\text { on top flange }\end{array}$ & Y-direction & Mounted on the deck for rail impact \\
\hline Gage-22 & 9 & & 4 & $\begin{array}{l}\text { Next to the reinforced steel patch } \\
\text { on top flange }\end{array}$ & Y-direction & Mounted on the deck for rail impact \\
\hline Gage-23 & 9 & & 4 & $\begin{array}{l}\text { Next to the reinforced steel patch } \\
\text { on top flange }\end{array}$ & Y-direction & Mounted on the deck for rail impact \\
\hline Gage-24 & 9 & & 4 & $\begin{array}{l}\text { Next to the reinforced steel patch } \\
\text { on top flange }\end{array}$ & Y-direction & Mounted on the deck for rail impact \\
\hline Gage-25 & 9 & & 4 & $\begin{array}{l}\text { Next to the reinforced steel patch } \\
\text { on top flange }\end{array}$ & Y-direction & Mounted on the deck for rail impact \\
\hline
\end{tabular}




\subsection{TESTING OF TRAILER}

\subsubsection{LOAD CASE 1(a) - UNIFORMLY DISTRIBUTED LOAD - 40,000 LBS.}

This load case simulates the loading of the deck with break bulk cargo and other loads which are uniformly distributed. In order to simulate this loading, six concrete blocks each weighing around 6,500 lbs were stacked one next to the other along the length of the deck as shown in Figure 5.5. This covered the entire surface of the deck and thus replicated the static uniformly distributed load of approximately 40,000 lbs.

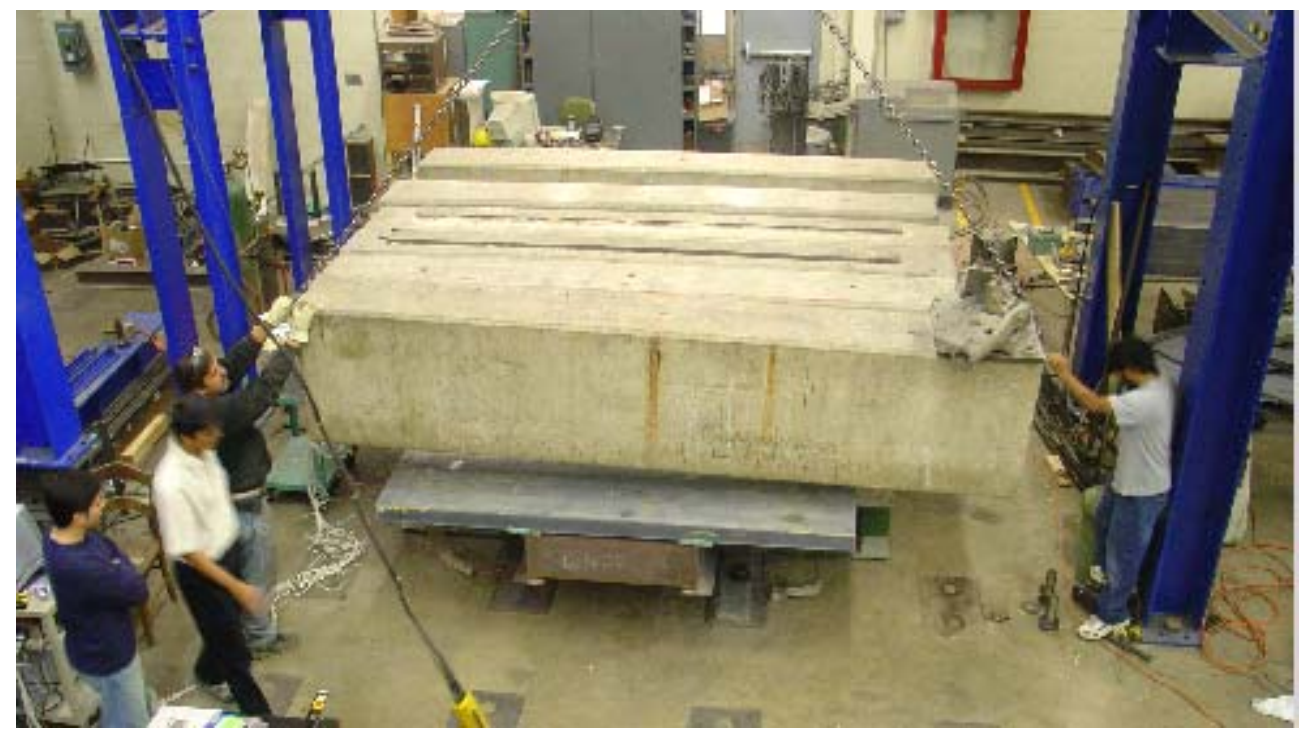

Figure 5-5 Load case 1(a) - 40 kips Uniformly Distributed Load 


\subsubsection{LOAD CASE 1(b) - SIXCON CONTAINER LOAD TEST - 40,000 LBS. DOWNWARD PATCH LOADING}

This load case represents the loading of the MTVR trailers with standard SIXCON cargo containers. The container corner castings were replicated by half-inch steel plates - 7 inch x 6 inch in dimension, resting on the same size elastomeric pads. This was followed by laying two distribution beams over the plates and then a cross beam over the two distribution beams (Figure5.4). The load of 40 kips was applied to the decking system through a hydraulic actuator as shown in Figure 5.6. As mentioned earlier, strain gages were mounted at critical locations over and under the deck surface, under the load patches - both in the strong and weak directions of the FRP deck, the stringers, and the cross-beams.

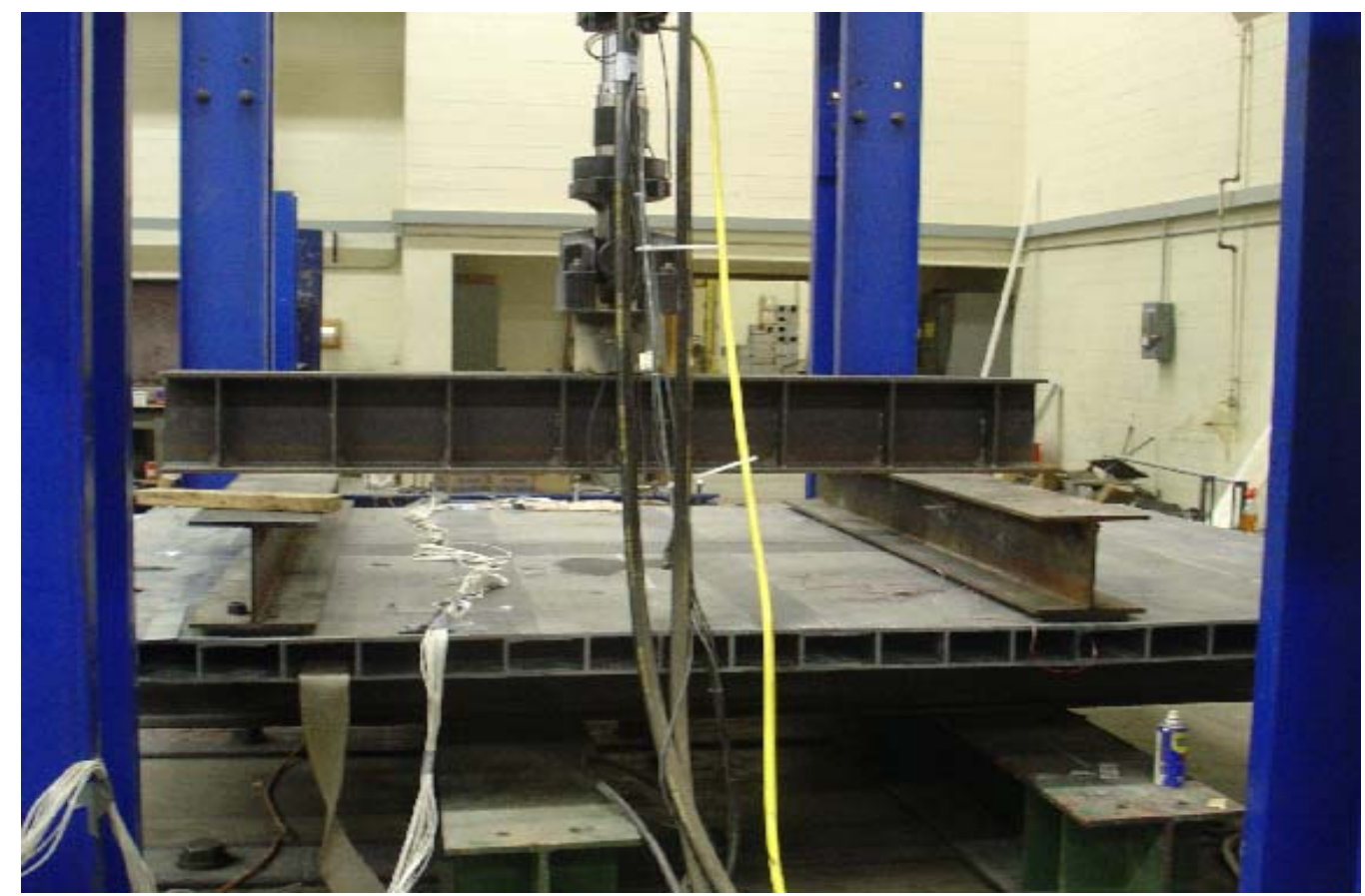

Figure 5-6 Load case 1(b) - SIXCON Load Test (40 kip-patch loading.) 


\subsubsection{LOAD CASE 2 - HELICOPTER LIFT (32,000 LBS. - UPWARD PATCH}

\section{LIFT)}

This load case simulates the lifting and transportation of the trailer with a helicopter, amounting to an upward load of about $32,000 \mathrm{lbs}$ on a trailer. The distribution beam set up for this load case was similar to the Sixcon loading condition except that the corner castings were replaced by a set of four, $3 / 4$-inch plates at the four corners of the deck. These plates were secured to the deck using bolts and a bottom plate. Each plate had a set of four bolts, thus holding the plate in place.

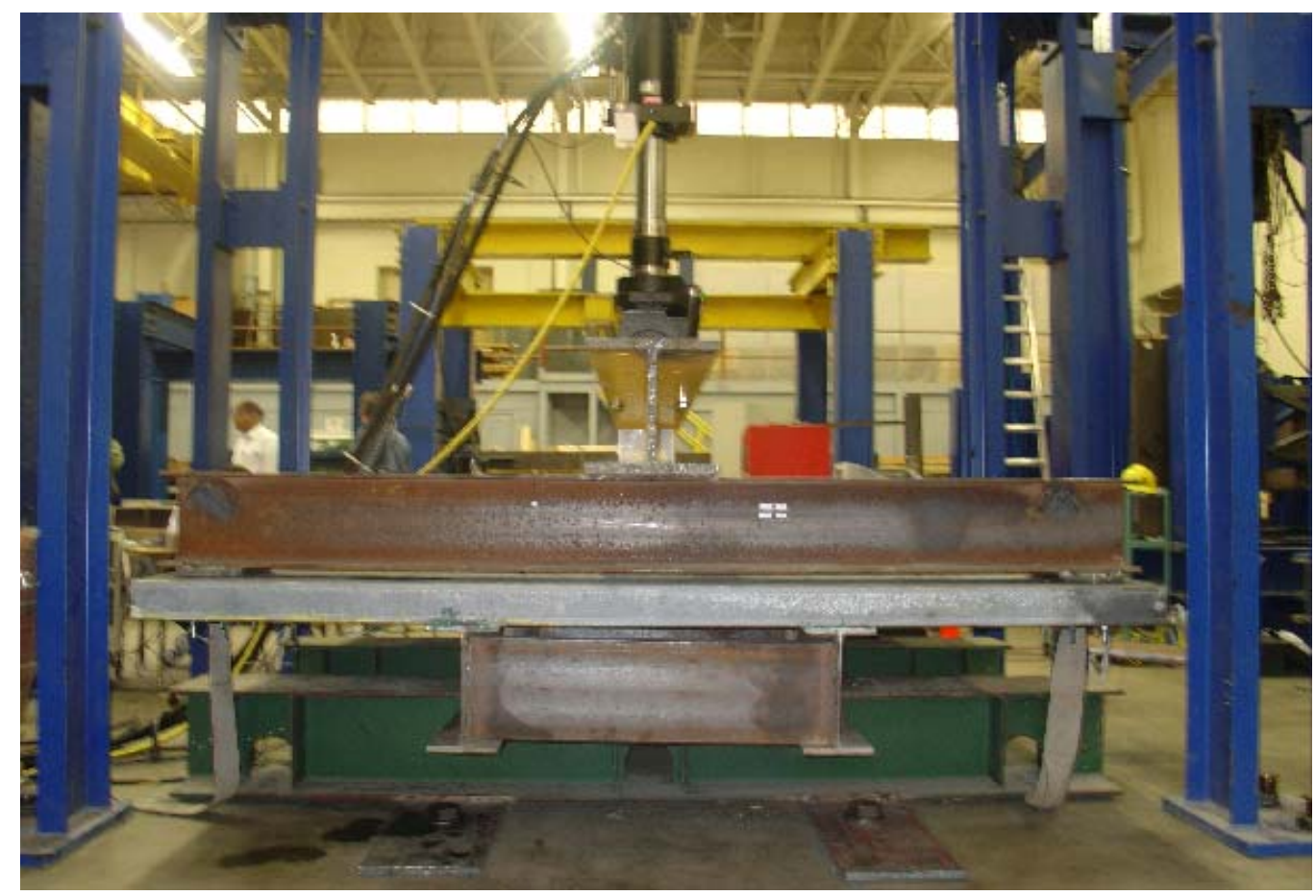

Figure 5-7 Load Case 2 - the Helicopter Lift Test 
The spacing of the distribution beams for this case was different than in the SIXCON loading case. The distribution beams were now welded to the corner plates and the cross beam was welded to the actuator as shown in Figure 5.7. In this set up, the actuator applied an upward load of 32,000 lbs. to replicate a helicopter lift.

\subsubsection{LOAD CASE 3 - RAIL IMPACT (50,000 LBS. - INPLANE SHEAR LOAD)}

The test set up of this load case involved bolting two I-beams to the top surface of the deck, along the deck length with a cross beam welded on top of the longitudinal Ibeams. The hydraulic ram was then mounted in a horizontal position in order to apply a horizontal force of about 50,000 $\mathrm{lbs}$ as shown in the Figure 5.8. The center of the hydraulic ram was located at a height of 24 inches from the top surface of the deck to simulate the CG of the payload, thereby creating a moment in addition to the shearing force. The areas around the bolt holes in the deck were reinforced with $1 / 4$ inch steel plates (4"x4") glued to both the top and bottom surfaces of the deck. 


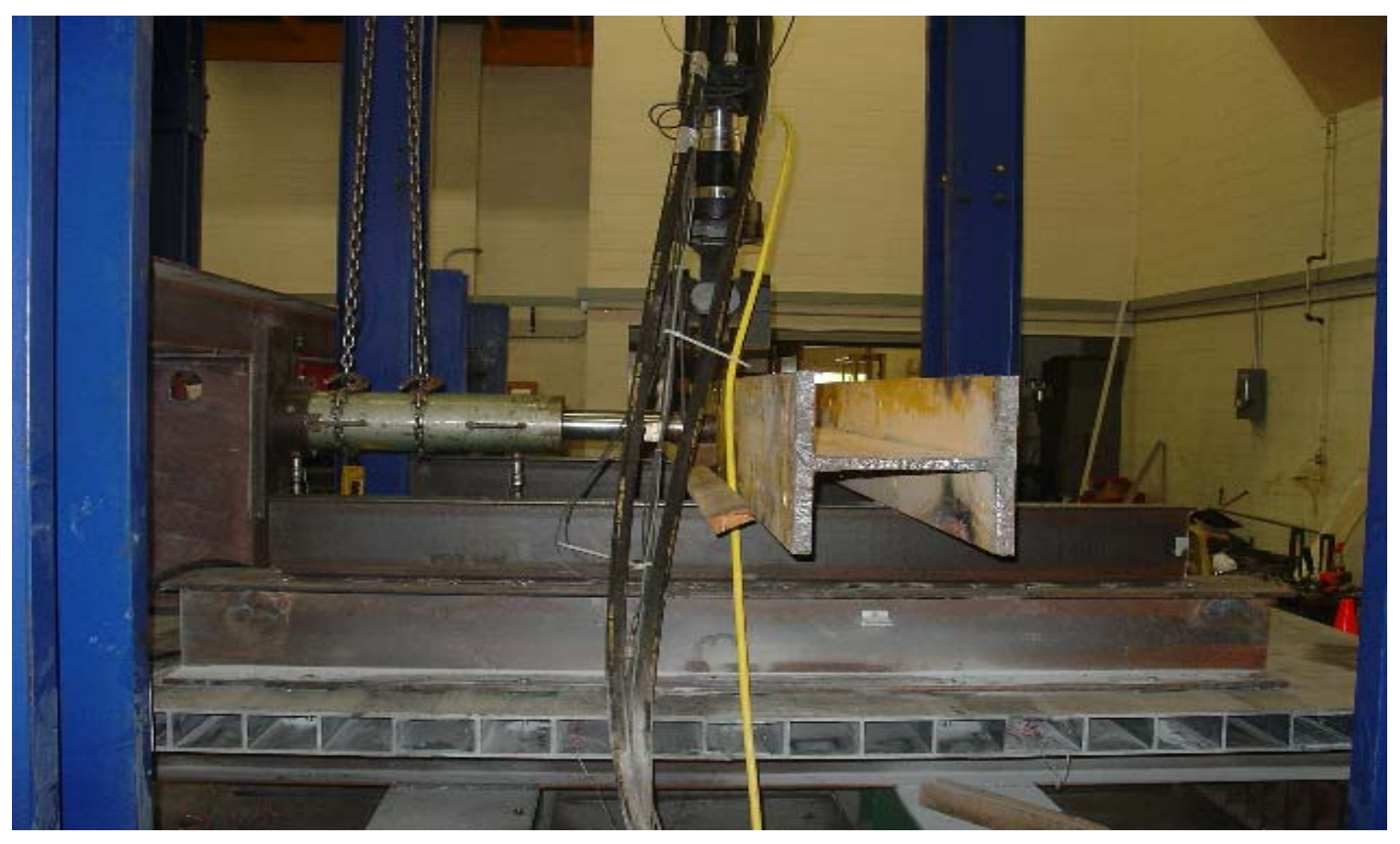

Figure 5-8 Load case 3 - Rail Impact Test. 


\section{CHAPTER 6 - RESULTS AND DISCUSSIONS}

\subsection{INTRODUCTION}

The results obtained from the static tests of the trailer deck are presented in this chapter. Also, the strains and deflections from the finite element analysis are compared to the experimental results. Various contour plots of stresses, strains, and deflections obtained from the finite element analysis are provided.

\subsection{LOAD CASE 1 (a) - UNIFORMLY DISTRIBUTED LOAD - 40,000 LBS.}

\subsubsection{DEFLECTION ANALYSIS}

A uniformly distributed load (UDL) of 40,000 lbs was applied to the FRP trailer FE Model (Chapter 5) and the results were compared to the experimental results obtained by loading the FRP deck with concrete blocks. Figure 6.1 shows the deflection profile of the FRP trailer under the UDL. A maximum deflection of approximately 0.0838 " was calculated by FEA at the side edge of the FRP deck in the negative z-direction (downwards) due to the applied load of 40,000 lbs. 


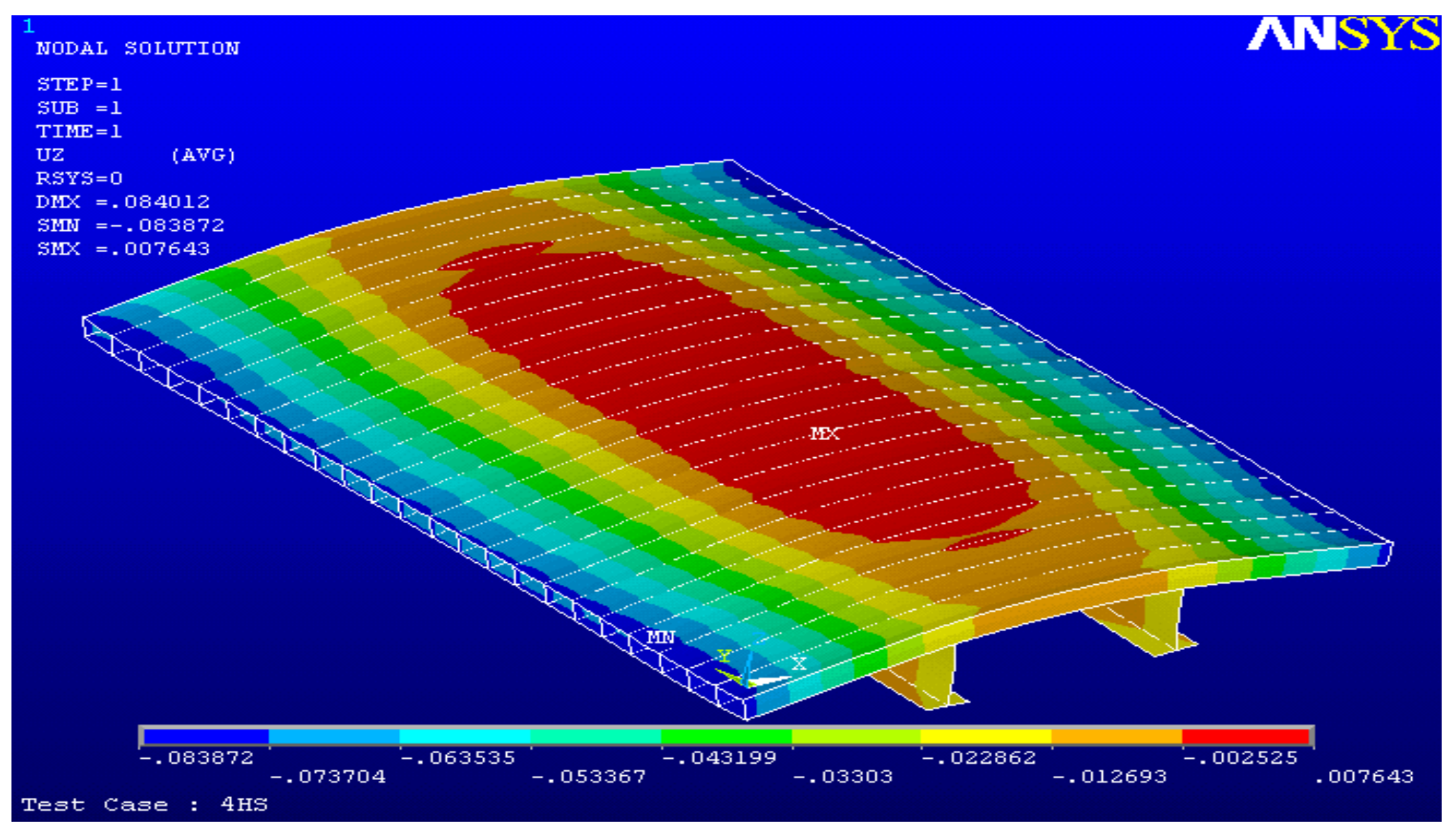

Figure 6-1 Deflection profile of the deck due to UDL of 40,000lbs.

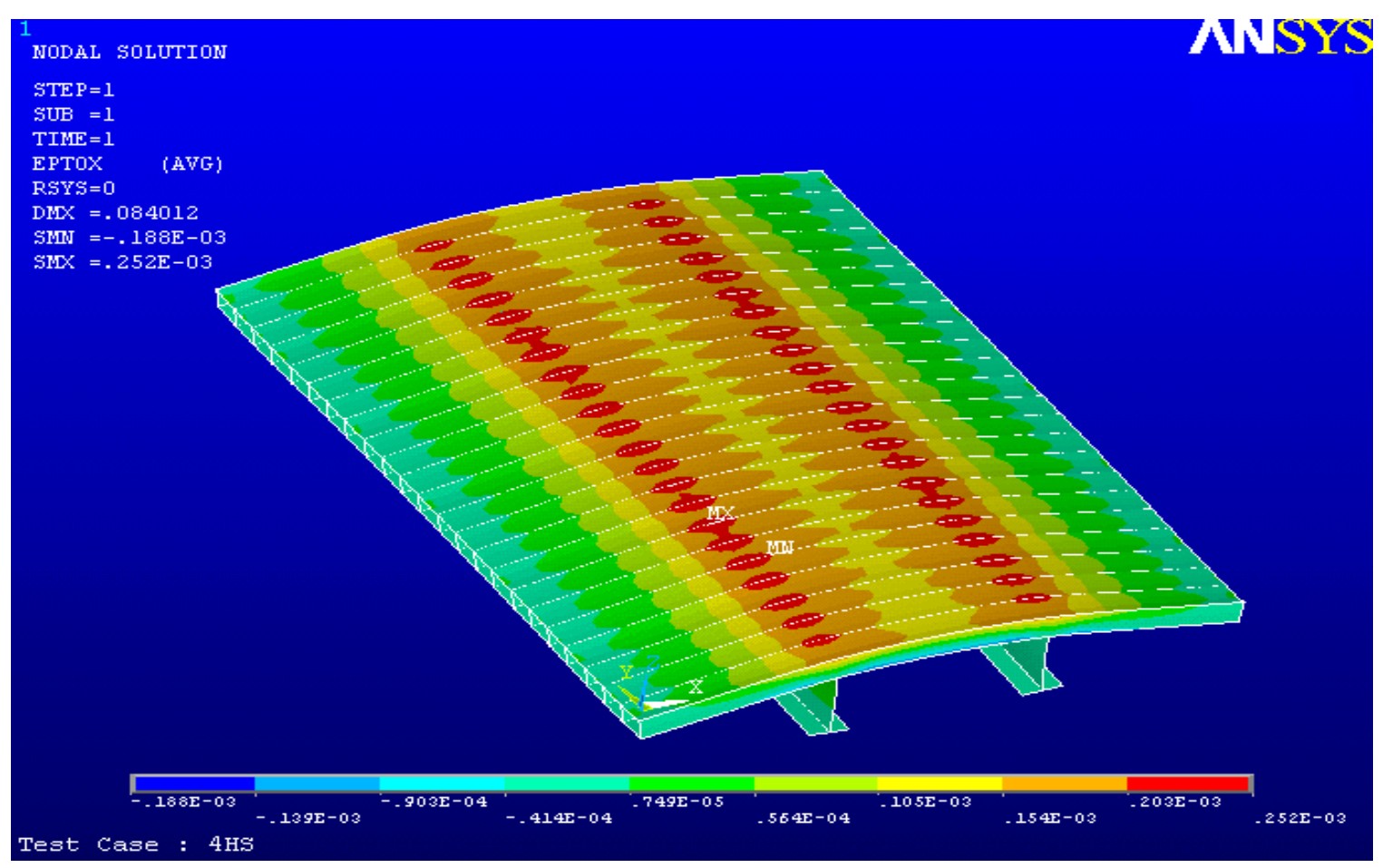

Figure 6-2 Strains in the $z$ direction due to UDL 
Next, stresses in the x-direction (cell direction) from FE analysis were compared with that of experimental data. It should be noted that only strains can be measured experimentally using strain gages; the measured strains were converted to stresses for comparison. The maximum FE strain values observed were on the top surface of the deck over the steel stringers, approximately 250 micro-strains, corresponding to a stress value of approximately $1 \mathrm{ksi}$. The ultimate stress of the deck in the cell direction is approximately $30 \mathrm{ksi}$. Based on the ultimate stress level, the FRP trailer deck can carry significantly more load than the applied 40 kips. Based on the uniformly distributed load test data, the FRP deck cross-section can be optimized to a lower self-weight, thereby decreasing the cost of manufacturing the deck.

\subsection{LOAD CASE 1(b) - SIXCON CONTAINER LOAD TEST (40,000 LBS. - DOWNWARD PATCH LOADING)}

\subsubsection{DEFLECTION ANALYSIS}

Load Case 1(b), which simulates the loading of a SIXCON container, is more severe than the uniformly distributed load since the entire load of the container is transferred to the four corner castings. Figure 6.3 shows the contour plot of the deflection due to Sixcon container loading. The plot shows large deflections at the location of the corner castings. The experimental deflection at location A of 0.281 inches compares well with the deflection value obtained using FE analysis (see Figure 6.4). 


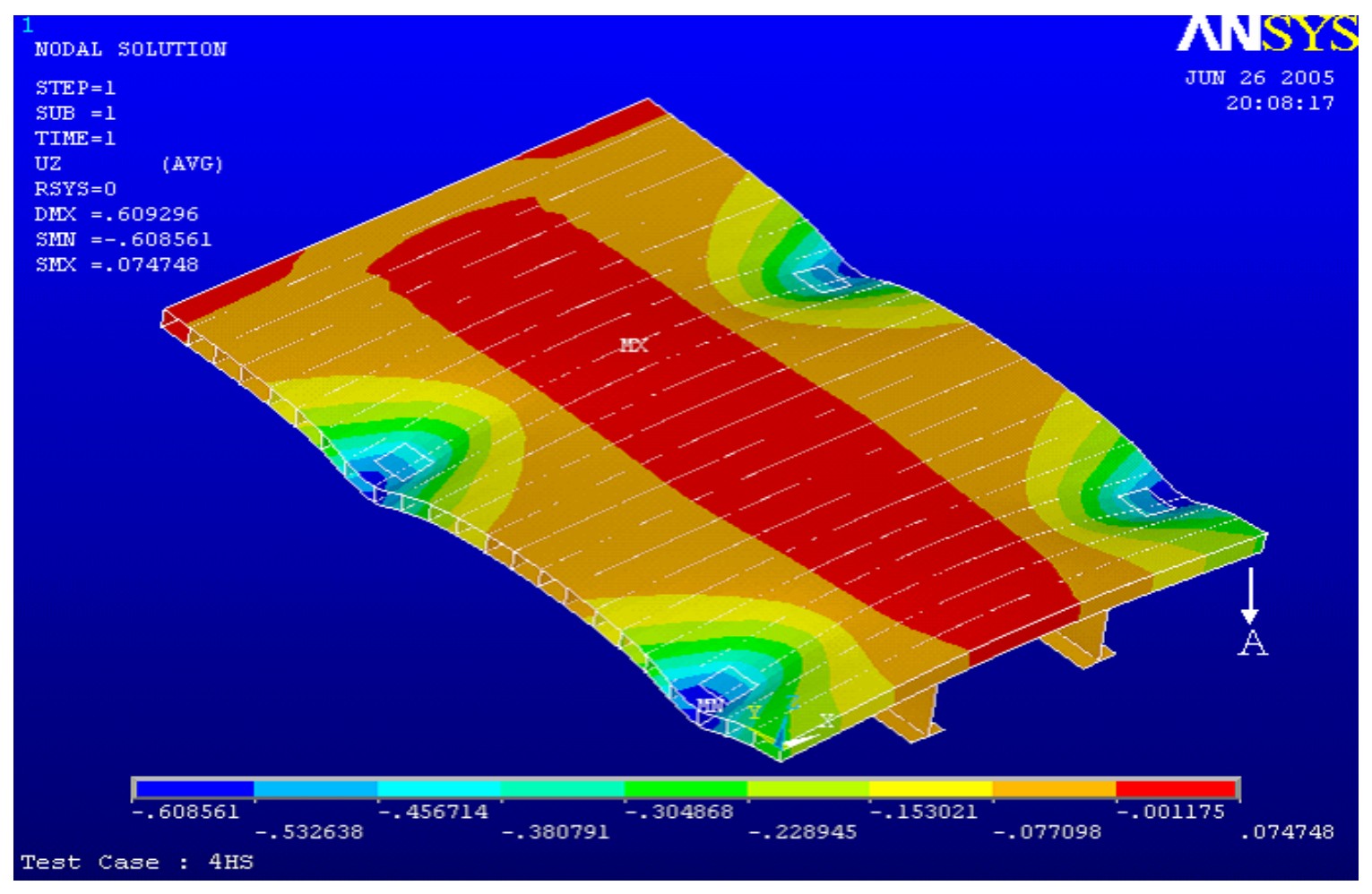

Figure 6-3 Deflection profile of the deck in z-direction due to SIXCON patch loading

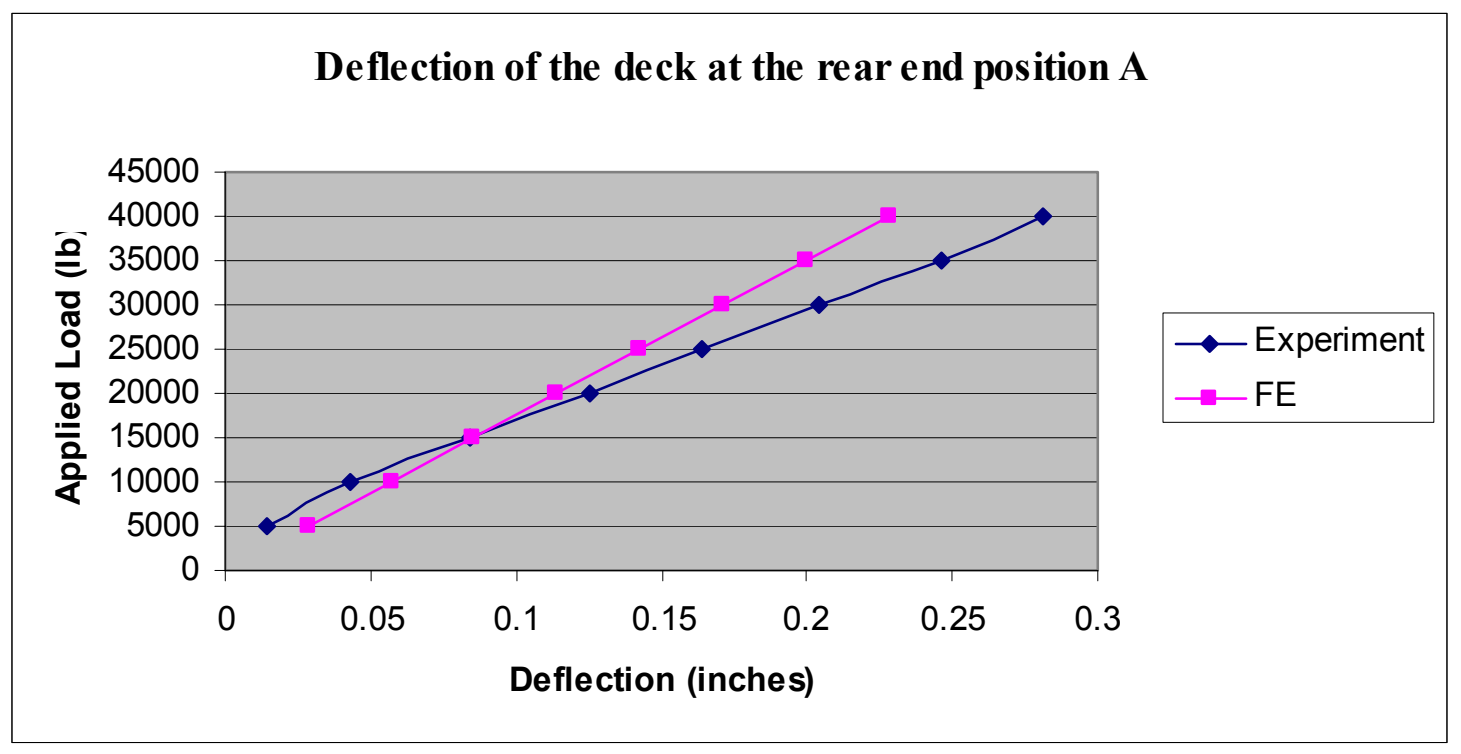

Figure 6-4 Comparison of Experimental and FE deflections at location A 


\subsubsection{STRESSES UNDER CORNER CASTING LOCATIONS}

The critical stress locations on the deck for the SIXCON container loading are under the four corner castings of the SIXCON container. Several strain gages were mounted under the corner casting locations in the $\mathrm{X}$ and $\mathrm{Y}$ directions. Gages were also mounted on the top surface of the deck, at the center of the two stringers, and in line with the corner end casting locations. The stresses computed from experimentally obtained strains were compared to the FE results and are shown in Figures 6.7 and 6.8.

As seen in the Figure 6.7 there is a significant difference between the experimental and the FE stresses (strains) in the Y-direction. In the FE model the load distribution between the four patches is equal (see Figure 6.5). However, based on the readings from the strain gages 10 and 12 (see Table 6.1), which are located in the $\mathrm{Y}$ direction under patches 2 and 1 respectively; it is obvious that the load distribution on these patches is not uniform. Similar behavior was found for the strains in the X-direction obtained using gages 11 and 13 mounted under patches 1 and 3 respectively. The unequal distribution of load could be one of the reasons for the discrepancy between the experimental and FE results. In addition, it can be seen from Figure 6.7 that the experimental load - stress curve has a bilinear characteristic. This is due to the fact that every system (specimen and setup) undergoes some amount of adjustment structurally until a certain applied load. Typically only the data after the initial adjustment is considered for analysis. The experimental data corrected for this initial structural adjustment would be closer to the FE. 
Table 6.1 Measured experimental strains

\begin{tabular}{|l|c|c|c|c|c|c|c|c|c|}
\hline $\begin{array}{c}\text { Applied } \\
\text { Loads (lb) }\end{array}$ & 0 & 5000 & 10000 & 15000 & 20000 & 25000 & 30000 & 35000 & 40000 \\
\hline Gage 10 $\mu \varepsilon$ & 0 & 450 & 893 & 1268 & 1586 & 1874 & 2149 & 2421 & 2608 \\
\hline Gage 11 $\mu \varepsilon$ & 0 & 88 & 157 & 213 & 269 & 327 & 377 & 432 & 465 \\
\hline Gage 12 $\mu \varepsilon$ & 0 & 307 & 549 & 810 & 1118 & 1435 & 1738 & 2052 & 2255 \\
\hline Gage 13 $\mu \varepsilon$ & 0 & 231 & 433 & 613 & 796 & 970 & 1117 & 1244 & 1317 \\
\hline
\end{tabular}

The maximum experimental deck stresses near the corner-casting location in the $\mathrm{X}$ and $\mathrm{Y}$ directions of the deck are approximately 1800 psi and 3600 psi respectively. The $\mathrm{X}$ and $\mathrm{Y}$ stresses are calculated by multiplying the experimentally measured strain values to the corresponding Young's modulus values.

$\left(\sigma_{x}=E_{x} * \varepsilon_{x}=3.8 * 10^{6} p s i * 465 * 10^{-6}\right.$ in $/$ in $) \approx 1800$ psi.

These stresses include the effects of global bending due to overhang and local bending and compressive stresses due to the concentrated load. The allowable local flange bending stress for Prodeck 4 is 6 ksi $(4300 \mu \varepsilon)$ [8]. Although, there was no failure in the FRP deck during the test simulation, the FRP deck should be reinforced with carbon/Eglass plates near the corner casting locations. The reinforcement of high stress locations will ensure adequate factor of safety and will reduce the risk of failure due to local bending of the flange at these locations, in addition to the possibility of punching shear. 


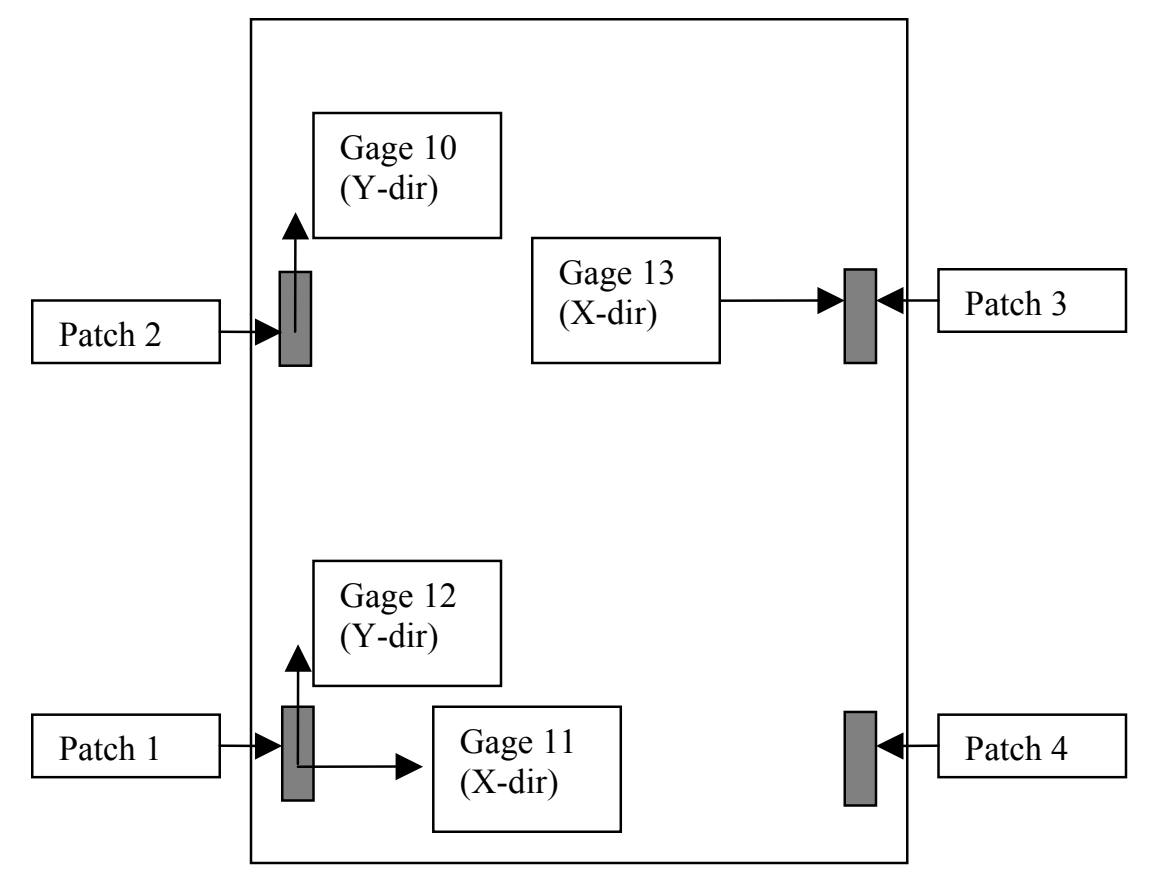

Figure 6-5 SIXCON container loading patches

Stresses at the mid-span of the stringers for the SIXCON load case were negligible. Based on this load condition, the size of stringer could be optimized to reduce the overall weight of the trailer.

Woraphot, 2005 [8] provided a description of punching shear as: "Punching shear is induced by loads acting perpendicular to the FRP deck (i.e., horizontal plane) leading to punching stresses in the top flange of FRP decking around the perimeter of the loading area. Punching shear is one of the vertical load induced out-of-plane shears, punching through the top flange of a composite deck. Punching forces induce failure of the FRP deck by shearing through the top flange thickness. In addition, the size of loading area (patch or contact area), cross-section and contact shape of the applied load with top flange affect punching shear resistance." 


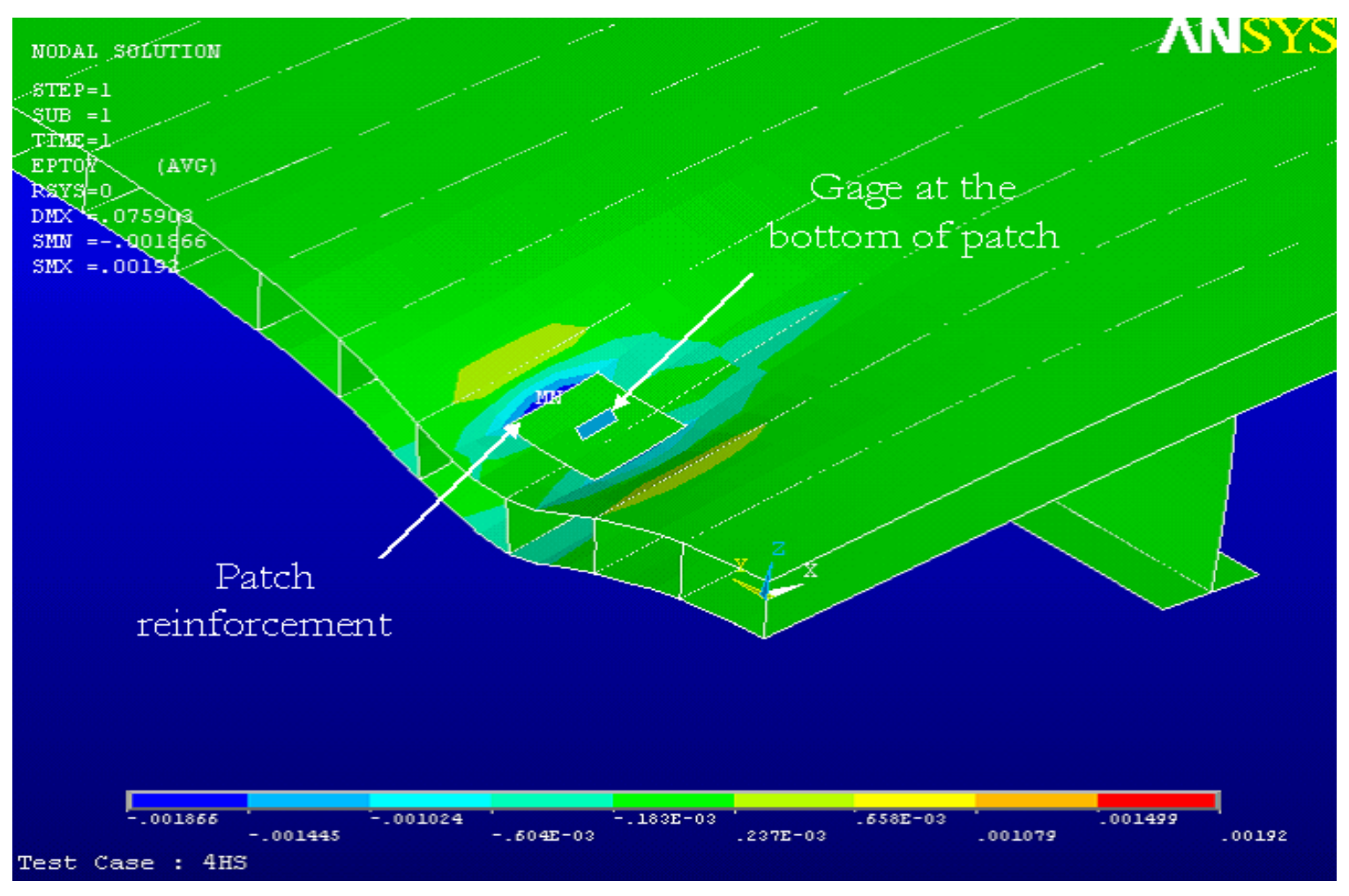

Figure 6-6 Patch reinforcement and strain gage location

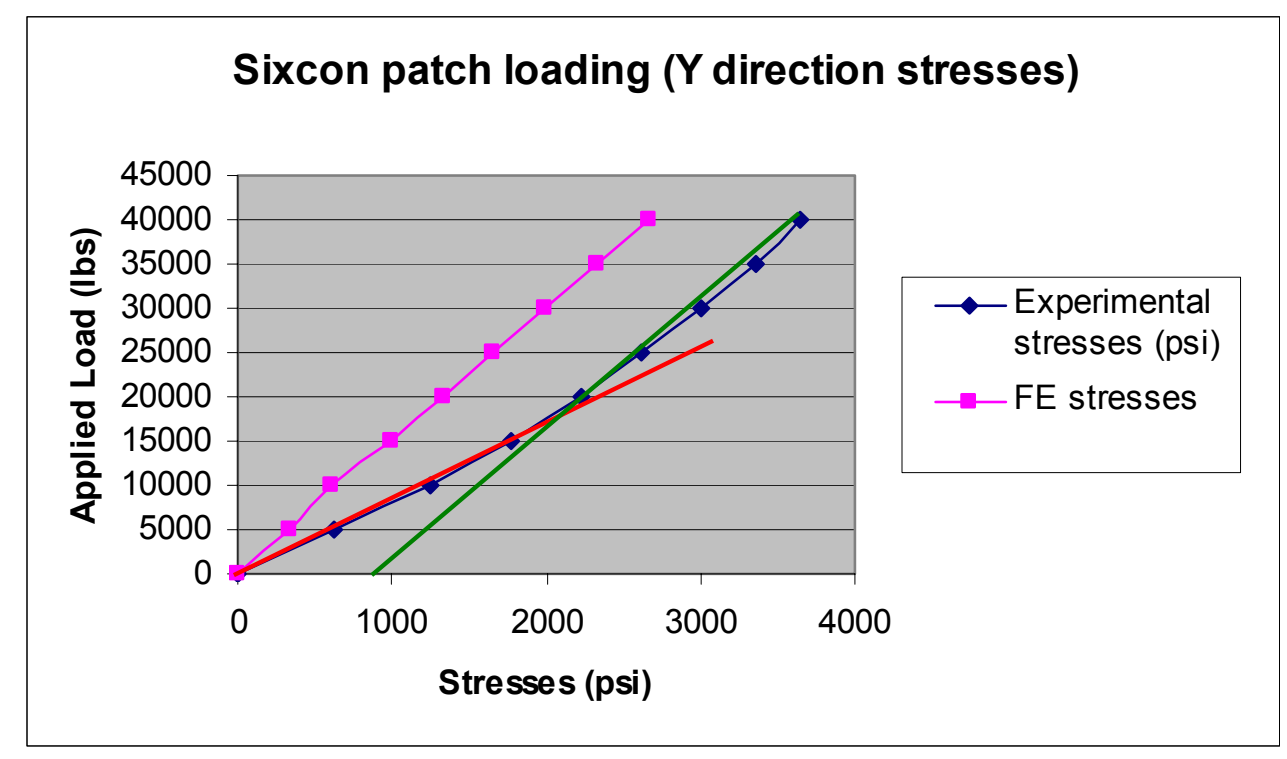

Figure 6-7 Stress in Y-direction under the SIXCON patch 


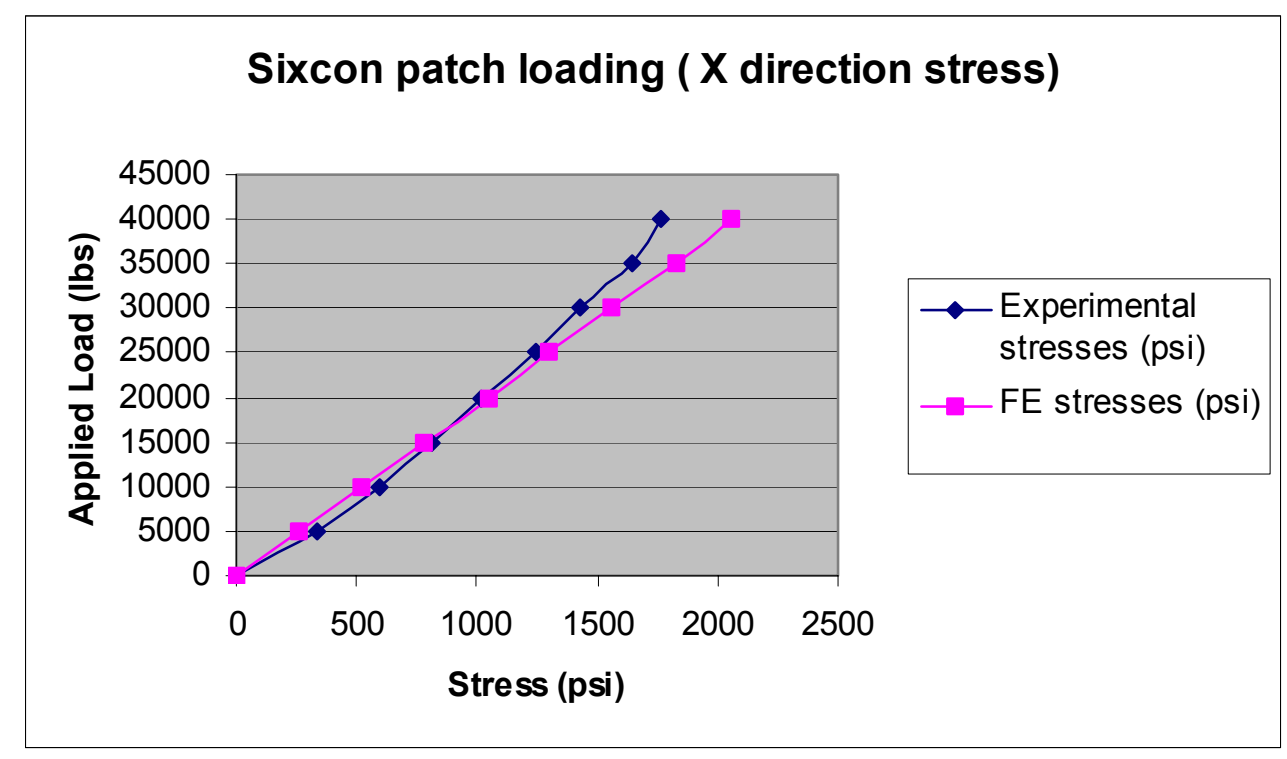

Figure 6-8 Stress in X-direction under the SIXCON patch

Local deflection is the displacement of the top flange between two contiguous webs stiffening the top flange due to application of load on that particular flange. The 6 ksi allowable stress value for local bending mentioned earlier is derived from the local flange deflection limit of $0.06 "$ [8].

\subsection{LOAD CASE 2 - HELICOPTER LIFT (32,000 LBS. - UPWARD PATCH LOADING)}

This load case is designed to simulate the loads applied on the FRP trailer during transportation using a helicopter. The dynamic loads were converted to equivalent static loads. Figure 6.5 shows the deflection profile in the $\mathrm{Z}$ direction for the helicopter lift load case. 


\subsubsection{DEFLECTION ANALYSIS}

By FEA, a maximum deflection of 0.586 " was obtained at the four corners of the FRP deck. The experimental deflection at the same location was found to be 0.5686 ".

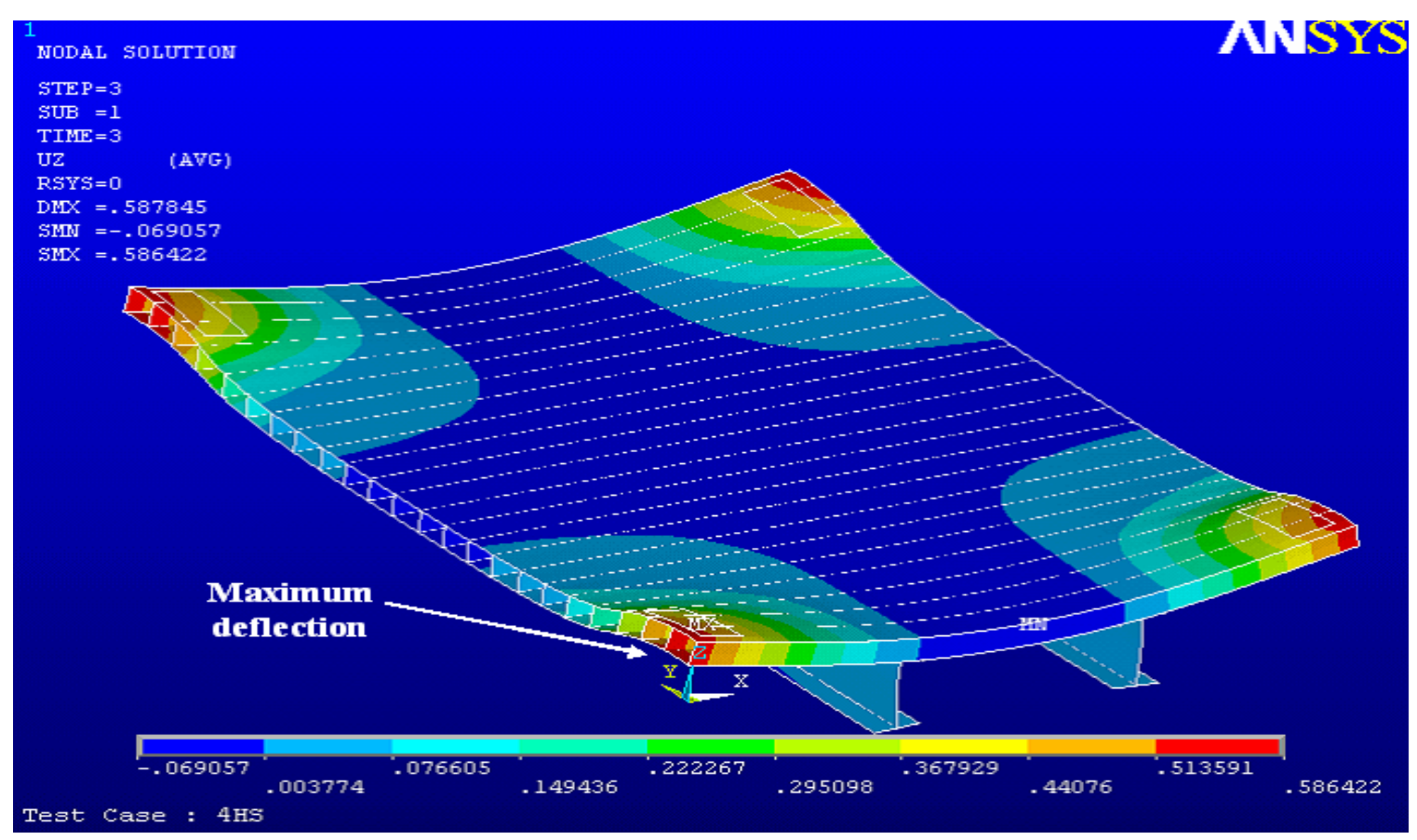

Figure 6-9 Deflection profile in the Z-direction due to Helicopter lift loading.

\subsubsection{STRESS ANALYSIS}

Strain gages were mounted on the top and bottom of the deck at the center of stringers and the center line of the plates where the trailer would be lifted using the helicopter (see Figure 5.7). Strain gages were also mounted under the steel plates. Details of instrumentation can be found in Chapter 5. The maximum center line stresses due to a helicopter lift obtained using FE model was 5.8 ksi whereas the stresses computed from experimentally measured strains were only about $3.5 \mathrm{ksi}$. The difference in the stress 
levels between the FE and the experimental values can be attributed to the fact that the cross members were not included in the FE model. The cross members carry a part of the applied helicopter lift load and the stress in cross members due to helicopter lift loading was found to be $360 \mathrm{psi}$, which is significantly less than the failure stress of steel. Based on this load condition, the size of cross members can be reduced to decrease the overall weight of FRP Trailer.

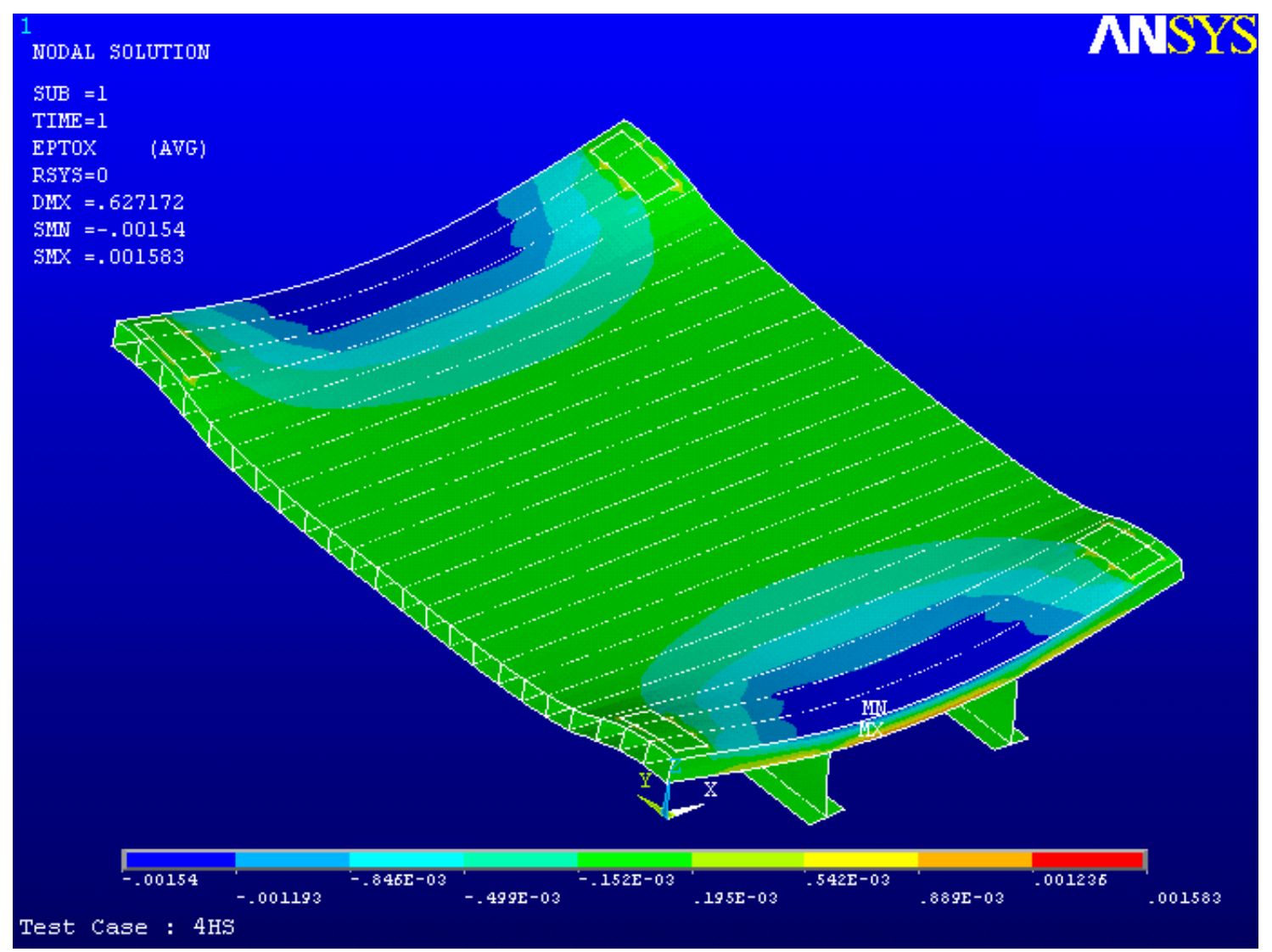

Figure 6-10 Strains in the $\mathrm{X}$-direction showing compression on top flange 


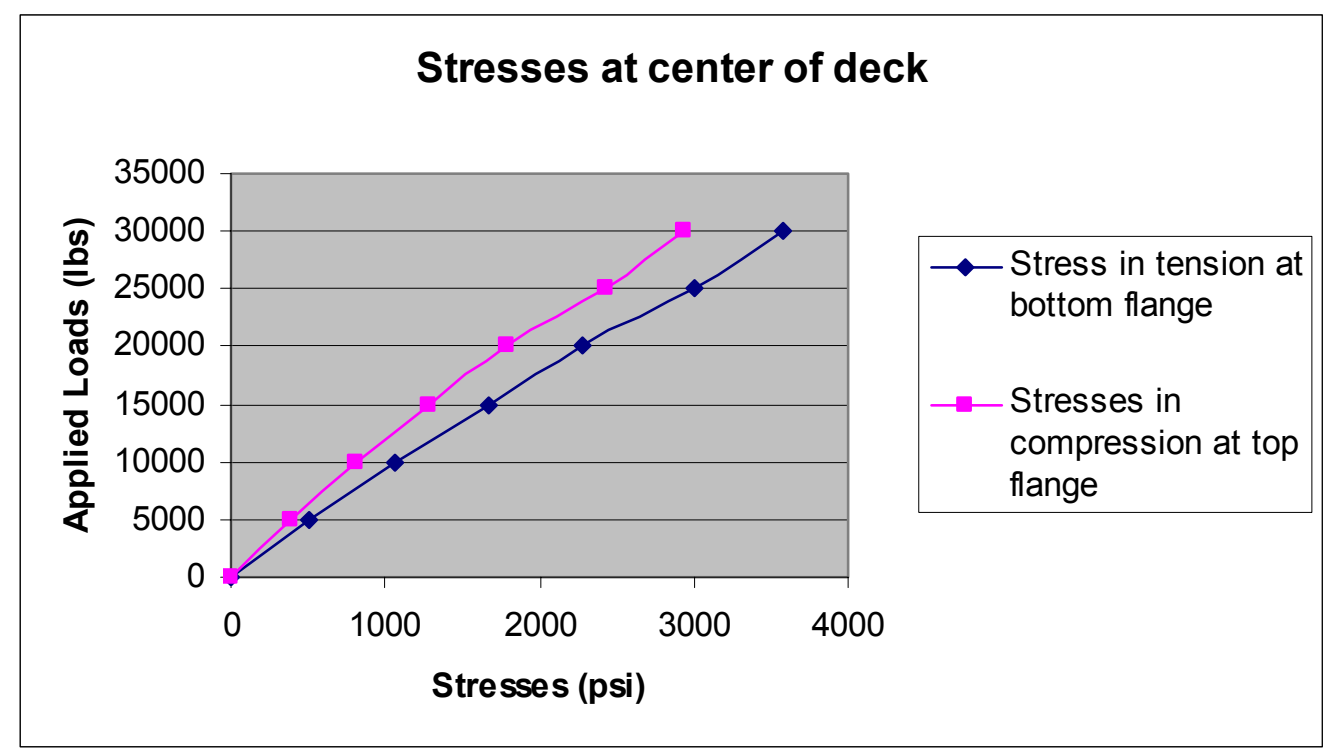

Figure 6-11 Plot of centerline stresses in the deck for Helicopter Lift case.

\subsection{LOAD CASE 3 - RAIL IMPACT (50,000 LBS. - INPLANE SHEAR LOADING)}

This load case was designed to simulate the effect of a sudden deceleration/acceleration (here, due to rail impact) on the loaded trailer. The details of simulation of this load case in FE modeling are provided in Chapter 5, in addition to the details of test setup. 


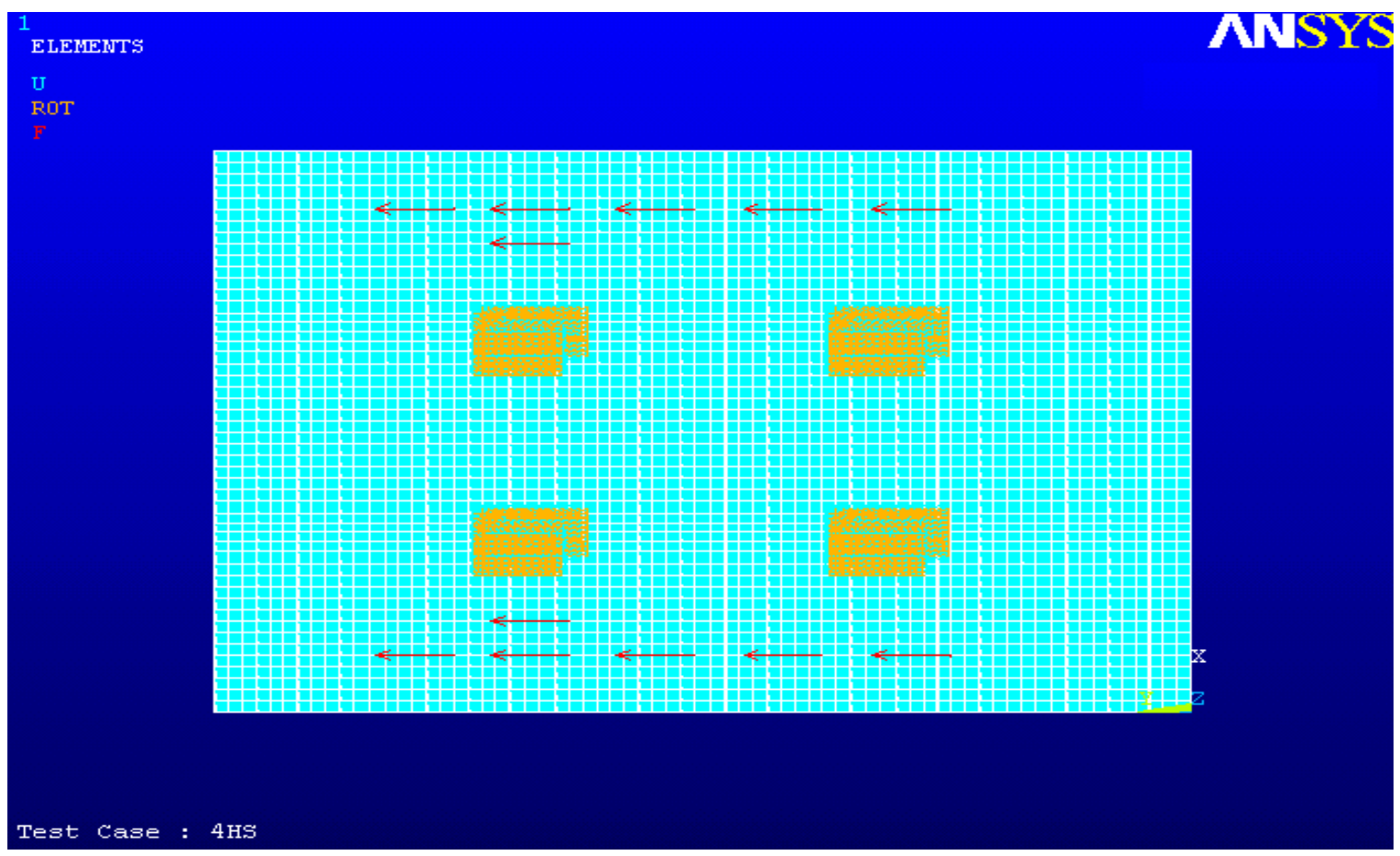

Figure 6-12 Loading pattern used in FE for the rail impact test

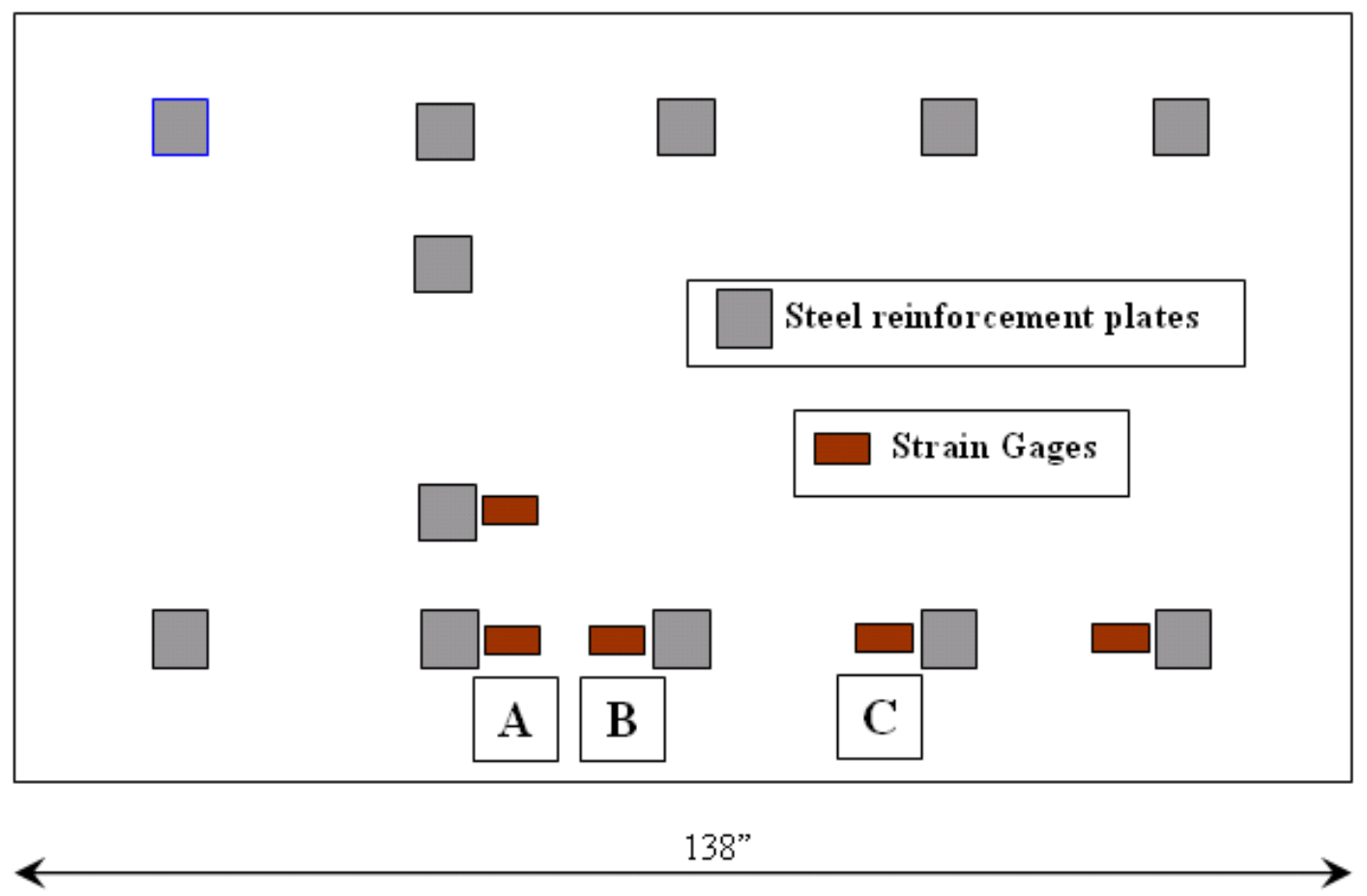

Figure 6-13 Strain gage locations of the rail impact test 
Several strain gages were mounted near the location where loads are applied to the deck (see Figure 6.13). A maximum stress of 450 psi was obtained at location A, and a maximum stress of 785 psi was obtained at location C. These stresses are well within the ultimate bearing stress of the FRP deck, which is about 16.7 ksi (evaluated based on a single test on a Prodeck 4 component).

The loading pattern used in FE for this load case is complex and could not be accurately matched with the experimental setup. Hence there is a significant discrepancy between the results. However, the test results indicate the FRP trailer design can withstand a rail impact while carrying a full 10kip payload.

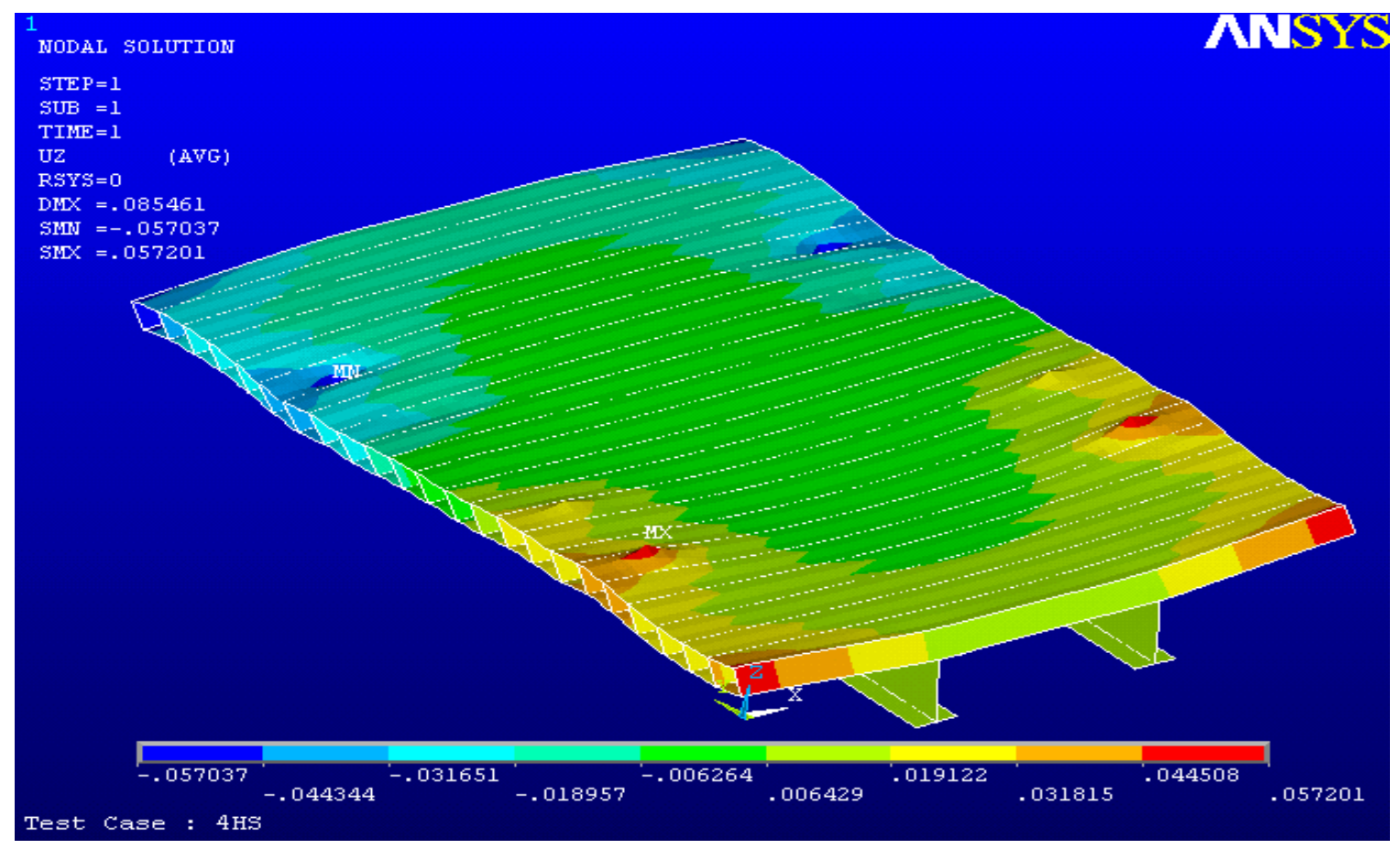

Figure 6-14 The $Z$ component of displacement due to rail impact 


\section{CHAPTER 7 -FRP COMPOSITE REPAIR TECHNIQUES}

\subsection{INTRODUCTION}

Fielded trailer decking systems are susceptible to damage due to various operational and battlefield conditions. One key factor for FRP deck trailers gaining acceptability in the U.S. Military is the ease of repairing an FRP deck in case of damage. As mentioned in Chapter 6, punching shear is one of the potential failure modes for FRP components. This type of failure mode was also identified in Prodeck 8 FRP composite deck [10]. An overview of the various stages of FRP composite repair will be provided in this Chapter, using the rehabilitation of Prodeck 8 after punching shear failure as an example. Also, the aerospace industry has been using FRP composites for several decades and an extensive knowledge base on repair of composites in aircraft structures is available to be readily adopted for FRP trailers. A few useful references on FRP composite repairs are listed.

\subsection{IDENTIFICATION AND REPAIR OF DAMAGE}

Prodeck 8 is a precursor to Prodeck 4 which was used as part of this research. Prodeck 8 is an 8 " deep, deck module made using E-glass fabrics and Polyester and Vinylester resins (Figure 7.1) through the pultrusion process. Prodeck 8 was developed at Constructed Facilities Center and is manufactured by Bedford Reinforced Plastics, Inc. 


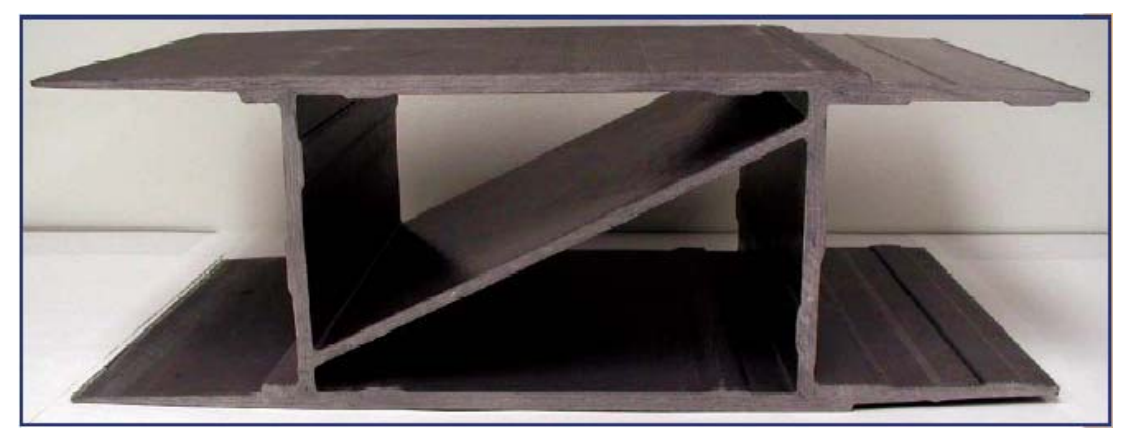

Figure 7-1 Prodeck 8 Component [9]

Static tests for determining the ultimate load and failure modes of four Prodeck 8 modules revealed that two modules failed due to punching shear [10]. One of those modules was repaired and retested to evaluate the strength regained after repair. The following are the various steps that were involved in repair of the deck [10]:

Step 1 - Identification of damage: Damage in composites can often be invisible, i.e., internal delaminations of laminates inside a composite. Several nondestructive techniques such as Visual Inspection, Tap Test, Infrared Thermography [11], X-rays, etc., are available to identify and quantify the extent of damage. Figure 7.2 shows an Infrared Thermography image of FRP deck with debonds, the bright spots indicating the debond locations. In the case of Prodeck 8, the punching shear failure was obvious and therefore there was no need for any nondestructive evaluation. 


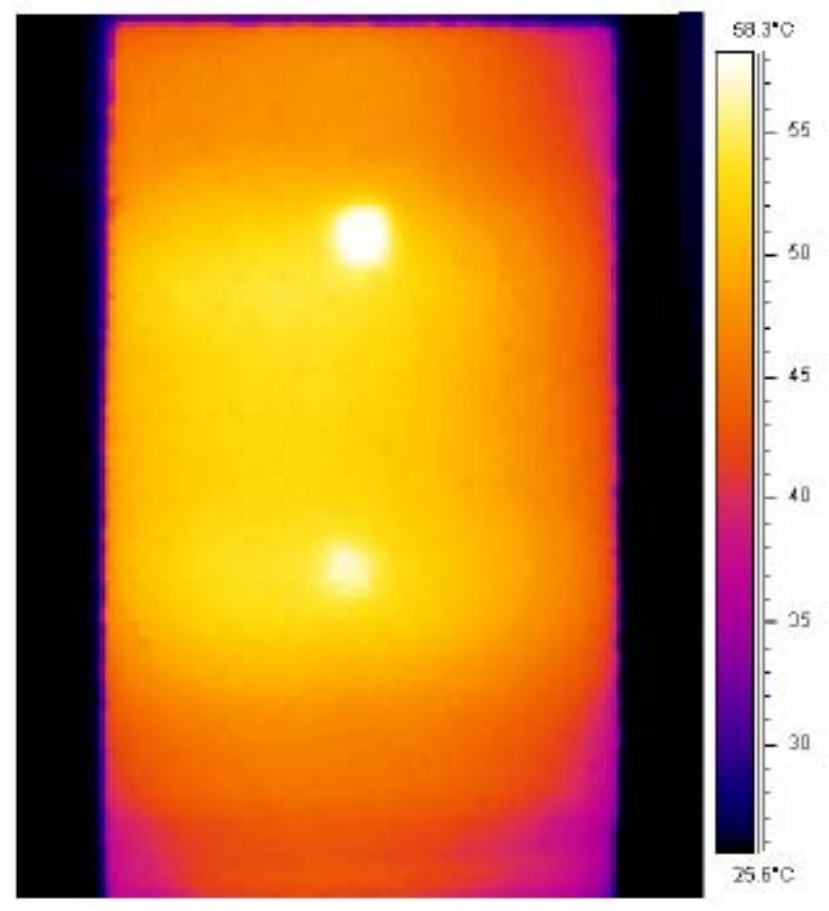

Figure 7-2 Infrared image of FRP Deck with debonds [11]

Step 2 - Removal of damaged material: Once area and extent of damage is identified, some part of the damaged material may have to be removed before repair. In the case of Prodeck 8 , the exterior flanges of the deck module were delaminated and had to be removed (Figure 7.3).

Step 3 - Surface preparation of damaged area: The damage area must be cleaned before repair to remove contaminants such as oil, dust and debris. For repair of Prodeck 8 the area to be repaired was cleaned with a 40-grit sand paper and the excess dust was removed. The sanded area was then cleaned with acetone and left undisturbed for twenty minutes before vacuuming the residue. 


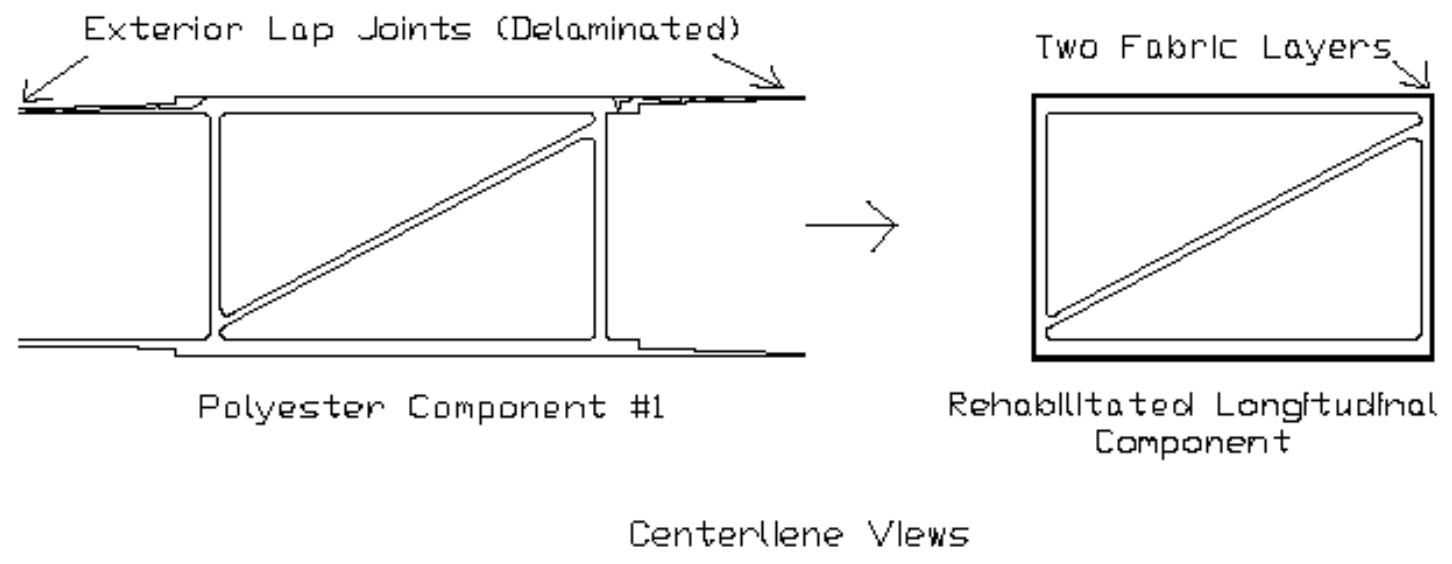

Figure 7-3 Cross section of damaged and repaired component [10]

Step 4 - Bonding or bolting of new composite plates/fabrics: Depending upon the size and location of damage, the damaged area can be reinforced by either bolting or bonding prefabricated composite plates or by bonding wet fabrics. MBRACE primer (parts a and b) was applied to the cleaned area of Prodeck 8 module and cured for 24 hours. Next, two layers of $26 \mathrm{oz} / \mathrm{yd}^{2}$ glass fabrics were wet-out in resin and wrapped around Prodeck 8 component and fabrics were tightly pressed to remove excess resin and air voids [10]. The module was allowed to cure for 7 days. While the long time for curing may be acceptable for depot level repairs, faster curing resin systems can be used for in-situ repairs.

Step 5 - Quality control of repair: Visual inspection and/or the NDT techniques mentioned in Step 1 can be used to determine the quality of repair. 
The repaired Prodeck 8 module was tested and results showed that the module has $75 \%$ of the load carrying capacity of the original Prodeck 8 module.

\subsection{LITERATURE OF COMPOSITE REPAIR}

Several sources provide details on repair of composite structures. NetComposites [12] provides an excellent summary on various composites repair methods and an overview of basic repair procedure. Several books and hundreds of technical papers/articles are also available on repair of composites. "Care and Repair of Advanced Composites," by Keith Armstrong and Rick Barrett, (Published by Society of Automotive Engineers) provides a comprehensive presentation of damage and repair assessment, repair method selection, and various composite repair techniques. The following is a partial list of books with information on composite repair:

1. Advances in the Bonded Composite Repair of Metallic Aircraft Structure, Edited by A.A. Baker, L.R.F. Rose, and R. Jones, Published by Elsevier Sciences Ltd.

2. The Fiberglass Boat Repair Manual, Allan H. Vaitses, Published by International Marine/Ragged Mountain Press.

3. SailBoat Hull and Deck Repair, Don Casey, International Marine/Ragged Mountain Press. 


\section{CHAPTER 8 - COST ANALYSIS}

\subsection{INTRODUCTION}

The use of FRP composite decking as a trailer bed has been successfully demonstrated through extensive finite element analysis and laboratory testing. The FRP trailer design has satisfied the U.S. Marine Corps operation and transportation load requirements seen to be critical to the preliminary design of an MTVR Trailer. Apart from the structural performance of the FRP trailer, cost issues are also a predominant factor in gaining the acceptance of the end-user i.e., the U.S. Military.

As described in Chapter 1, FRP composites offer significant advantages in terms of increased service life and lower maintenance costs. Reasonable cost comparison between steel/aluminum cargo trailers and FRP trailer should consider the entire life cycle costs including initial costs and maintenance costs.

\subsection{LIFE CYCLE COSTS}

Life cycle costs include the initial costs, maintenance, inspections, and repair costs over the service life of the MTVR-Trailer. Life Cycling Costing (LCC) is defined as "The total cost of the system or the product under study over its complete life cycle or the duration of the period of study, which ever is shorter" [13]. The study period of LCC is 
the time period over which the investment is evaluated [14]. In other words the trailer might have a functional life of say 15 years, but the U.S. military might only consider using these trailers for say 10 years. In that case, ten years should be taken as the time period for evaluating the life cycle costs. The different cost components in LCC are briefly discussed below.

\subsubsection{INITIAL COSTS}

Initial costs for FRP trailers can be broadly divided into two components: 1) initial cost of FRP deck manufacturing and 2) fabrication of the trailer using the manufactured FRP deck. The initial FRP cost reductions were achieved by optimizing the structural response of FRP decks thereby reducing the FRP component weight and costs. Therefore 4" deep FRP components can be bought at \$30-35 per square foot which compares favorably against the concrete deck cost of $\$ 40-45$ per square foot. Based on the extensive FE and experimental results of FRP trailer, it is clear that the FRP deck can be further optimized in terms of both cost and weight. With prior experience of CFC in optimizing the FRP bridge decks we can state that the deck weight can be reduced by about $1 / 3$ to around $600-700 \mathrm{lbs}$, which will reduce the deck cost to around $\$ 20-25$ per square foot. Transportation costs from the FRP deck manufacturing plant to the trailer fabrication facility is another component of the initial costs to be considered in life cycle costing. 
While comparison of steel/aluminum cargo trailers with the current FRP trailer on the basis of initial costs generally favors the conventional trailers, FRP trailers have certain initial cost advantages such as fabrication and labor costs. Optimizing the FRP decks would make the initial cost comparison of FRP deck more favorable with respect to the steel deck e.g., $600 \mathrm{lb}$ FRP deck with a $\$ 20-25$ per square foot manufacturing cost $\$ 1800-\$ 2300$ compares favorably to $1300 \mathrm{lb}$ fabricated and galvanized steel deck with a $\$ 1.50 / \mathrm{lb}$ manufacturing cost $=\$ 1950$. Fabrication costs for FRP decks are small compared to steel/aluminum decks, since the FRP deck can be mass-produced through the pultrusion process, even up to 8 feet widths. Labor costs for fabrication of FRP decks will be lower than steel/aluminum deck because of the lower skill level labor required. FRP trailers will have a lower weight compared to steel/aluminum trailers, which will reduce the transportation costs of fully built trailers to the end user.

\subsubsection{MAINTENANCE, INSPECTION, AND REPAIR COSTS}

FRP decks have several advantages over conventional materials in terms of 1) increased service life due to environmental durability, 2) greater payload carrying capacity due to lower self-weight of FRP decks than steel/aluminum decks, 3) reduced maintenance costs, and 4) ease of in-situ repair of damaged FRP deck.

Glass fiber reinforced polymer (GFRP) composites were exposed to moisture, salt, and alkali environments to arrive at GFRP component service life [15]. An alkali 
environment is most severe for glass fibers and test data has shown that they have a service life of 90 years under high $\mathrm{pH}$, i.e., 13.0 [15]. Thus, excellent durability response of GFRP composites will translate into lower maintenance costs due to corrosion resistance.

Unit weight of GFRP is $110 \mathrm{lb} / \mathrm{ft}^{3}$ as compared to $490 \mathrm{lb} / \mathrm{ft}^{3}$ for steel, therefore optimized design of an FRP trailer can lead to significant weight reductions. Lower self-weight of the trailer (1320 lbs for steel deck vs $600-700 \mathrm{lbs}$ for optimized FRP deck) will help augment its payload carrying capacity by about 600-700 lbs, thereby lowering the operational costs. Repair costs for FRP decks are lower due to ease of repair, as discussed in Chapter 7. Composite repair kits can be specifically developed for these decks eliminating the need for equipment such as welding machines. Simplified repair procedures for training (see Chapter 7) can be prepared for in-situ repair of these decks.

Accurate estimation of maintenance and repair costs for FRP decks is difficult without an established deterioration rate model and without prior knowledge of factors contributing to damages [16]. Although accurate maintenance and repair costs are not available, it is obvious from the preceding discussion that FRP trailers would have lower operational, maintenance, and repair costs compared to steel/aluminum trailers. 


\section{CHAPTER 9 - SUMMARY AND FUTURE WORK}

\subsection{SUMMARY}

The purpose of this study was to evaluate the use of FRP composite decks for MTVR trailers. Based on the initial evaluation and discussions, Prodeck 4 was selected for application in the MTVR trailers. A detailed FE model was developed for the FRP trailer. The FE model was used to evaluate the FRP trailer response under various operational and transportation loads. The four operational and transportation loading conditions were: 1) Uniformly distributed load of 40,000 lbs, 2) SIXCON container loading, 3) Helicopter Lift loading and 4) Loading to simulate rail impact.

The FE results from the four load cases were used to modify the FRP trailer design and in determining the instrumentation plan for extensive laboratory testing. Test setups were designed to simulate each of the above-mentioned load cases. A full scale trailer decking system prototype, consisting of the FRP deck and the support assembly, was fabricated. The structural response of the fabricated system (MTVR Trailer) has been evaluated under various static loading conditions. The strains and deflections recorded under the above four loading conditions were used to evaluate the structural performance of the system. Results obtained from these tests have been correlated with the FE results.

One key factor for acceptance of FRP deck trailers by the U.S. Military will be the ease of repairing an FRP deck trailer in case of damage. A step-by-step procedure for identifying and repairing of composite decks is provided; several references on composite 
repair are also listed. Another important factor in favor of FRP trailers is the potential life-cycle cost savings. Different life-cycle cost advantages of FRP decks over steel/aluminum decks are provided in Chapter 8 . Some of the advantages are: 1) increased service life due to environmental durability, 2) greater payload carrying capacity due to lower self-weight of FRP decks, 3) reduced maintenance costs, and 4) ease of in-situ repair of damaged FRP deck.

\subsection{CONCLUSIONS}

The test data and FE results for various loading conditions reveal that the current trailer design meets all critical preliminary load requirements. Results from the uniformly distributed load case indicate that induced stresses in Prodeck 4 are significantly lower than its failure stresses. The SIXCON container loading and the Helicopter Lift loading are more severe than the UDL case, since most of the loading is applied over a small area of the deck. Test and FE results for the SIXCON container load case indicate high local stresses. The FRP deck should be reinforced at locations of high local stresses to provide adequate factors of safety for the SIXCON container loading condition. However, stresses away from the loading points were again significantly lower than the failure stresses of the FRP deck. Based on the rail impact load test data, the current trailer design appears to perform satisfactorily.

The current FRP trailer design using Prodeck 4 can be further optimized both in terms of reducing the size and shape of the deck cross-section and the support assembly. 
Specifically, the FRP deck can be optimized by reducing the web and flange thicknesses while locally reinforcing the high stress regions. The reduced cross-sectional area will result in additional reduction in initial cost of the FRP deck and some improvement in the payload carrying capacity of the MTVR trailers. Based on the test and FE data, the stresses in the main support beams were also found to be significantly lower than their ultimate stresses suggesting a need for optimization of the support assembly.

\subsection{FUTURE WORK}

Several important issues need to be evaluated further in order to develop a prototype trailer ready for user trials. Some of the issues to be evaluated include:

1. Design of ISO locks attachments and tie-downs.

2. Review of additional load requirements not considered during the course of this project.

3. Design of local reinforcements for SIXCON container loading.

4. Optimization of the FRP deck cross-section.

5. Optimization of trailer support assembly including the use of FRP composite beams.

6. Design of FRP Head-board assembly.

7. Field testing of prototype trailer.

8. Large amplitude fatigue response evaluations, with special emphasis on joints.

9. Aging evaluation of FRP composite prototype trailer under harsh environments and high intensity mechanical loads.

10. Estimate the life cycle costs for FRP Trailers 


\section{REFERENCES}

1. http://www.globalsecurity.org/military/systems/ground/mtvr.htm

2. http://jedsite.info//trailers/mike-number-us/m149_series/m149-series.html

3. www.montagar.com/ patj/m105/MVC-721F.JPG

4. http://www.bedfordplastics.com/pdf/BProdeck4.pdf

5. Zhou, A., Stiffness and Strength of Fiber Reinforced Polymer Composite Bridge Deck Systems, PhD Dissertation, Faculty of the Virginia Polytechnic Institute and State University, Blacksburg, Virginia, September, 2002.

6. Ansys v8.1 Reference Manual.

7. GangaRao, H.V.S., Shekar, V., Punyamurthula, D., Prachasaree, W., (2005) Structural Performance of Prodeck 4, CFC-WVU Report No. 05-001.

8. Prachasaree, W., (2005) Shear Behavior and Performance of FRP Composite Bridge Deck, Ph.D Dissertation, College of Engineering and Mineral Resources, West Virginia University, Morgantown, West Virginia.

9. http://www.bedfordplastics.com/pdf/BProdeck8.pdf

10. Howard, I., (2002) Development of Lightweight FRP Bridge Deck Designs and Evaluations, Master's Thesis, College of Engineering and Mineral Resources, West Virginia University, Morgantown, West Virginia.

11. Vasudevan, A., (2004) Application of Digital Infrared Thermography for Nondestructive Evaluation of Composite Bridge Components, Master's Thesis, College of Engineering and Mineral Resources, West Virginia University, Morgantown, West Virginia.

12. http://www.netcomposites.com/education.asp? sequence $=83$

13. Nystrom, H., Watkins, S. E., Namni, A., and Murray, S., Financial Viability of Fiber-Reinforced Polymer (FRP) Bridges.

14. Sahirman S., Creese R. C., GangaRao, H., (2003) Economic Feasibility of FiberReinforced Polymer (FRP) Bridge Decks, AACE International's 2003 Annual Meeting, Orlando, Florida. 
15. Vijay, P.V. and GangaRao, H.V.S. (1999) Development of Fiber Reinforced Plastics for Highway Application: Aging Behavior of Concrete Beams Reinforced with GFRP bars. CFC-WVU Report No.99-265 (WVDOH RP \#T-699-FRP1).

16. Sahirman S., Creese R. C., GangaRao, H., (2005), Preliminary Study of Life Cycle Cost Model for Fiber Reinforced Polymer Bridge Deck, Proceedings of $4^{\text {th }}$ International Workshop on Life-Cycle Cost Analysis and Design of Civil Infrastructures Systems, Cocoa Beach, Florida. 


\section{APPENDIX A -THEORETICAL EVALUATION OF STRUCTURAL PROPERTIES OF PRODECK 4}

The Classical Laminate Theory (CLT) approach is used for computing the bending stiffness of the multicellular shaped FRP deck. The Classical Laminate Theory (CLT) approach is used for computing the bending stiffness of the multicellular shaped FRP deck. One of the important parameters in the deck design is the Fiber Volume Fraction $\left(V_{f}\right)$. For continuous strand mat and fiber, the fiber volume fraction is given by,

$$
V_{f}=\frac{W_{f}}{\rho_{f} L_{v}}
$$

where,

$W f=$ weight of CSM/ fabric per square foot (lb)

$L_{v}=$ volume of 1'x 1' ply of composite lamina (in $\left.{ }^{3}\right)$

$\rho_{f}=$ density of CSM or fabric $\left(0.092 \mathrm{lb} / \mathrm{in}^{3}\right)$

For Rovings the fiber volume fraction is given by,

$$
V_{f}=\frac{n \pi D^{2}}{4 b t}
$$

where,

$\mathrm{n}=$ number of bundles

$\mathrm{b}=$ width of laminate (in)

$\mathrm{t}=$ thickness of composite layer (in)

$\mathrm{D}=$ diameter of fiber $=\sqrt{\frac{1}{\rho_{f} Y 9 \pi}}$

$\rho_{f}=$ density of fiber $\left(0.092 \mathrm{lb} / \mathrm{in}^{3}\right)$ 
$\mathrm{Y}=$ yield

\section{EVALUATION OF LAMINA PROPERTIES}

For Continuous Strand Mat:

Elastic Modulus (psi)

$$
E_{\text {ran }}=\frac{3}{8} E_{11}+\frac{5}{8} E_{22}
$$

Shear Modulus (psi)

$$
G_{\text {ran }}=\frac{1}{8} E_{11}+\frac{1}{8} E_{22}
$$

Poisson's Ratio (psi)

$$
v_{\text {ran }}=\left(\frac{E_{\text {ran }}}{2 G_{\text {ran }}}\right)-1
$$

For Rovings and Fabrics:

Longitudinal Modulus (psi)

$$
E_{11}=E_{f} v_{f}+E_{m}\left(1-v_{f}\right)
$$

Transverse Modulus (psi)

$$
E_{22}=\frac{E_{f} E_{m}}{E_{f}\left(1-v_{f}\right)+E_{m} v_{f}}
$$

\section{Product Specification}

The deck contained the three different types of lamina;
○ CDBM 3415
○ DDBM 4015
○ $56 \mathrm{Y}(4$ rovings/inch $)$

Tables show the product specifications of the lamina mentioned above while Table shows the obtained material properties of the lamina. 
Table A 1 Product Specifications of CDBM 3415

\begin{tabular}{|c|c|c|c|}
\hline Fiber Type & $\begin{array}{c}\text { Nominal Weight } \\
\left(\mathbf{O z} / \mathbf{y d}^{\mathbf{2}}\right)\end{array}$ & $\begin{array}{c}\text { Thickness } \\
\text { (in) }\end{array}$ & $\begin{array}{c}\mathbf{L}_{\mathbf{y}} \\
\mathbf{( i n}^{\mathbf{3}} \mathbf{)}\end{array}$ \\
\hline $0^{0}$ Fabrics & 15.71 & 0.017 & 2.448 \\
\hline$+45^{0}$ Fabrics & 9.04 & 0.0099 & 1.4256 \\
\hline$-45^{0}$ Fabrics & 9.04 & 0.0099 & 1.4256 \\
\hline Mat (CSM) & 13.5 & 0.014 & 2.016 \\
\hline Totals & 47.29 & 0.0508 & 7.3152 \\
\hline
\end{tabular}

Table A 2 Product Specifications of DDBM 4015

\begin{tabular}{|c|c|c|c|}
\hline Fiber Type & $\begin{array}{c}\text { Nominal Weight } \\
\left(\mathbf{O z} / \mathbf{y d}^{\mathbf{2}}\right)\end{array}$ & $\begin{array}{c}\text { Thickness } \\
\text { (in) }\end{array}$ & $\begin{array}{c}\mathbf{L}_{\mathbf{y}} \\
\text { (in }^{\mathbf{3}} \mathbf{)}\end{array}$ \\
\hline$+45^{0}$ Fabrics & 11.44 & 0.013 & 1.872 \\
\hline $90^{0}$ Fabrics & 17.28 & 0.019 & 2.736 \\
\hline$-45^{0}$ Fabrics & 11.44 & 0.013 & 1.872 \\
\hline Mat (CSM) & 13.5 & 0.014 & 2.016 \\
\hline Totals & 53.66 & 0.059 & 8.496 \\
\hline
\end{tabular}


Table A 3 Material Properties of the Lamina

\begin{tabular}{|c|c|c|c|c|c|}
\hline Material & $\begin{array}{c}\text { Fiber } \\
\text { Volume } \\
\text { Fraction(\%) }\end{array}$ & $\begin{array}{c}\text { Matrix } \\
\text { Volume } \\
\text { Fraction(\%) } \\
\end{array}$ & $\begin{array}{c}\mathbf{E}_{11} \times 10^{6} \\
(\mathrm{psi})\end{array}$ & $\begin{array}{c}\mathbf{E}_{22} \times 10^{6} \\
(\mathrm{psi})\end{array}$ & $\begin{array}{c}E \times 10^{6} \\
(\mathrm{psi})\end{array}$ \\
\hline $\begin{array}{c}\text { CDBM }(3415) \\
0^{0} / 45^{0} /-45^{0}\end{array}$ & 48 & 52 & 5.46 & 1.33 & - \\
\hline $\begin{array}{c}\text { CDBM(3415) } \\
\text { Mat }\end{array}$ & 48 & 52 & - & - & 2.88 \\
\hline $\begin{array}{c}\operatorname{DDBM}(4015) \\
45^{0} / 90^{0} /-45^{0}\end{array}$ & 48 & 51 & 5.52 & 1.35 & - \\
\hline $\begin{array}{c}\text { DDBM(4015) } \\
\text { Mat }\end{array}$ & 49 & 51 & - & - & 2.91 \\
\hline 56 Y Roving & 54 & 46 & 6.03 & 1.48 & - \\
\hline
\end{tabular}

\section{EVALUATION OF STRUCTURAL PROPERTIES}

\section{Elastic Modulus}

Elastic modulus of a lamina in a given direction in an approximate manner is as follows:

$$
\begin{aligned}
& E_{X} \approx E_{11} \cos ^{4}(\theta) \\
& E_{Y} \approx E_{11} \cos ^{4}(90-\theta)
\end{aligned}
$$

Where,

$\theta=$ angle of fiber orientation with respect to $\mathrm{x}$-axis 


\section{In-Plane and Extensional Bending Coupling Stiffness}

$$
A_{f}=A_{w}=b \sum_{k=1}^{N}\left(E_{i}\right)_{k} t_{k}
$$

Where,

$A_{f}=A_{w}=$ In-phase stiffness

$\left(E_{i}\right)_{k}=E_{i}$ in $k^{\text {th }}$ layer, where ' $i$ ' corresponds to global axis

$t_{k}=$ Thickness of $\mathrm{k}^{\text {th }}$ layer (in)

$\mathrm{b}=$ width of laminate (in)

Note: The subscript ' $\mathrm{f}$ ' corresponds to flange, while ' $w$ ' refers to web. $b$ is in the vertical direction for web computations, and in the horizontal direction for the flange computations.

\section{Flange and Web Bending Stiffness}

(Lopez 1995) computed for web as follows:

$$
D_{w} \approx \frac{d^{3}}{12} \sum_{k=1}^{N}\left(E_{i}\right)_{k} t_{k}
$$

\section{Global Bending Stiffness}

$$
E I \approx \sum_{f=1}^{n}\left[D_{f}+A_{f} e_{f}^{2}\right]+\sum_{w=1}^{m}\left[D_{w}+A_{w} e^{2}{ }_{w}\right]
$$

where,

$\mathrm{n}=$ number of flanges

$\mathrm{m}=$ number of webs

$e_{f}=$ eccentricity of a flange from the mid-surface of component 
$e_{w}=$ eccentricity of a web from the mid-surface of component

\section{Theoretical Bending Stiffness}

Theoretical bending stiffness was computed [Punyamurtula et.al, 2004] in both the transverse and the longitudinal directions by utilizing all the above equations, the material and lamina properties, and the product specifications.

\section{References}

Lopez-Anido, R., (1995) Analysis and Design of Orthotropic Plates Stiffened by Laminated Beams for Bridge Superstructures, Ph.D. Dissertation, College of Engineering and Mineral Resources, West Virginia University, Morgantown, West Virginia.

Punyamurthula, D., (2005) Structural Performance of Low-profile FRP Composite Celluar Modules, Master's Thesis, College of Engineering and Mineral Resources, West Virginia University, Morgantown, West Virginia. 